\title{
6 Ideologie und Propaganda vor Ort
}

Propaganda wurde von allen Kriegsteilnehmern als Mittel betrachtet, den Feind zu zersetzen und so seine Schlagkraft zu mindern. Während der Begriff „Propaganda“ jedoch nach den Erfahrungen im Ersten Weltkrieg in den westlichen Demokratien eine negative Konnotation erfuhr und gemieden wurde, war der Begriff in den totalitären Regimes durchaus positiv besetzt. Das nationalsozialistische Deutschland und das faschistische Italien maßen der Meinungslenkung auch im Frieden eine große Bedeutung zu. Dies äußerte sich etwa in der Schaffung des Reichsministeriums für Volksaufklärung und Propaganda und des Ministero per la Stampa e la Propaganda (ab 1937 Ministero per la Cultura Popolare, MinCulPop). ${ }^{1}$ Die Wehrmacht ging seit 1936 dazu über, die psychologische Kriegsführung gezielt zu organisieren. Bereits 1938 wurden im Deutschen Reich mit Unterstützung der Reichspropagandaämter unter anderem sogenannte Propagandakompanien (PKs) mit Arbeitsgruppen für Kriegsberichterstattung durch Wort, Bild, Film und Rundfunk sowie für Lautsprecherpropaganda gebildet. $^{2}$ Die PKs waren eine typisch deutsche Schöpfung, die auf den Erfahrungen aus dem Ersten Weltkrieg beruhte. Ein äquivalentes Instrument gab es in der italienischen Armee nicht. ${ }^{3}$ Erst 1940 wurden in Italien die Aufgaben der Militärpropaganda im Krieg festgelegt. Sie sollten von Propaganda-Abteilungen und dem Militärischen Nachrichtendienst (Servizio Informazione Militare, SIM) ausgeführt werden. Erstere übten dabei eine den deutschen PKs ähnliche Funktion aus. ${ }^{4}$

Im folgenden Kapitel soll die Propaganda der deutschen und der italienischen Besatzer untersucht werden, wobei der Fokus auf der militärischen Propaganda liegt. Der Begriff Propaganda im Allgemeinen soll hierbei den Versuch von „Machtgruppen oder Institutionen, die Meinungen und Attitüden und oft auch das Verhalten der Menschen im Sinne der Zwecke und Ziele dieser Macht-

1 Vgl. hierzu Siebers, Tonia: Mussolinis Medienmacht. Themen und Instrumente der Propaganda im faschistischen Italien, Saarbrücken 2007, S. 10; Garzarelli, Benedetta: „Parleremo al mondo intero“. La propaganda del fascismo all'estero, Alessandria 2004, S. 39-41. In Italien ließ man 1937 mit der Umbenennung des Ministeriums den Begriff „Propaganda“ dann allerdings doch verschwinden.

2 Deist/Messerschmidt/Volkmann/Wette: Ursachen und Voraussetzungen, S. 126.

3 Uziel, Daniel: Propaganda, Kriegsberichterstattung und die Wehrmacht. Stellenwert und Funktion der Propagandatruppen im NS-Staat, in: Rother, Rainer/Prokasy, Judith (Hg.): Die Kamera als Waffe. Propagandabilder des Zweiten Weltkrieges, München 2010, S. 13-36, hier S. 28.

4 Della Volpe, Nicola: Esercito e propaganda fra le due guerre (1919-1939), hgg. v. Ufficio Storico dello Stato Maggiore dell'Esercito, Rom 1992, S. 54 f. 
gruppen zu beeinflussen“ kennzeichnen. ${ }^{5}$ Unter im engeren Sinne militärischer Propaganda wird die „geplante Verwendung irgendeiner Form von Mitteilung, die dazu bestimmt ist, den Geist und das Gemüt eines Feindes oder einer neutralen oder feindlich gesinnten ausländischen Gruppe für einen besonderen strategischen oder taktischen Zweck zu beeinflussen“ verstanden sowie auch Propaganda für die eigene Truppe. ${ }^{6}$ Die Bezeichnung „ausländische Gruppe“ wird dabei auf die unterschiedlichen Bevölkerungsgruppen des NDH angewendet. Darunter wird auch die Überläuferpropaganda, die von dieser kaum zu trennen ist, subsumiert.

Gleichzeitig betrieben Italien und Deutschland Propaganda für die eigenen Soldaten. Die italienische Propaganda sollte die Soldaten so beeinflussen, dass sie eine hohe Kampfmoral und einen starken kriegerischen Geist entwickelten bzw. beibehielten. Ihre konkreten Aufgaben bewegten sich dabei im geistigen, kulturellen und juristischen Bereich. ${ }^{7}$ Auch dies übernahmen die Propagandaabteilungen. Die geistige Betreuung der Truppen, als kriegswichtig klassifiziert, hatte als oberstes Ziel, das Zusammengehörigkeitsgefühl und die geistige Festigkeit der Einheiten zu sichern, die als wichtige Faktoren für ihre Effizienz im Krieg angesehen wurden. ${ }^{8}$ In der Wehrmacht wurde die „wehrgeistige Führung“ als ein Teil der militärischen Gesamtführung betrachtet und auf die gesamte Kriegslänge gesehen als nicht minder wichtig betrachtet. Diese bestand aus der politisch-weltanschaulichen Führung einerseits und der geistigen Betreuung und Freizeitgestaltung andererseits. Beiden lag das Gedankengut der nationalsozialistischen Weltanschauung zu Grunde. Die geistige Betreuung sollte die deutschen Soldaten während des Krieges zu Zuversicht, Kampfgeist und Abwehrbereitschaft anspornen und die soldatischen Tugenden betonen. Außerdem wurde die Erziehung zur „Krisenfestigkeit, Härte und einer gewissen Brutalität“ als „unbedingt erforderlich“ angesehen. Die rein militärische Ausbildung sollte durch die nach innen gewandte „Führung der Gedanken“ ergänzt werden. ${ }^{9}$

Bisherige Untersuchungen der Besatzung in Jugoslawien haben die von den Besatzern verbreitete Propaganda und propagandistische Aktionen, die darauf zielten, die Bevölkerung für sich einzunehmen, weitestgehend ignoriert. Die

5 Maletzke, Gerhard: Grundbegriffe der Massenkommunikation, München 1964, S. 43.

6 Buchbender, Ortwin/Schuh, Horst: Die Waffe, die auf die Seele zielt. Psychologische Kriegführung 1939-1945, Stuttgart 1983, S. 13.

7 AUSSME, DS, b. 646, All. 80, SMRE, Servizio „A“, 28.1.1943.

8 AUSSME, M 7, b. 223, SMRE, Assistenza morale alle truppe, 19.1.1942.

9 BArch, RM 35/III/164, Anl. 9, Politische Fragen, Abwehrdienst und geistige Betreuung, 5.11.1941; BArch, RH 26/117/12, Anl. 25, Besprechung am 28.4. 1943 beim Befehlshaber Südgriechenland; BArch, RM 35/III/164, Wehrgeistige Führung der Truppe, 15.10.1943. 
Historiker konzentrierten sich stattdessen häufig entweder auf die Untersuchung der diplomatischen Beziehungen oder auf die militärische Bekämpfung der Aufständischen. Doch gehörte die Propaganda zum Krieg und zum Besatzungsalltag dazu. Nach der Schaffung des NDH betrieben seine beiden „Schutzmächte“ über ihre Gesandtschaften die für befreundete Staaten vorgesehene Propaganda. Diese sollte in erster Linie das jeweilige Land und seine Errungenschaften positiv darstellen und dadurch zur Entwicklung guter Beziehungen zwischen Deutschland bzw. Italien und Kroatien beitragen. Da der NDH jedoch beim Aufbau der eigenen Propaganda Hilfe brauchte, schalteten sich hier deutsche Stellen ein. ${ }^{10}$ Durch den beim kroatischen Ministerium für Volkskultur schließlich eingesetzten Propagandaberater Dr. Katschinka stellte die deutsche Gesandtschaft ihre Einflussnahme sicher.

Als sich zeigte, dass es sich beim NDH nicht um ein befriedetes besetztes Territorium handeln würde, sondern der Aufstand immer weiter um sich griff, war eine der Hauptaufgaben der Propaganda, diesen zu bekämpfen. Da der Aufstand zunächst als eine Angelegenheit der kroatischen Innenpolitik erschien, war es auch das kroatische Propagandaamt, das die gegen die Aufständischen gerichtete Propaganda betrieb. Doch ähnlich wie die kroatische Bekämpfung der Aufständischen, konnte auch die kroatische Propaganda die Deutschen nicht überzeugen. Obwohl die Besatzer in Zusammenarbeit mit dem NDH versuchten, ein „Wahrheitsmonopol“ wie in der Heimat aufzubauen ${ }^{11}$, indem sie beispielsweise Radios einzogen, damit die Bevölkerung nicht BBC hören konnte und ausschließlich von den Informationen der Besatzer abhing, ${ }^{12}$ schafften es die Partisanen, dieses schnell zu durchbrechen. Sie betrieben ihrerseits eine sehr gut gemachte Gegenpropaganda, die sich nicht nur gegen den NDH, sondern auch gegen die Achse richtete und weite Bevölkerungsteile erreichte. Daher sahen sich Italien und Deutschland gezwungen, die militärische Propaganda in die eigene Hand zu nehmen, um die Bevölkerung nicht der gegnerischen Propaganda zu überlassen.

Grundsätzlich können zwei Arten der Propaganda im Krieg unterschieden werden: Die strategische und die taktische Propaganda. Erstere verfolgt das

10 PA-AA, StS Kroatien, Bd. 1, R. 29.665, Nr. 677, Nr. 162, Telegramm des Gesandten Kasche an das Auswärtige Amt, 20.5.1941.

11 Dies ist für Italien nur mit Einschränkungen richtig, da die faschistische Propaganda keinen Einfluss auf die Informationsmedien des Vatikans, vor allem den Oservatore Romano und Radio Vaticano, hatte. Vgl. Arnold, Vincent: The Illusion of Victory. Fascist Propaganda and the Second World War, New York [u. a.] 1998, S. $127 \mathrm{f}$.

12 Genauso sind die Italiener in Griechenland vorgegangen. Vgl. Lecoeur, Sheila: Mussolini's Greek Island. Fascism and the Italian Occupation of Syros in World War II, New York 2009, S. 122. 
langfristige Ziel, den Kampfwillen und die Kriegsanstrengungen der feindlichen Nation - oder im NDH der Aufständischen - zu verringern. Hierzu kann beispielsweise die von der Abteilung „P“ beim italienischen Kommando der 2. Armee verbreitete Propaganda gezählt werden. Dazu konnten Flugblätter benutzt werden, die sich an die Bevölkerung wandten und die durch Flugzeugabwurf über weite Teile des „Feindesgebietes“ verteilt wurden. Die taktische Propaganda ist hingegen auf kurzfristige Ziele ausgerichtet und unterstützt momentane Entwicklungen. Sie soll vor allem gegnerische Soldaten zum Einstellen des Widerstandes bzw. zum Überlaufen bringen. Klassischerweise werden autorisierte Passierscheine, die feindliche Soldaten zum Überlaufen auffordern und im Gegenzug gute Behandlung versprechen, hinzugezählt, aber auch Aufrufe an abgeschnittene Truppenteile, sich zu ergeben. Die taktische Propaganda ist vor allem dann erfolgreich, wenn die Gegner sich in einer ausweglosen Situation befinden und sie ein moralisches Alibi liefern kann, die Bindung an die eigenen Führer und Kameraden aufzugeben. ${ }^{13}$ Solche Propaganda wurde beispielsweise beim deutschen Unternehmen „Kugelblitz“ durchgeführt.

Bezüglich ihrer Quellen lässt sich die Kriegspropaganda in drei Gruppen gliedern: Die „Weiße Propaganda“ nennt klar den Absender. Das sind beispielsweise Aufrufe an Aufständische, die Waffen niederzulegen. Auch Propaganda, die auf gegnerische Propaganda Bezug nimmt, um ihre Behauptungen zu widerlegen, zählt hierzu. Die Graue Propaganda lässt den Empfänger im Unklaren, wer sie verfasst hat, und gaukelt Objektivität vor. Die Schwarze Propaganda schließlich gibt vor, aus einer anderen als der tatsächlichen Quelle zu stammen. ${ }^{14}$ Alle drei Arten wurden von den deutschen und italienischen Truppen eingesetzt.

\subsection{Italienische Armee}

Wie wurden die Soldaten der 2. Armee für die Aufgaben der Besatzung, die einen zähen und demotivierenden Kampf gegen Aufständische sowie Repressalien an der Bevölkerung vorsah, vorbereitet, wie dabei begleitet? Welche Rolle spielte die Idee des Imperiums, der eigenen Überlegenheit und der italienischen Zivilisierungsmission? Auf diese Fragen kann teilweise eine Antwort gegeben werden, wenn italienische Ansätze zur Betreuung der Soldaten und der unter

13 Buchbender/Schuh: Die Waffe, S. $13 \mathrm{f}$.

14 Buchbender/Schuh: Die Waffe, S. 14. 
ihnen verbreiteten Propaganda untersucht werden..$^{15}$ Auch wenn diese Aufgabe theoretisch der gesamten militärischen Hierarchie zufiel und jeder Kommandeur sich um die Erziehung seiner Soldaten kümmern sollte, wurde sie in erster Linie Propagandaabteilungen überlassen. ${ }^{16}$ Die besonderen Umstände der Besatzung auf dem Balkan - in erster Linie das Vorhandensein einer starken Widerstandsbewegung mit einer gut organisierten eigenen Propaganda - führten im Verlauf der Zeit dazu, dass der Propagandaapparat der 2. Armee so groß und weit verzweigt wurde wie bei keiner anderen italienischen Armee. Im April 1942 wurden die Sektionen „P“, die bis dahin den Abteilungen „Information“ unterstanden, unter die direkte Kontrolle der Stabschefs der entsprechenden Großeinheiten gestellt. ${ }^{17} 1943$ zählte die mittlerweile in „Abteilung Presse und Assistenz“ (Ufficio stampa e assistenza = „A“) umbenannte Abteilung „Propaganda“ 23 Offiziere, einen Militärkaplan und 55 Unteroffiziere und Soldaten. ${ }^{18}$

Das letztendliche Ziel der Abteilungen „A“ war es, sowohl den individuellen Wert eines jeden Soldaten als auch den kollektiven Wert der Truppe zu steigern. Die Eckpfeiler der Betreuung der Soldaten bestanden aus materieller Hilfe und Beeinflussung, wobei vor allem aufs Erstere viel Wert gelegt wurde: Ein vielfältiges Freizeitangebot, Zuwendungen unterschiedlichster Art sowie die Sicherung verschiedener Komfortbedürfnisse hatten Vorrang vor der verbalen Indoktrination mit der offiziellen Propaganda. ${ }^{19}$ Für die Letztere waren Informationen von anderen Kriegsschauplätzen, die die Größe und Stärke der Achse demonstrierten und den Gesamtsieg erahnen ließen, wichtig. Tägliche Kriegsnachrichten (Bollettini giornalieri di guerra) wurden von den Kommandos an alle Einheiten weitergeleitet, damit die Soldaten über die Geschehnisse in Itali-

15 Rodogno, Davide: Italian soldiers in the Balkans. The experience of the occupation (19411943), in: Journal of Southern Europe and the Balkans, 6 (2004) 2, S. 125-144. In einem sehr frühen Aufsatz thematisierte zudem Theodoro Sala die Propaganda für Soldaten auf dem jugoslawischen Kriegsschauplatz. Sala, Teodoro: Guerriglia e controguerriglia in Jugoslavia nella propaganda per le truppe occupanti italiane (1941-1943), in: Il Movimento di liberazione in Italia, 108 (1972), S. 91-114.

16 Die Propagandaabteilungen (Abteilungen „P“) wurden am 06. November 1942 in Abteilungen für Assistenz (Abteilungen „A“) umbenannt. AUSSME, L 10, rac. 28, cart. 2, SMRE, Cambio di denominazione dell'Ufficio Propaganda, 16.11.1942. In der deutschen Wahrnehmung fehlte es beim italienischen Offizierskorps an der Fürsorge für die Truppe. Vgl. Förster, Jürgen: Die Wehrmacht und die Probleme der Koalitionskriegsführung, in: Klinkhammer/Osti Guerrazzi/ Schlemmer (Hg.): Die „Achse“ im Krieg, S. 108-121, hier S. 119.

17 AUSSME, M 7, b. 313, SMRE, Sezioni „P“ di A. e sottosezioni „P“ di C. d’A., 2.4.1942.

18 AUSSME, L 10, rac. 28, cart. 2, SMRE, Cambio di denominazione dell'Ufficio Propaganda 16.11.1942; Della Volpe, Nicola: Esercito e propaganda nella Seconda Guerra Mondiale (19401943), Rom 1998, S. 81.

19 Della Volpe: Esercito e propaganda, S. 60 f. 
en und in der Welt informiert waren. ${ }^{20}$ Wenig Beachtung widmete die Propaganda hingegen dem eigenen Kriegsschauplatz.

Die Abteilungen für Propaganda verfassten monatlich ca. zehnseitige Berichte über die „Moral der Truppe“, die fast für die ganze Besatzungsdauer in Kroatien überliefert sind. ${ }^{21}$ Sie waren gemäß der Weisung vom 28. Juni 1941 nach einem festen Schema angefertigt und sollten von der realen Situation berichten. ${ }^{22}$ Doch wurden sie immer wieder beschönigt, indem die Verfasser Positives weiterleiteten und Unerfreuliches verschwiegen. So sah sich der Leiter des Generalstab des Heeres im Oktober 1942 dazu veranlasst, eine objektive Berichterstattung einzufordern. ${ }^{23}$ Obwohl man davon ausgehen kann, dass die Situation schlechter war, als in den Berichten dargestellt, geben sie doch Einblick in das alltägliche Leben der Soldaten, in ihre Freizeitgestaltung, Nöte und Sorgen. Sie zeigen, wie sich die Kampfmoral graduell verschlechterte, verursacht durch die an den Nerven zehrenden Umstände der Guerillakriegsführung und verstärkt durch die Unzulänglichkeiten bei der Betreuung der Einheiten. ${ }^{24}$

\section{Betreuung und Propaganda für Soldaten}

Bereits im Mai 1941 ordnete das Kriegsministerium adäquate Maßnahmen an, um den Soldaten, die an den vorausgegangenen Militäroperationen teilgenommen hatten, deutlich zu machen, dass ihre Aufgaben mit dem Sieg über Griechenland und Jugoslawien nicht zu Ende waren. Sie sollten darauf eingestimmt werden, dass der Kampf noch nicht vorbei war und weitere Opfer fordern würde. Dies erfolgte über Vorträge von Vorgesetzten über den Krieg im Ganzen, über den Krieg im Osten usw. sowie über zwanglose Gespräche der Offiziere mit der Truppe. ${ }^{25}$ Im Jahr 1941 wurde die Moral der Soldaten noch als sehr hoch eingestuft, denn diese zeigten sich zuversichtlich, dass die Achse den Krieg gewinnen würde. Das V. Armeekorps machte dies daran fest, dass die Erschießung

20 AUSSME, DS, b. 543, All. 563, Attività svolta nel mese di novembre 1941.

21 Es fehlen nur die Berichte Juli - August 1943.

22 AUSSME, DS, b. 727, All. 776, Comando della 2. Armata: Servizio „P“, 6.9.1941.

23 AUSSME, L 10, b. 22, cart. 2, SMRE: Relazione mensile sul servizio „P“, 22.10.1942.

24 Anderer Ansicht ist Davide Rodogno, der argumentiert, dass die Kampfmoral der italienischen Truppen bis zum 25. Juli 1943 relativ hoch gewesen sei und sich danach schlagartig verschlechtert habe. Rodogno: Il nuovo ordine mediterraneo, S. 194.

25 So forderte der Befehlshaber des V. Armeekorps bereits am 5. Juni 1941 bei den Soldaten „spirituelle Grundlagen“ zu schaffen, die für „gute Soldaten“ notwendig seien. AUSSME, DS, b. 332, All. 18, Promemoria addestrativo n. 7; AUSSME, DS, b. 726, All. 660, Preparazione morale, 28.6.1941. 
von Personen, die als Kommunisten galten, von allen positiv kommentiert wurde. Desweiteren hätten die anstrengenden Durchkämmungsaktionen die Kampfmoral nicht gemindert, und die Truppe hätte den Willen gezeigt, die gefallenen Kameraden zu rächen. ${ }^{26} \mathrm{Um}$ die Tapferkeit zu fördern, begann man schon im Sommer mit der Verteilung von Geldpreisen für Soldaten, die sich besonders ausgezeichnet hatten. Im Zeitraum 15. August - 15. September 1941 wurden beim VI. Armeekorps insgesamt 51.625 Lire Prämien an diejenigen gezahlt, die sich bei Durchkämmungsaktionen sowie bei der Bewachung von Bahnlinien, Telefon- und Telegraphenverbindungen hervorgetan hatten. Hinzu kamen noch 11.120 Lire für bedürftige Familien der Soldaten. ${ }^{27}$ In den kommenden Monaten wuchsen die Hilfen auf über 100.000 Lire im Monat an. Im Sommer 1941 wurde Ernteurlaub genehmigt - eine Maßnahme, welche die Kampfmoral der Truppe zusätzlich stärkte.

Auch die Freizeitgestaltung wurde am Anfang umfassend geregelt. Beim Lesen der Berichte wird verständlich, woher die Auffassung von einer „fröhlichen Besatzung“'28 stammen könnte. Bereits ab Mai 1941 bekam das VI. Armeekorps das erste mobile Kino, das jeden Abend an einem anderen Ort eine Vorstellung gab. Mit der Radiosendung „Notizie a casa“ konnten Soldaten ihre Angehörigen $\mathrm{zu}$ Hause grüßen. In dieser Phase wurden auch viele neue Radioapparate, Spiele und Karten, sowie Abos für Zeitschriften und Zeitungen verteilt, Theater- und Filmvorführungen fanden statt. Beim V. Armeekorps wurden im September 194121 Filme und 21 LUCE $^{29}$ - Dokumentarfilme in insgesamt 110 Vorführungen gezeigt. ${ }^{30}$ Die Soldaten engagierten sich zudem musikalisch, sportlich oder im Theater. Den Vorstellungen wohnte auch die Bevölkerung der Umgebung bei. Mit dem anbrechenden Winter begann sich die Freizeitgestaltung der Soldaten jedoch zu ändern, da viele Beschäftigungen, die im Freien betrieben wurden, nun nicht mehr ausgeübt werden konnten. Zudem wurde es schwieriger, das Freizeitangebot in die Garnisonen hinter der Küste zu bringen, wo im Winter große Schneemengen die Straßen unpassierbar machten. Dies schlug auf die Stimmung, obschon mit der Rückkehr des schönen Wetters die Freizeitangebote wieder intensiviert werden konnten.

26 AUSSME, DS, b. 585, cart. 278, Nr. 4, Relazione mensile sul servizio „P“ per il periodo dal 15. novembre al 15. dicembre 1941.

27 AUSSME, DS, b. 584, cart. 175, Nr. 3, Relazione mensile sul servizio „P“ per il periodo dal 15. agosto al 15. settembre 1941.

28 Eine Bezeichnung, die von Eric Gobetti gebraucht wird. Gobetti: L’occupazione allegra, S. 175.

29 L'Unione Cinematografica Educativa.

30 AUSSME, DS, b. 449, All. 335, Attività svolta nel mese di Settembre (1941). 
Da Dalmatien und der NDH zunächst nicht als Operationsgebiet klassifiziert wurden, erhielten die Soldaten nur die Hälfte der täglichen Extrazuweisung, die durch ein Dekret des Duce für alle Truppen im Operationsgebiet festgelegt worden war. ${ }^{31}$ Dies war von Anfang an wichtig, um die Truppenverpflegung aufzubessern, da bereits im Sommer 1941 bestimmte Einheiten meldeten, dass es keine Waren zu kaufen gab. Als im Spätsommer die Essensrationen gekürzt wurden, verschlechterte sich die Situation noch mehr. Darüber beschwerten sich die Soldaten auch in ihren Briefen nach Hause. ${ }^{32}$

Wie gut die Truppen versorgt wurden, hing auch davon ab, ob sie in der Nähe der großen Zentren, wie Zara oder Split, stationiert waren oder kleine Abteilungen irgendwo im dalmatinischen Hinterland bildeten. Diese hatten nicht nur einen gefährlicheren Dienst zu verrichten, sondern litten auch mehr unter unzureichenden sanitären Verhältnissen, schlechterem Essen und hatten weniger Gelegenheiten, sich zu vergnügen. Im Winter 1941/42 waren einige entlegene Garnisonen durch den vielen Schnee und Blockaden der Partisanen vom Nachschub abgeschnitten und mussten z. T. aus der Luft versorgt werden. Um die Moral der Soldaten zu heben, wurde daher versucht, sie häufiger in ruhigere Garnisonen zu versetzen. ${ }^{33}$

Obwohl der Oberbefehlshaber der 2. Armee die Errichtung von Verkaufsläden, in welchen die Soldaten Komfortgüter verbilligt kaufen konnten, als besonders wichtig erachtete, fehlte es bald auch an primären Gütern. ${ }^{34}$ Von Anfang an waren die Tabakrationen unzureichend. Im Dezember 1941 hieß es, dass der Mangel sich schlecht auf die Moral der Raucher auswirke. ${ }^{35}$ Seit Winter 1941 fehlte es an Seife. Und weil es aufgrund von Sabotagen manchmal auch kein Wasser gab, gewöhnten sich die Soldaten daran, nicht auf Hygiene zu achten. Als Folge breitete sich Krätze aus. ${ }^{36}$ Der harte Winter forderte zusätzlich seinen Tribut. Es fehlte an Wollsachen, die aufgrund der klimatischen Verhältnisse dringend notwendig waren. Schon im ersten Winter versagten auch die Schuhe in den unwirtlichen Verhältnissen der dinarischen Berge. Die angeforderten

31 AUSSME, DS, b. 585, cart. 278, Nr. 4, Relazione mensile sul servizio „P“ per il periodo dal 15. novembre al 15. dicembre 1941.

32 VA, TA, k. 543, reg. br. 10/17-4, Commissione provinciale censura di guerra, sezione militare, Zara (CPCG, Zara), Relazione quindicinale dal 16 al 30 novembre 1941.

33 AUSSME, H 1, b. 34, Sintesi delle Relazioni sul servizio „A“ per il mese di marzo [1942] inviate dai Comandi delle G. U. dislocate fuori del territorio.

34 AUSSME, DS, b. 727, All. 776, Comando della 2. Armata: Servizio „P“, 6.9.1941.

35 AUSSME, H 1, b. 34, Sintesi delle Relazioni sul servizio „P“ inviate dai Comandi Superiori FF. AA. Albania e Grecia e dal Comando della 2. Armata per il mese di dicembre, 22.1.1942. 36 Bedeschi, Giulio (Hg.): Fronte jugoslavo-balcanico: c'ero anch'io, Mailand 1985, S. 195. 
zweiten Paare Schuhe ließen auf sich warten und es kam zu Erfrierungen. ${ }^{37}$ Die Schuhe sollten sich zu einem Dauerproblem entwickeln, das auch durch Antigefriercreme nicht gelöst werden konnte. ${ }^{38}$ Das Kommando der 2. Armee berichtete, dass neue Schuhe nach einer Woche im steinigen Gelände kaputt waren, und dass es notwendig war, die Einheiten mit Flickzeug auszustatten. ${ }^{39}$

Ein weiterer Umstand, der sich negativ auf die Moral der Truppen auswirkte, waren die Ustascha-Gräuel, die im Frühsommer 1941 ihren ersten Höhepunkt erreichten. Durch die ihnen erteilten Befehle waren die italienischen Truppen offiziell dazu gezwungen, den Verfolgungen tatenlos zuzusehen. Ihre Situation wurde noch dadurch erschwert, dass häufig „Frauen und Kinder, verängstigt und weinend" für ihre verhafteten Männer und Väter bei den italienischen Soldaten Schutz suchten. ${ }^{40}$ So mehrten sich auch unter italienischen Soldaten die Stimmen, die solche Aktionen nicht nur anprangerten, sondern sie als Beleidigung für „die Humanität und die Kultur“ (Italiens) ansahen. Nach der Übernahme der zivilen und militärischen Befugnisse in der II. Zone im September 1941 verbesserte sich die Situation in dieser Hinsicht, da die Ustascha entfernt wurde und die Massaker aufhörten. Sie verschlechterte sich jedoch bald darauf wieder mit den immer häufigeren Angriffen der Partisanen. Aufgrund dieser Ereignisse sah sich die Armeespitze gezwungen, die Betreuung der Soldaten immer mehr in Richtung einer auf den (Partisanen)Kampf ausgerichteten Propaganda zu verschieben.

So betonte Ambrosio bereits in seinem Neujahrsschreiben vom Dezember 1941, dass die Zeit nach der Besetzung des Landes, nämlich die der Durchkämmungsaktionen und der Unterdrückung der Kommunisten, noch schwieriger und unbequemer als die eigentlichen Kampfhandlungen sei. Die hohe Kampf-

37 AUSSME, H 1, b. 34, Sintesi delle Relazioni sul servizio „P“ per il mese di marzo inviate dai Comandi Superiori FF. AA. Albania - Grecia - Governatorato del Montenegro e dal Comando della 2. Armata, 27.4.1942; AUSSME, H 1, b. 34, Sintesi delle Relazioni sul servizio „P“ inviate dai Comandi Superiori FF. AA. Albania e Grecia e dal Comando della 2. Armata per il mese di dicembre, 22.1.1942. Auch in Dalmatien lösten kaputte Schuhe Empörung aus. Vgl. Della Volpe, Nicola: „Werden wir es jemals schaffen, nach Italien zurückzukehren?“ Italienische Feldpostbriefe aus dem Zweiten Weltkrieg, in: Vogel, Detlef/Wette, Wolfram (Hg.): Andere Helme andere Menschen? Heimaterfahrung und Frontalltag im Zweiten Weltkrieg. Ein internationaler Vergleich, Essen 1995, S. 113-134, hier S. 128.

38 AUSSME, DS, b. 819, All. 25, Relazione „P“ dal giorno 16 agosto al 15 settembre 1942.

39 AUSSME, H 1, b. 34, Sintesi delle Relazioni sul servizio „A“ per il mese di ottobre inviate dai Comandi delle G. U. dislocate fuori del territorio, 30.11.1942.

40 ASMAE, GAB-AP 1923-1943, b. 1493, Comando generale dell'arma dei carabinieri reali: Notizie varie, ohne Datum, jedoch Sommer 1941; Milizia ustascia, 11.6.1941, abgedr. i. Talpo: Dalmazia, Bd. 1, S. 468-471. 
moral solle dennoch auch während der Winterzeit erhalten bleiben. ${ }^{41}$ Doch die zermürbende Guerillataktik der Partisanen, - es handelte sich dabei um kleinere, aber konstante Attacken, welche ihren Blutzoll forderten, - setzte „spürbar die Moral der Soldaten“ herab. ${ }^{42}$ In den monatlichen Propagandaberichten wurde in Anbetracht der winterlichen Strapazen die Kampfmoral der Truppe im Januar 1942 erstmalig als „befriedigend“ beschrieben. Durchkämmungsaktionen bei bis zu minus dreißig Grad hinterließen ihre Spuren. In der Kälte versagten sogar die Waffen, da das Öl darin gefror. ${ }^{43}$ In den Briefen der Soldaten verdichteten sich ab dem Herbst 1941 Berichte über nächtliche Alarme, Erschießungen, abgesägte Telefonmasten, Eisenbahnanschläge usw.:

Die Verwüstung ist überall, niedergebrannte Häuser, völlig zerstörte Dörfer und ganze Familien ohne Dach über dem Kopf. Die Übeltäter sind immer die Kommunisten [...]. Hier ist der Krieg zu Ende, aber es ist etwas viel Schlimmeres als der Krieg geblieben. Geblieben ist der Guerillakampf, ... und so lauert der Tod auf uns, wenn wir ihn am wenigsten erwarten. $^{44}$

Doch der Schreiber dieses Briefes war im Herbst 1941 noch zuversichtlich: „In jedem Fall sind sie [die Durchkämmungsaktionen, Anm. d. Verf.] immer ein Vergnügen, denn dafür sind wir da, nicht umsonst sind wir Soldaten und Bersaglieri.“ Ob diese Einschätzung an dem relativ frühen Stadium des Guerillakrieges oder dem besonderen Status des Verfassers als Angehöriger der Eliteeinheit Bersaglieri lag, bleibt offen. Immerhin stellte die Kriegszensur zu jener Zeit fest, dass ,in den meisten Briefen das Gefühl der Ergebenheit gegenüber den größten Opfern, um den Sieg zu erringen, überwog. “ Doch es gab auch Soldaten, die einen solchen Optimismus vermissen ließen. Je weiter der Krieg voranschritt,

41 AUSSME, DS, b. 727, All. 930, Comando 2. Armata: Compiacimento-Direttive-Auguri, 16.12.1941.

42 ASMAE, GAB-AP 1923-1943, b. 1500, Telegramm des Verbindungsbüros bei der 2. Armee an das Außenministerium, GAB-AP, 14.1.1942

43 AUSSME, H 1, b. 34, Sintesi delle Relazioni sul servizio „P“ inviate dai Comandi Superiori FF. AA. Albania e Grecia e dal Comando della 2. Armata per il mese di gennaio, 1942; Mafrici, Armando: Guerriglia sulla ferrovia del petrolio (Croazia 1942-1943), Neapel 1981, S. 65.

44 VA, TV, k. 543, reg. br. 10/17-6, CPCG, Zara, Relazione quindicinale dal 16 al 30 novembre 1941. Die Bildung von Partisanengruppen wurde im italienischen Besatzungsgebiet dadurch erleichtert, dass noch vor dem Ausbruch des Krieges die illegal arbeitende KP besonders erfolgreich ein Zellensystem in den Dörfern Dalmatiens, der Lika und des Gorski Kotar, die alle im italienischen Interessensgebiet lagen, geschaffen hatte. Dies bot der KP eine gute Ausgangsbasis für den „Volksbefreiungskrieg“. Sundhaussen: Wirtschaftsgeschichte, S. 68. 
desto häufiger stellten sich Ermüdungserscheinungen ein. ${ }^{45}$ Die zunehmenden Aktionen der Partisanen sowie meist ineffektive Reaktionen der italienischen Armee waren für die Anzeichen von Müdigkeit und Resignation verantwortlich:

...und dann sind wir hier im Schlammassel, es ist schlimmer als an einer Front zu sein, wo ununterbrochen gekämpft wird. Hier denkt man sicher zu sein, aber jeden Tag verschwinden Kameraden... ${ }^{46}$

Für acht Tage haben wir ein Höllenleben oder besser ein Nordpolleben geführt...es reicht, wenn du weißt, dass wir mehr als fünfzig Erfrorene, etwa dreißig Verwundete und siebzehn Tote hatten, all das bei einer Stärke von weniger als dreihundert Mann. ${ }^{47}$

Um die sinkende Stimmung zu bekämpfen, sollte unterschiedliche Propaganda die Kampfmoral der Soldaten steigern und zur besseren Ausführung der Befehle beitragen. Am 15. März 1942 verschickte z. B. das Oberkommando des königlichen Heeres ${ }^{48}$ eigens eine Broschüre für die Truppen in den jugoslawischen Gebieten mit Direktiven für die Propaganda. Sie sollte den Kommandeuren der Abteilungen und den Mitarbeitern des Servizio $P$ Normen und Inspirationen zur schriftlichen Propaganda sowie zu Gesprächen mit der Truppe geben. Tatsächlich sollte durch die Propaganda „bei den in Kroatien und Montenegro dislozierten Abteilungen die Überzeugung eingeflößt werden, dass der Kampf, den sie führten, notwendig, verdienstvoll, von Bedeutung sowie reich an Resultaten für die Zukunft sei und deshalb mit vertrauensvollem Einsatz, mit totaler Bestimmung geführt werden müsse. “49

Einen weiteren Grund für Unzufriedenheit sahen italienische Soldaten auf dem Balkan in der mangelnden Berichterstattung über ihren Einsatz, der nicht als Kriegseinsatz gewertet wurde. Uber die dortigen Operationen wurde aus politischen Gründen nicht geschrieben. Erst Ende April 1942 meldete die Feldzeitung Tascapane, dass zum ersten Mal im Radio das Schweigen über ihren Kriegsschauplatz gebrochen worden war. ${ }^{50}$ Die Propagandaoffiziere kamen zum

45 VA, TV, k. 543, reg. br. 10/17-10, CPCG, Zara, Relazione quindicinale dal 16 al 30 novembre 1941; VA, TV, k. 565a, reg. br. 1/6, Censura postale di guerra - relazione quindicinale dal 15 al 31 gennaio 1942.

46 VA, TA, k. 565a, reg. br. 3/6-5, Censura postale di guerra - relazione settimanale dal 23 al 30 marzo 1942. Ähnlich VA, TV, k. 565a, reg. br. 2/6-4, Censura postale di guerra - relazione settimanale dal 1 al 7 marzo 1942.

47 VA, TA, k. 565a, reg. br. 4/6-6, Censura postale di guerra - relazione quindicinale dal 15 al 31 marzo 1942. Siehe auch Bedeschi (Hg.): Fronte jugoslavo-balcanico, S. 194-196.

48 Dessen Leiter war Vittorio Ambrosio, der kurze Zeit vorher noch Befehlshaber der 2. Armee gewesen war und daher den jugoslawischen „Kriegsschauplatz“ sehr gut kannte.

49 AUSSME, DS, b. 994, All. 1152, Direttive per la propaganda alle nostre truppe in territorio ex jugoslavo, 15.3.1942, S. 15.

50 NARA, T-821, R. 415, Nr. 930, Nostro Fronte, in: Tascapane vom 27./28.4.1942. 
Schluss, dass die Soldaten unzufrieden waren, weder in den Bolletini di Guerra noch in italienischen Zeitungen etwas über ihren Kriegsbeitrag lesen zu können, obwohl sie täglich ihr Leben im Kampf mit den Aufständischen riskierten. Stattdessen herrschte in Italien die Ansicht vor, sie würden ein relativ angenehmes Leben führen. ${ }^{51}$ Deshalb wurde in der Propagandabroschüre darauf hingewiesen, dass man den Soldaten zeigen müsse, dass ihr Beitrag zum Krieg genauso wichtig wie derjenige der Truppen in Afrika und in der Sowjetunion sei. Das Schweigen über ihre Taten im Vaterland sei militärisch begründet und würde eines Tages enden, so die Verfasser im Oberkommando des Heeres. ${ }^{52}$

Das Gebiet wurde aber weiterhin nicht zum Kriegsgebiet erklärt, da es sich bei Dalmatien um italienisches Staatsgebiet handelte. Dies hatte allerdings zur Folge, dass die Familien der in Kroatien und Dalmatien gefallenen Soldaten nicht die Privilegien erhielten, welche den Hinterbliebenen von im Krieg Gefallenen zustanden. Dies änderte sich im März 1942. ${ }^{53}$

Im August 1942 hatten die Truppen auf dem Balkan mehr Tote zu beklagen als diejenigen in Russland und nur unbedeutend weniger als diejenigen in Afrika, was ihre Wichtigkeit nochmals herausstellte. ${ }^{54}$ Die Berichterstattung änderte sich daher im Sommer 1942, woraufhin die Sektionen „P“ meldeten, dass die Soldaten zufrieden waren, Nachrichten von ihrem Kriegsschauplatz zu lesen und sich somit nicht mehr vergessen fühlten. Dies war scheinbar aber nur von kurzer Dauer, denn im März 1943 meldete das XVIII. Armeekorps wieder, dass aufgrund der Ausrichtung der italienischen Propaganda die Soldaten das Gefühl hätten, ihre Opfer müssten in der Heimat verschwiegen werden. ${ }^{55}$ Auf diese Beschwerden reagierte auch die Soldatenzeitung La Tradotta del Fronte Giulio. Darin wurde den Soldaten zu erklären versucht, dass jeder bereits wisse, dass der Balkan ein harter Kriegsschauplatz war, der sich nicht von anderen unterschied. Die Aufgaben dort seien zwar undankbar, aber heroisch. ${ }^{56}$

Aus allen Berichten vom Frühjahr 1942 wird deutlich, dass die Partisanenbekämpfung der dominierende Faktor der Besatzung geworden war, und sich

51 AUSSME, DS, b. 859, Df Murge: Relazione mensile sul servizio „Propaganda“, 18.8.1942; AUSSME, b. 543, All. 452, V. CdA, Propaganda comunista, 18.11.1941; Casanuova, Mario: I \%/51, Florenz 1965, S. 23.

52 AUSSME, DS, b. 994, All. 1152, Direttive per la propaganda alle nostre truppe in territorio ex jugoslavo, 15.3.1942.

53 AUSSME, H 1, b. 38, Ministero della guerra: Direzione generale leva sottoufficiali e truppa, 03.03.1942.

54 AUSSME, DS, b. 859, Df Murge: Relazione mensile sul servizio „Propaganda“, 18.9.1942.

55 AUSSME, DS, b. 1188, All. 97, Relazione mensile sul servizio „A“ dal 15 febbraio al 15 marzo 1943.

56 „Posta“ in La tradotta, Nr. 15, 11.4.1943, zit. nach: Sala, Teodoro: Guerriglia e controguerriglia, S. 98. 
die Betreuungssituation gleichzeitig verschlechterte. Jeder Division wurden ein Ton-Filmvorführgerät und 15 Filme geschickt. Darüber hinaus müssen auch einige der zusätzlichen Kopien der Giornali Luce sowie der LUCE-Dokumentarfilme die 2. Armee erreicht haben. Doch gleichzeitig untersagte die Propagandaabteilung dem Ministerium für Volkskultur die Verschickung von Filmen, die revolutionäre oder aufrührerische Gefühle hätten erzeugen können. ${ }^{57}$ Aufgrund der häufigeren Einsätze als im Sommer 1941 konnten einige Aktivitäten und Wettbewerbe nicht durchgeführt werden. Berichte der Division „Lombardia“ von August 1942 zeichneten eine nicht mehr so günstige Situation: Es war nur noch ein Kinosaal vorhanden, der nur eine Woche lang tatsächlich funktionierte; es gab nur eine Theatervorstellung, und die konnte nur deshalb stattfinden, weil die Theatertruppe in Ogulin wegen unterbrochener Verbindungen eine Zwangspause nehmen musste; immer weniger Radioapparate funktionierten, während kaputte nicht ersetzt wurden; es gab nicht genügend Zeitungen, und sportliche Übungen fanden wegen des Operationszyklus auch kaum statt. ${ }^{58}$

Im April 1942 wurden Urlaubssperren verhängt, die sich natürlich negativ auf die Truppenmoral auswirkten, je länger sie andauerten. Im August 1942 wurden sie für Soldaten, die 18 Monate und länger von zuhause weg waren, kurzfristig aufgehoben..$^{59}$ Trotzdem gab es ständig Probleme mit Heimaturlaub, da der Verkehr nicht gut funktionierte. Auch Abteilungen, die Zugverbindungen oder Fabriken überwachten, sollten aufgrund des anstrengenden Dienstes ausgetauscht werden. ${ }^{60}$

Im Mai 1942 wurde angeregt, den in Kroatien stationierten Truppen eine gewisse Summe zur Verfügung zu stellen, damit sie Nahrungsmittel zur Verbesserung der Verpflegung in den annektierten Gebieten kaufen konnten. Doch in Kroatien gab es immer weniger zu kaufen, und der Tauschhandel nahm zu. ${ }^{61}$ Dieser Vorschlag wurde abgelehnt, die Beschwerden wiederholten sich aber monatlich. Gleichzeitig war man zumindest daran gegangen, eigenständig die Verpflegung zu verbessern. In Garnisonseigenen „Kriegsgärten“ bauten die Sol-

57 AUSSME, M 7, b. 223, SMRE: Propaganda e Contropropaganda, 17.4.1942; AUSSME, H 1, b. 34, SMRE: Assistenza a favore delle truppe operanti, 20.5.1942.

58 AUSSME, DS, b. 819, All. 25, Relazione „P“ dal giorno 16 agosto al 15 settembre 1942.

59 Soldaten erreichen im Durchschnitt nach 50 Tagen im Kampfgeschehen den Zustand emotionaler Erschöpfung. Siehe: Collins, Randall: Dynamik der Gewalt. Eine mikrosoziologische Theorie, Hamburg 2011, S. 78.

60 AUSSME, H 1, b. 43, cart. 3, Sintesi delle relazioni del servizio „P“ per il mese di settembre inviate dai comandi delle G. U. dislocate fuori del territorio, 31.10.1942; AUSSME, DS, b. 993, Schreiben von General Roatta an Comando Supremo, 23.10.1942.

61 AUSSME, DS, b. 782, All. 19, al DS luglio 1942, Relazione mensile sul servizio „P“, dal 15 maggio al 15 giugno 1942. 
daten Gemüse an, die im Spätsommer tatsächlich eine deutliche Verbesserung der Mahlzeiten brachten. ${ }^{62}$ Die Reduktion der Brotration war aber so stark, dass sogar in Briefen an die Familie von „Hunger“ und „Unterernährung“ berichtet und um Lebensmittelpäckchen gebeten wurde. ${ }^{63}$

Ein weiteres Problem, das 1942 immer noch auf seine Lösung wartete, war das der fehlenden Bordelle. Bereits 1941, noch vor dem Angriff auf Jugoslawien, hatten Kontakte von Soldaten mit „fremdstämmigen“, also slawischen, Frauen in Fiume und Gorizia den Unmut des Befehlshabers der 2. Armee erregt, der sich um militärische Geheimnisse sorgte. ${ }^{64}$ Ein anders gelagertes Problem war bei der Division „Lombardia“ aufgetaucht:

Wir befinden uns im Krieg, doch viele haben die Mentalität der „Großmanöver“; in manchen Orten werden mit offensichtlicher Leichtfertigkeit Frauenbekanntschaften zur Schau gestellt, und es wird zu viel an oberflächliches Vergnügen gedacht.

Dies hatte zur Folge, dass einige Soldaten bei ihren Rendezvous in PartisanenHinterhalte gerieten. Damit sich dies nicht wiederholte, sollten Offiziere ihre Untergebenen kontrollieren und selbst mit gutem Beispiel vorangehen. ${ }^{65} \mathrm{Nach}$ dem einige Fälle von ansteckenden Sexualkrankheiten registriert worden waren, sollte die Einrichtung von Bordellen die Verbreitung von Geschlechtskrankheiten verhindern. ${ }^{66}$ Das XVIII. Armeekorps schlug im Mai vor, wenigstens bei jedem Divisionssitz ein Bordell zu eröffnen. ${ }^{67}$ Auch die „Murge“ und die „Eugenio di Savoia“ meldeten im Sommer 1942 eine „Entsittlichung der weiblichen

62 AUSSME, DS, b. 646, All. 287 al DS Aprile 1942, Relazione mensile 15 marzo - 15 aprile, 29.4.1942; AUSSME, DS, b. 819, All. 6, Df Lombardia, Relazione „P“ dal giorno 16 luglio al 15 agosto 1942.

63 AUSSME, H 1, b. 34, Sintesi delle relazioni sul servizio „P“ inviate dai comandi dislocati in Egeo, Grecia, Albania, Montenegro e Slovenia-Dalmazia per il mese di Aprile 1942.

64 AUSSME, DS, b. 235, Comando 2. Armata, Relazioni di ufficiali con donne, 9.2.1941. Diese Sorgen sollten über die ganze Besatzungszeit bestehen bleiben. Vgl. VA, TA, k. 647, reg. br. 13/ 13, Relazione sul spirito e sul morale delle truppe e delle popolazioni, 14.2.1943. Noch im Juni 1943 stand im ersten Berichtsentwurf des XXIII. Bataillons der Carabinieri: „Die Liebesbeziehungen zwischen allen Militärs mit Frauen von zweifelhafter Moral bleiben bestehen.“ (der Korrektor ließ den Satz streichen). VA, TA, k. 647, reg. br. 23/13, Relazione sul spirito e sul morale delle truppe e delle popolazioni, 16.6.1943.

65 HDA, TV, k. 5, Nr. 757, Relazioni femminili, 25.8.1942. Davon berichtet auch Francesco Amadei, ehemals Angehöriger der Division „Casale“, in: Frontali, Arturo (Hg.): Dai fronti di guerra, 1940-1945, (Testimonianze fra cronaca e storia, Seconda guerra mondiale) Milano 2001.

66 AUSSME, H 1, b. 34, Sintesi delle Relazioni sul servizio „P“ inviate dai Comandi Superiori FF. AA. Albania e Grecia e dal Comando della 2. Armata per il mese di dicembre, 22.1.1942.

67 AUSSME, DS, b. 782, All. 19 al DS luglio 1942, Relazione mensile sul servizio „P“, dal 15 maggio al 15 giugno 1942. 
Bevölkerung" und machten wegen der Gefahr von ansteckenden Krankheiten auf die Notwendigkeit von Bordellen aufmerksam, scheinbar jedoch ohne Erfolg. ${ }^{68}$

Die immer weiter sinkende Kampfmoral konnte auch dadurch nicht aufgefangen werden, dass im Juni 1942 der teilweise italienische Rückzug aus der II. und der komplette Rückzug aus der III. Zone mit den Kroaten vereinbart wurde. ${ }^{69}$ Castellani berichtete im Juli 1942 zwar von einer Verbesserung der Situation in manchen Gebieten unter italienischer Besatzung, meldete aber gleichzeitig, dass einige Abteilungen „Müdigkeitssymptome“ zeigten. ${ }^{70}$ Der Bericht der Division „Lombardia“ liest sich wie eine Zusammenfassung des vorher Angeführten. Sie berichtete vorsichtig, dass die Kampfmoral der Truppe zwar hoch sei, aber dass es einige Faktoren gab, die sich schlecht auf diese auswirkten. Dazu gehörte in erster Linie die Art der Guerillakriegsführung, welche die Division führte - ein beträchtlicher Verschleiß von Männern und Mitteln ohne nennenswerte Resultate. ${ }^{71}$

Im September 1942 war die Stimmung aufgrund des nahenden Winters und der erwarteten entscheidenden Kämpfe des kommenden Jahres weiter gefallen. In der Division „Re“ machte sich im Oktober 1942 eine Depression breit. Die „Re“ war sehr lange in einer Gegend mit weit zerstreuten Garnisonen stationiert. Davon wurden einige belagert, und viele Soldaten von den Partisanen gefangen genommen. Die Division selbst konnte den Aufständischen keine schweren Schläge versetzen und hatte somit keine Chance, Erfolgserlebnisse zu verbuchen. Hinzu kam, dass die Truppe von Unteroffizieren wohl relativ hart behandelt wurde. Ihr Befehlshaber schlug zur Verbesserung der Situation die Entfernung der Soldaten, die Gefangene der Partisanen gewesen waren, sowie die Verlegung der exponierten Abteilungen ins Innere der Division vor. ${ }^{72}$ Auch der anbrechende Winter brachte eine erneute Verschlechterung der Situation mit sich - obwohl die Truppen nicht mehr im dinarischen Gebiet stationiert waren. Die Winterausrüstung ließ wieder zu Wünschen übrig. Auch das Essen ver-

68 AUSSME, DS, b. 859, Df Murge: Relazione mensile sul servizio „Propaganda“, 18.8.1942; AUSSME, DS, b. 1309, All. 96, Relazione mensile „A“, 21.5.-20.6.1943.

69 Ciano hielt in seinem Tagebuch fest, dass sich Adelchi Serena, der frühere Sekretär des PNF, der zu dieser Zeit als Offizier bei den italienischen Einheiten in Kroatien kämpfte, abfällig über die Kampfstimmung des Heeres äußerte. Ciano: Tagebücher, 12.6.1942, S. 448.

70 ASMAE, GAB-AP 1923-1943, b. 1501, Situazione del movimento ribelle, 1.7.1942.

71 Die Kämpfe gegen die Partisanen wurden auch in den Memoiren von Armando Mafrici als der entscheidende Faktor gesehen, der zur Absenkung der Kampfmoral geführt hatte. Mafrici war bei der VIII. Kompanie des 2. Bataillons des 74. Regiments der Infanteriedivision „Lombardia“. Mafrici: Guerriglia, S. 46.

72 AUSSME, DS, b. 1222, General Roatta an den Kommandanten des V. Armeekorps, 2.10.1942. 
schlechterte sich. Ein Soldat schrieb scherzhaft, dass sie eine „Heißwasserkur“ machten, doch wenn sie genug und mit Geduld in ihrer Suppe fischten, dann könnten sie auch manchen Löffel Reis darin finden. ${ }^{73}$

Nach den Desastern in Afrika und im Osten ließen Alliierte Bombenangriffe auf italienische Städte und Urlaubsstopp für die Soldaten aus Sizilien und Sardinien die Kampfmoral manch eines Soldaten sinken. Anfang 1943 sah es das SMRE als erforderlich an, die Betreuungsarbeit zu intensivieren und den aktuellen Erfordernissen des Krieges anzupassen. Die Beeinflussung wurde jedoch durch den Verlauf des Krieges behindert. So gab auch das Kommando der 2. Armee nach einem zweiten Winter im kroatischen Hinterland zu, dass die Einheiten Zeichen von körperlicher Müdigkeit aufwiesen. ${ }^{74}$ Deutlicher war da der Bericht über die Kampfmoral des XXIII. Bataillons der Carabinieri:

Die Haltung der Offiziere, Unteroffiziere und der Truppe bleibt etwas deprimiert und die Kampfmoral ist niedrig, insbesondere die des Soldaten, der mit seinem Benehmen und mit seinen andauernden, versteckten Beschwerden seine Müdigkeit zeigt. [...] Die Kampfmoral der Truppe drücken auch die beinahe negativen Resultate der Militäroperationen gegen die Partisanenbanden aus, die in der Lika unternommen wurden, und die von uns demonstrierte Unfähigkeit, die Rebellenbewegung zu zerschlagen sowie das Funktionieren der Bahnlinie zu sichern. ${ }^{75}$

Die beschriebene Kriegsmüdigkeit der Soldaten sollte während der Operation „Weiß“ drastisch zum Vorschein kommen. Ein ganzes Bataillon der Division „Murge“ wurde von den Partisanen vernichtet. Milovan Đilas schrieb darüber in seinen Memoiren:

Alle Italiener - das gesamte 3. Bataillon des 259. Regiments der Division „Murge“ - wurden niedergemacht, da sie unsere Bedingungen nicht erfüllt hatten und um der Verbitterung unserer Krieger Luft zu machen. Nur die Fahrer ließ man am Leben, damit sie die Munition und die Verwundeten beförderten. Viele, wenn nicht sogar alle Leichen wurden in die Rama geworfen. Ich sah einige von ihnen, die an Aststummeln junger Bäume im Wasser hängen geblieben waren, und teilte mit Kommandanten und Kämpfern die boshafte Freude bei der Vorstellung vom Entsetzen der italienischen Offiziere auf den Brücken und Ufern von Mostar, wenn sie die von der Neretva haufenweise angeschwemmten Leichen sehen würden. ${ }^{76}$

73 VA, TA, k. 565a, reg. br. 15/6-7, CPCG, Zara, Relazione quindicinale dal 1 al 15 dicembre 1942.

74 AUSSME, M 7, b. 223, SMRE, Intensificazione all'assistenza morale alle truppe, 29.1.1943; AUSSME, H 1, b. 34, Sintesi delle Relazioni sul servizio „A“ per il mese di marzo inviate dai Comandi delle G. U. dislocate fuori del territorio.

75 VA, TA, k. 647, reg. br. 12/3, Relazione sullo spirito e sul morale delle truppe e delle popolazioni, 14.2.1943.

76 Đilas: Der Krieg der Partisanen, S. $288 \mathrm{f}$. 
Darüber hinaus nahmen die Partisanen ein weiteres Bataillon der Italiener gefangen. Ein höherer Offizier wurde erschossen, die anderen Gefangenen mussten verwundete Partisanen transportieren, oder sie wurden den Versorgungseinheiten zugeteilt. Diejenigen, die die Anstrengungen und die schlechte Verpflegung überlebten, - sie mussten schwerere Arbeiten verrichten und wurden gleichzeitig schlecht versorgt, - blieben bei den Partisanen bis zur Operation „Schwarz“. Als in den Bergen Montenegros die Situation immer aussichtsloser wurde, besiegelte ein Zwischenfall das Schicksal der italienischen Gefangenen. Der italienische Gehilfe von Vladimir Nazor ${ }^{77}$ floh und stahl dabei ein Manuskript Nazors. Man vermutete weiterhin, er habe den Deutschen Angaben über den Standort des Obersten Stabes gegeben, was diesen dazu veranlasste zu befehlen, alle übrigen Italiener - es handelte sich um „zwei-, dreihundert, vielleicht auch mehr“, - zu erschießen. Dazu schreibt Đilas:

Aber schon in Vučevo, inmitten des Sterbens und der Bombenangriffe, erreichten uns ergreifende Berichte: Es hatte Partisanen gegeben, die weinend die italienischen Gefangenen töteten - ihre Leidensgenossen, mit denen sie sich während der zahlreichen Qualen und Anstrengungen angefreundet hatten, und denen sie - aus Sympathie - bisweilen jugoslawische Namen gaben... ${ }^{78}$

Angesichts solcher Desaster der „Murge“ sprach der italienische Konsul in Sarajevo von Soldaten „in wahrlich Mitleid erregendem physischen und moralischen Zustand“. ${ }^{79}$ Wie sehr der Guerillakrieg an den Nerven der Soldaten zehrte, machen auch Hoffnungen deutlich, dem Gegner eines Tages in die Augen sehen zu können. ${ }^{80}$ Ein Soldat schrieb nach Hause:

... ich sage euch nur, dass ich mehr Freude hätte, in Russland zu sein, weil ich mir sicher bin, dass man dort dem Feind gegenüber steht, und er nicht wie hier von allen Seiten kommt. ${ }^{81}$

77 Vladimir Nazor (1876-1949) war ein bekannter kroatischer Dichter, der sich trotz seines hohen Alters den Partisanen angeschlossen hatte. Dies hinterließ großen Eindruck im ganzen Land und bei den Besatzern, da sein Aufruf zur Brüderlichkeit über das Partisanenradio die pro-kommunistische Gesinnung bei der Bevölkerung verstärkte. NARA, T-821, R. 248, Nr. 440445, Notizie della Croazia, 19.5.1943.

78 Đilas: Der Krieg der Partisanen, S. 355 f.

79 ASMAE, GAB-AP 1923-1943, b. 1497, Sintesi del telespresso inviato a questo R. Ministero in data 22.3. (1943) dal R. Console Generale in Serajevo a riguardo della situazione politica (ohne Datum).

80 AUSSME, DS, b. 1309, All. 96, Relazione mensile „A“, 21.4.-20.5.1943.

81 Zit. nach Ceva, Lucio: Voci dai vari „Fronti“, in: Carlotti, Anna Lisa (Hg.): Italia 1939-1945. Storia e memoria, Mailand 1996, S. 173-204, hier S. 174. 
Mit dem Beginn des Jahres 1943 konnte in Kroatien schließlich gar nichts mehr gekauft werden, entweder weil es die Produkte nicht gab, oder weil die Inflation die Produkte so verteuert hatte, dass die Soldaten sich nichts leisten konnten. Von der Abteilung „A“ des SMRE wurde auf eine Lösung gedrängt, da sich die Situation negativ auf den geistigen und physischen Zustand der Truppe auswirkte. Einige Garnisonsläden mussten sogar ihre Arbeit einstellen, weil sie keine Lieferungen bekamen. Zwar wurde auch 1943 von den Kriegsgärten profitiert, aber diese reichten nicht aus, um die Mahlzeiten richtig aufzuwerten. In Knin gab es Fälle von Vitaminmangel. ${ }^{82}$ Trotzdem blieb das Verbot erhalten, Waren aus Italien einzuführen, und erschwerte auch weiterhin die Versorgung der in Kroatien dislozierten Verbände. Um die Versorgung zu erleichtern, wurde im April 1943 angedacht, zwei Sammelzentren in Zara und Split zu errichten, um dort Waren zur Verbesserung der Mahlzeiten zu sammeln. Dort hätten dann einzelne Einheiten fehlende Waren kaufen können. ${ }^{83}$ Ob dies vor der Kapitulation erfolgt ist, kann nicht festgestellt werden, wahrscheinlich ist es jedoch nicht, da sich die italienische Armee im Sommer 1943 weitgehend nach Dalmatien zurückgezogen hatte. Wie sehr die Versorgungsfrage die Soldaten beschäftigte, sieht man an Karikaturen, die Soldaten an die Feldzeitung La Tradotta del Fronte Giulio schickten. In den Träumen der illustrierten Soldaten taucht am häufigsten Essen auf, dicht gefolgt von der Sehnsucht nach der Familie, die man im Urlaub zu sehen hoffte. ${ }^{84}$

Neben der bereits vorgestellten, materiellen Betreuung erhielten die Soldaten auch speziell auf sie zugeschnittene Propaganda in Form von Armeezeitungen, die von der 2. Armee, den Armeekorps oder Divisionen herausgegeben wurden. Sie transportierten genau die von der Armeespitze und den Verantwortlichen in der Propagandaabteilung gewünschten Inhalte. Häufig bildeten sie die Grundlage für die propagandistische Arbeit der Offiziere mit ihren Soldaten. Neben

82 AUSSME, H 1, b. 34, Sintesi delle Relazioni sul servizio „A“ per il mese di febbraio inviate dai Comandi delle G. U. dislocate fuori del territorio; AUSSME, DS, b. 1290, All. 226, Relazione mensile sul servizio „A“, 15.5.-15.6.1943.

83 AUSSME, DS, b. 1138, All. 14, Relazione mensile „A“, 18.4.1943; AUSSME, H 1, b. 34, Sintesi delle Relazioni sul servizio „A“per il mese di marzo inviate dai Comandi delle G. U. dislocate fuori del territorio.

84 NARA, T-821, R. 440, Nr. 423, „All'ospedale“; Nr. 433, „Quando le esigenze non lasciano esitare“; Nr. 450 „Il sogno“; Nr. 453 „L'ora del riposo“; Nr. 455, ohne Überschrift (schlafender Soldat, der von Zuhause träumt). 
den Zeitungen waren noch die Befehle der Vorgesetzten, die ebenfalls Propagandainhalte transportierten, für die Beeinflussung der Soldaten wichtig. ${ }^{85}$

Auf kroatischem Gebiet wurden mehrere dieser Zeitungen verteilt. La Tradotta del Fronte Giulio wurde von der Propagandaabteilung der 2. Armee produziert und an alle drei Korps der Armee kostenlos im Verhältnis 1:10 zur Stärke der Truppe verteilt. Sie erschien seit dem 6. Juni 1942 wöchentlich in einer Auflage von 25.000 Stück. ${ }^{86}$ So kann man davon ausgehen, dass ihre Inhalte die meisten Soldaten erreichten. Mit dem Namen knüpften die Macher an die populäre Tradotta der 3. Armee an, als deren Nachfolgerin sich die 2. Armee sah. Die erste Tradotta war im Jahr 1916 herausgegeben worden. Die „neue“ Tradotta sollte die Soldaten mit politischen Informationen versorgen und ihnen insbesondere den Charakter des laufenden Krieges erklären. Das primäre Ziel war es dabei, die Soldaten moralisch zu unterstützen: ihnen Heimweh zu nehmen und $\mathrm{zu}$ zeigen, dass die Heimatfront ihre Anstrengungen verfolgte, würdigte und mit ihnen litt. Zudem sollte stets der aggressive Geist der Soldaten hochgehalten werden, ihre Zähigkeit und ihre moralische Kraft. Bezüglich der Propaganda hieß es: „Die Zeitung wird für die Soldaten gemacht - Soldaten im Krieg. Also keine Trommelpropaganda, sondern entschiedene Propaganda: linear ausgedrückt, mit gelassener Einfachheit.“87 Alle Soldaten wurden dazu aufgefordert, bei der Gestaltung der Tradotta mit Texten, Bildern, Fotos oder Spielen mitzumachen. ${ }^{88}$ Die Tradotta war, wenn man den Berichten der Propagandaabteilungen Glauben schenken darf, ein voller Erfolg. Beim XVIII. Armeekorps kam sie ab Mai 1942 an und wurde gut aufgenommen. Im August meldete die „Lombardia“, die Tradotta habe sofort den größten Erfolg gehabt und sei sehr populär. Sie wurde für ihren Humor, für die aktuellen Einfälle sowie für die „sympathischen“ Beiträge über das Militärleben auf dem Balkan geschätzt. ${ }^{89}$ Ähnliches berichtete im Sommer 1942 auch die „Murge“.

Zudem hatten die Armeekorps und einige Divisionen (evtl. auch alle, doch ist dies nicht für alle überliefert) ihre eigene Zeitung. Das XVIII. Armeekorps

85 Ähnliches hat Messerschmidt für die Wehrmacht festgestellt. Messerschmidt: Ideologie, S. 222.

86 AUSSME, DS, b. 994, All. 1218, Schreiben der Propagandaabteilung der 2. Armee, 1.6.1942. Die Division „Re“ bekam beispielsweise 6.000 Kopien. NARA, T-821, R. 436, Nr. 4, Df „Re“: Andamento e sviluppo del servizio „A“, 21.6.1943.

87 NARA, T-821, R. 414, Nr. 614-619, Comando della 2. Armata, sezione propaganda: „La tradotta del fronte Giulio“.

88 AUSSME, DS, b. 994, All. 1181, Intendanz der 2. Armee an alle Einheiten, 11.5.1942.

89 AUSSME, DS, b. 819, All. 6, Relazione „P“ dal giorno 16 luglio al 15 agosto 1942; AUSSME, DS, b. 1068, All. 125, Comando XVIII. CdA: Relazione mensile sul servizio „P“ dal 15 dicembre 1942 al 15 gennaio 1943. 
profitierte von der Popolo di Spalato, die zwar eine handelsübliche Zeitung war, aber eine Seite per voi soldati produzierte, die von der Propagandaabteilung des XVIII. Armeekorps redaktionell betreut wurde. ${ }^{90}$ Das XVIII. Armeekorps bekam täglich im Durchschnitt 4.000-4.500 Exemplare, und erreichte damit ungefähr 15.000-20.000 Leser. Bis September 1942 wurde sie auch an bestimmte Einheiten des VI. Armeekorps verteilt, die das Abonnement kündigten, als das VI. Armeekorps eine eigene Zeitung bekam. ${ }^{91}$ Die Meinungen über die Beliebtheit und den Wert dieser Zeitung gingen weit auseinander. Die Abteilung „P“ der Division „Murge“ meldete beispielsweise, dass die Popolo di Spalato uninteressant sei. Viel lieber hätten die Soldaten Zeitungen aus Piemont bekommen, woher die meisten von ihnen stammten. Sehr gut wurde hingegen die Tradotta aufgenommen, die auch als wertvoll für die Truppe erachtet wurde. ${ }^{92}$ Die Popolo di Spalato ging ab Herbst 1942 ebenfalls verstärkt auf den Guerillakrieg auf dem Balkan ein. Ein Problem hatte sie allerdings, das jedoch technischer Natur war: Da ihre Zustellung von den einzelnen Kommandos organisiert war, erreichte sie viele Einheiten mit Verspätung, was ihren Wert minderte. ${ }^{93}$

Das VI. Armeekorps war sehr fleißig, was die Herausgabe der Zeitungen anging. Neben dem Bulletino publizierte es ab dem 1. September 1942 seine eigene Zeitung La Sentinella. ${ }^{94}$ Diese kam bei den Soldaten deutlich besser an als die Popolo di Spalato, weil sie zeitnahe Informationen brachte. Daneben erschienen noch Il Tascapane, die Zeitung der Division „Marche“, und Notiziario der Abteilung „I“ der Division „Messina“. 95 Die Division „Lombardia“ publizierte ab August 1942 ihre Zeitung Cravatta azzurra.

Die Notizario di Corpo d'Armata des V. Armeekorps wurde von Beginn der Besatzung an herausgegeben. Im September 1941 verlangte das V. Armeekorps mehr antikommunistische Anregungen, da sie die Grundlage für die Offiziere für die Arbeit mit den Soldaten bildete und aufgrund der wöchentlich ankommenden 700 Stück bis zur Kompanie verteilt wurde. Dies geschah dann auch. Im November wurde ihr Erscheinungsrhythmus von sieben auf drei Tage umge-

90 AUSSME, DS, b. 1068, All. 29, Relazione sul servizio „A“, 15.11.-15.12.1942; AUSSME, DS, b. 782, All. 208, al DS luglio 1942, Relazione mensile dal 15 giugno al 15 luglio 1942.

NARA, T-821, R. 414, Nr. 429, Pubblicazioni di reparto, 21.4.1942.

91 AUSSME, DS, b. 1068, All. 29, Relazione sul servizio „A“ dal 15 novembre al 15 dicembre 1942.

92 AUSSME, DS, b. 859, Df Murge: Relazione mensile sul servizio „Propaganda“, 18.8.1942.

93 AUSSME, DS, b. 1068, All. 121, Comando XVIII CdA: Relazione mensile sul servizio „P“ dal 15 dicembre 1942 al 15 gennaio 1943.

94 AUSSME, DS, b. 782, All. 208, al DS luglio 1942, Relazione mensile dal 15 giugno al 15 luglio 1942.

95 NARA, T-821, R. 414, Nr. 429, Pubblicazioni di reparto, 21.4.1942. 
stellt, um die neuesten Nachrichten zu bringen, wobei gleichzeitig der Umfang auf drei bis vier Seiten reduziert wurde. Ihre Herausgeber behielten die ,antikommunistischen Stichpunkte" und hoben alle Kriegsnachrichten hervor, die die Stimmung der Soldaten positiv beeinflussten. ${ }^{96}$

Die Macher der Zeitungen hielten sich an die Direktiven für die Propaganda, die sie im März 1942 erhalten hatten. Darin wurde insbesondere auf die folgenden Punkte eingegangen: die Rebellen und ihre Bindung an England und Russland, Italiens Mission, politische und historische Propaganda. In der Darstellung der Ereignisse seit dem Feldzug gegen Jugoslawien wurde ein kroatienfreundlicher Kurs gefahren. Die in Kroatien verteilten Truppen sollten die Festigung der neuen staatlichen Behörden unterstützen sowie der vom „serbischen Joch" befreiten Bevölkerung Freundschaft und Hilfe anbieten und ein friedliches Leben miteinander ermöglichen. Die italienischen Truppen wurden als Opfer der leichtsinnigen einheimischen Personen dargestellt, die von ausländischen Agenten aufgehetzt wurden. Diese Elemente hatten laut der Propaganda den Fehler begangen, sich mit englischen und bolschewistischen Agenten zu verbünden, anstatt mit dem natürlichen Verbündeten Italien, das so „nah, stark und römisch gerecht“97 sei. Da die italienische „Gutherzigkeit“ auf dem Balkan für eine Schwäche gehalten würde, müssten alle mit unnachgiebiger Strenge gegen die einen Guerillakrieg führenden Aufständischen vorgehen und diese vernichten. Desweiteren sollten den Soldaten genau die Kriegsziele erklärt werden: die Sicherung des Sieges von April 1941, die Verhinderung eines neuen Jugoslawien sowie die Konsolidierung der neuen italienischen Grenzen in Dalmatien, die das Verteidigungssystem im Osten des Vaterlandes ergänzten. Diese Direktiven hatten eine eindeutige antiserbische Spitze. Darüber hinaus sollte die Angst vor der Ausbreitung des Bolschewismus geschürt werden. Unter dem Motto „Moskau oder Rom“ sollte den Soldaten deutlich gezeigt werden, dass Italiens Unabhängigkeit, Kultur, Religion und Familie bedroht wären, falls die kommunistischen Rebellen einen Sieg davon tragen würden..$^{98}$

Abgesehen vom Kampf gegen den Bolschewismus entsprachen die Vorgaben aus Rom nicht den Erfahrungen der Soldaten vor Ort, ja, sie stellten sie zum Teil

96 AUSSME, DS, b. 449, All. 335, Attività svolta nel mese di settembre (1941); AUSSME, DS, b. 543, All. 563, V. CdA: Attività svolta nel mese di novembre 1941.

97 AUSSME, DS, b. 994, All. 1152, Direttive per la propaganda alle nostre truppe in territorio ex jugoslavo, 15.3.1942, S. 5.

98 AUSSME, DS, b. 994, All. 1152, Direttive per la propaganda alle nostre truppe in territorio ex jugoslavo, 15.3.1942. Siehe auch Collotti, Enzo/Klinkhammer, Lutz: Zur Neubewertung des italienischen Faschismus. Gespräch mit Enzo Collotti, in: Geschichte und Gesellschaft. Zeitschrift für historische Sozialwissenschaft, 26 (2000) 2, S. 285-307, hier S. 293. 
auf den Kopf. ${ }^{99}$ Dies zeigt sich vor allem in ihren Briefen. So beurteilten sie die Dalmatiner besonders schlecht, denen Verlogenheit vorgeworfen wurde. Diese seien tagsüber ganz brav und grüßten faschistisch, würden aber einen erschießen, sobald man sich umdrehte. Besser schnitten die Bewohner der dinarischen Berge ab, da sie zumindest ihre Abneigung gegenüber den Italienern nicht verbergen konnten. ${ }^{100}$ Deshalb finden sich kaum Artikel, die die prokroatische Thematik aufnahmen. Grundsätzlich befand sich die Propaganda in einem unlösbaren Dilemma. Einerseits sollte zwischen der Bevölkerung und den Aufständischen unterschieden werden, andererseits machten aber viele Befehle diese Unterscheidung nicht und charakterisierten Slawen an sich als Verbrecher, Banditen oder Wilde. Dies übernahm dann manchmal auch die Propaganda. ${ }^{101}$

Der große Tenor der Propaganda in den Zeitungen und darüber hinaus war der antibolschewistische Kreuzzug. Das ist leicht verständlich, da von den kommunistischen Aufständischen auch die größte Gefahr für die italienischen Soldaten ausging, und das - vom Standpunkt der Propagandaoffiziere - in zweifacher Hinsicht: Zum Einen bedrohten sie das Leben der italienischen Soldaten, und zum Anderen versuchten sie durch ihre Propaganda, den Kampfgeist der Soldaten negativ zu beeinflussen. Daher ist es nicht verwunderlich, dass sich die Vorgaben bezüglich des Antibolschewismus fast wörtlich in den Soldatenzeitungen wiederfanden:

Dafür haben wir die dalmatinische Küste besetzt, in Erinnerung an die alte venezianische Pracht, um den Damm gegen die neue östliche Barbarei aus Moskau zu errichten. Und mehr denn je konkretisiert sich heute hier auf dem Balkan, wie auf den grenzenlosen Ebenen Russlands, unser sakrosankter Glaube: Entweder Rom oder Moskau. ${ }^{102}$

Die Propaganda stellte den Gegensatz Zivilisation - Barbarei auf. Dieser Gedanke durchzog alle Propagandaerzeugnisse wie ein roter Faden. ${ }^{103}$ Einerseits ging es darum, so wurde es den Soldaten eingeimpft, auf dem Balkan die „zivilisatorische Mission“ Italiens zu erfüllen. In der Propaganda manifestierten sich so-

99 Vergleiche Kap. 5.

100 VA, TA, k. 565a, reg. br. 10/6-4, Censura postale di guerra-relazione quindicinale dal $1^{\circ}$ al 15 settembre 1942; VA, TA, k. 565a, reg. br. 13/6-6, Censura postale di guerra-relazione settimanale dal 15 al 21 novembre 1942.

101 Ähnliches hat bereits Amedeo Osti Guerrazzi für Slowenien festgestellt. Osti Guerrazzi: L'esercito, S. 32.

102 „Guerriglia“, in La tradotta, Nr. 17, 27.9.1942, zit. nach Sala: Guerriglia e controguerriglia, S. 95 .

103 Collotti: Politica di repressione, S. 192 f. Zur Entstehung des Antislawismus an der östlichen Grenze Italiens siehe Ara, Angelo/Magris, Claudio: Trieste. Un'identità di frontiera, Torino 1982; Cattaruzza: L'Italia e il confine orientale, insbesondere S. 43-68, 168-188. 
mit die Inhalte des faschistischen Imperialismus, der versuchte, einen italienischen spazio vitale zu schaffen. ${ }^{104}$ Andererseits aber bezog sich die „Barbarei“ oft explizit auf die Partisanen, während versucht wurde, die „friedliche Bevölkerung“ von diesen zu distanzieren. Parallel zum Bemühen, die Bevölkerung für sich zu gewinnen, musste auch den Soldaten der Unterschied zwischen den „gottlosen, von Moskau bezahlten Banditen“ einerseits und der „friedlichen Bevölkerung“ andererseits deutlich gemacht werden. In diesem Zusammenhang passte der Antislawismus nicht gut, da es sich ja sowohl bei Partisanen als auch der Bevölkerung um Slawen handelte. Auch wenn antislawische Argumente hin und wieder bemüht wurden, um die Gesetzlosigkeit des Partisanen und seine niedere Stellung zu erklären, so war seine Anhängerschaft zum Bolschewismus entscheidend. ${ }^{105}$ In der Tradotta wurden häufig unter der Rubrik Notiziario telegrafico della Balcania kurze Nachrichten abgedruckt, die genau zwischen den Partisanen und der Bevölkerung unterschieden:

Die Anführer geben sich Redeorgien hin [...] und versuchen, die arme Landbevölkerung zu betäuben, die arbeiten und in Ruhe gelassen werden will. Welche Lügen werden diese Pädagogen der kommunistischen Internationale erfinden? Vielleicht werden sie sagen, dass die Razzien und die Gewalttaten, die von den Partisanen verübt werden, für den zukünftigen Wohlstand des Volkes notwendig sind? Diese Form der Propaganda hat, wie es scheint, keinen Erfolg gehabt, denn in sehr vielen Zonen bitten die Bauern inständig darum, sich unter den Schutz der italienischen Fahne stellen zu dürfen. ${ }^{106}$

Wie in diesem Text wurde in vielen anderen betont, dass die Bevölkerung vor den Partisanen fliehe und bei den Italienern Schutz suche. ${ }^{107}$ Eine große Rolle beim Vermitteln solcher Inhalte spielten auch die Bilder, welche die Texte begleiteten. Sie zeigten beispielsweise italienische Soldaten, wie sie den Armen spendeten. Der Kommentar zum Bild lautete: „Christliche Nächstenliebe des julianischen Infanteristen auf dem Balkan“. Auf vielen Bildern waren italienische Soldaten mit invaliden Kindern abgebildet. Die Bildüberschrift konnte lauten: „Unschuldige Opfer des balkanischen Kommunismus finden ihre Rettung im

104 Siehe auch Sala: Guerriglia e controguerriglia, S. 99.

105 Anders argumentiert Enzo Collotti, der im antislawischen Rassismus eine entscheidende Komponente für die Entmenschlichung der Partisanen sieht. Vgl. Collotti: Politica di repressione, S. 193-195; Collotti: Sul razzismo antislavo.

106 NARA, T-821, R. 440, Nr. 1009, „Basta con le conferenze!“, in: La tradotta, Nr. 12/II, 21.3.1943. Weitere ähnlche Artikel: NARA, T-821, R. 440, Nr. 866, 876, 879, 960, „Siamo in pochi!“, in: La tradotta Nr. 24/II, 13.6.1943, „Il pane e le donne“ und „Testimonianze“, in: La tradotta, ohne Nr. (nach Mai 1943), „I soldati sono buoni“, in: La tradotta Nr. 22/II, 30.5.1943, „Mentalità partigiana“, in: La tradotta Nr. 32/II, 8.8.1943.

107 NARA, T-821, R. 440, Nr. 1013, „Razzie, razzie, sempre razzie!“, in: La tradotta, Nr. 13/II, 28.3.1943. 
italienischen Infanteristen“. ${ }^{108}$ Ein Bild, das einen Soldaten zeigte, der einem kleinen, dünnen Jungen ein Stück Brot reichte, wurde von einem kurzen Artikel mit der Überschrift „Latinità“ begleitet. Darin wurde gezeigt, wie der italienische Soldat sich gegenüber seinen Gegnern sowie der Bevölkerung verhalten sollte:

\begin{abstract}
...Überall siegreich, überall mit seinem gutherzigen Lächeln des Mannes vom Land, bringt er jene echte menschliche Stärke, die großen und zivilisierten Nationen eigen ist. Und es ist keine hohle Rhetorik und auch keine Schwäche, wenn er sich, angehalten vom Augenausdruck des ausgehungerten kleinen Jungen, mit der väterlichen Geste - das Brot gebrochen - nach vorne lehnt mit einem Angebot, das die menschlichen Dinge übersteigt, und sie, den guten Infanteristen und das fremde Kind, vielleicht alleine vor Gott bringt. Aber auch wenn der italienische Infanterist in diesen durch den blinden Hass des Moskauer Kommunismus vergifteten balkanischen Ländern, der sie dazu gebracht hat, nach der Hand zu schnappen, die ihnen in Treue ausgestreckt worden war, noch fähig ist, sich einem nicht zu bremsenden Instinkt des Mitleids hinzugeben, soll der tödliche Feind diese Großzügigkeit nicht für Schwäche missverstehen: Wir wissen, mit welchen Schlangen wir es zu tun haben! Aber wir sind groß und zivilisiert sowie waffenstark genug, um den Hunger eines kleinen Jungen zu stillen und denjenigen, der sich als Feind Roms zeigt, ohne jedes Mitleid und bis zum Letzten zu zerstören. ${ }^{109}$
\end{abstract}

Wichtig ist in diesem Zusammenhang festzuhalten, dass es sich hierbei nicht um Propaganda für die Bevölkerung handelte, sondern für die Soldaten. Sie sollten lernen zwischen der friedlichen Bevölkerung - hier in Gestalt eines Jungen - und den kommunistischen Aufständischen zu unterscheiden. Die Zugehörigkeit zur römischen höheren Zivilisation wurde so ausgelegt, dass sie ein humanes Vorgehen gegenüber der friedlichen Bevölkerung erlaubte. Die „kommunistischen Schlangen“, die in einer weiteren den Text begleitenden Karikatur dargestellt wurden, sollten hingegen ohne Gnade bekämpft werden. Der italienische Soldat musste stets hart und unbeugsam diesen gegenüber treten. Da die Kommunisten sich des Guerillakampfes bedienten, wurden sie als „Banditen, falsche Kämpfer, Verräter oder Schurken“ bezeichnet. ${ }^{110}$ Der Befehlshaber des XVIII. Armeekorps sprach von „kommunistischen Horden, ohne Glauben und ohne Hoffnung“. Als eine vom Nachschub abgeschnittene Garnison sich mit Hilfe der Verstärkung aus der Isolation befreien konnte, lobte ihr Befehlshaber ihr Verhalten, mit dem sie am 28. Oktober 1942 das zwanzigjährige Jubiläum

108 NARA, T-821, R. 440, Nr. 875, Nr. 1009, 1012, La tradotta ohne Nummer, La tradotta, Nr. 12/ II, 21.3.1943, Titelseiten der tradotta, Nr. 13/II, 28.3.1943; NARA, T-821, R 414, Nr. 222, La tradotta Nr. 26/I, 29.11.1942.

109 NARA, T-821, R. 414, Nr. 222, „Latinità“, in: La tradotta Nr. 26/I, 29.11.1942.

110 NARA, T-821, R. 299, Nr. 141, XVIII Armeekorps an alle Einheiten, 8.12.1942; NARA, T-821, R. 440, Nr. 888, „Bande. Banditi“, in La tradotta Nr. 20/II, 16.5.1943. 
der Revolution würdig gefeiert habe - gegen die blinde kommunistische Wut. ${ }^{111}$ Im Tascapane vom 20. April 1942 wurde der Gegner folgendermaßen beschrieben:

Wer sind diese unsere Feinde? Vor allem sind es Räuber wie ihre Väter, ihre Großväter, ihre Urgroßväter, ihre Ahnen bis zur ersten ursprünglichen Generation. Menschen, die nicht arbeiten, weil sie den Raub vorziehen. Dann sind sie Bolschewisten. Authentische Bolschewisten, nicht geringer als diejenigen in Moskau. Vielleicht schlimmer. [...] Es sind Reste jener Armee, die uns letztes Jahr nicht Widerstand leisten konnte, weil sie als Räuber und Bolschewiken nicht in einer offenen Schlacht das Gesicht zeigend zu kämpfen wissen, sondern nur Hinterhalte und Fallen stellen und Massaker verüben, also treulose Aktionen begehen. Es sind keine „Feinde“, sie befinden sich außerhalb des Gesetzes. Sie genießen nicht das Recht, Menschen genannt zu werden. Sie sollen ohne Gnade getötet werden. ${ }^{112}$

Auch in einem 1943 verteilten Flugblatt, in dem die aus Russland zurückkehrenden Soldaten begrüßt wurden, wurde der Bogen von den „heldenhaft“ im Osten kämpfenden italienischen Truppen zum Feind auf dem Balkan gezogen. Der Feind war dabei derselbe wie in Russland. Die „Zerstörer des Bolschewismus auf dem Balkan“ sollten ihre „Brüder“ grüßen, die denselben unveränderbaren Hass gegen den gemeinsamen Feind gezeigt hatten. ${ }^{13}$

Die Gründe für die Bekämpfung der Aufständischen, die sich gegen den „gerechten Frieden“ auflehnten, wurden bald durch das Motiv der Rache für die getöteten Kameraden erweitert. In derselben Ausgabe der Tradotta, die den zitierten Artikel „Latinità “ beinhaltete, findet sich auch ein Artikel über eine Durchkämmungsaktion, die unternommen wurde, um drei Soldaten zu rächen, die in einen Hinterhalt geraten waren. ${ }^{114}$ Diese Propaganda bestätigte nur das, was die Soldaten täglich erfuhren: Hinterhalte, Überfälle, Guerillakrieg. Hinzu kam, dass sie erstaunt beobachteten, wie die „Slawen“ sich gegenseitig umbrachten und ihre Häuser niederbrannten. Die eigenen Erfahrungen zusammen mit der Propaganda schürten ihre Vorurteile und Rachegedanken. Bereits im Herbst 1941 zeigten die in Dalmatien stationierten Soldaten in den Briefen nach Hause Hass auf die „Unruhestifter“ und sehnten sich nach „ehrlicheren“ Feinden. Die Zensur stellte aufgrund des nervenzehrenden Guerillakampfes einen „rachsüchtigen Geist“ fest. ${ }^{115}$ Die Aufständischen in Kroatien wurden als „wilde Banditen, mit Kommunismus durchtränkt“ oder als „kommunistische Banditen,

111 AUSSME, DS, b. 881, All. 350 al DS di Ottobre 1942, Alle truppe del XVIII CdA, 29.10.1942.

112 NARA, T-821, R. 415, „Nostro Fronte“, in Tascapane Nr. 84, 20.4.1942.

113 HDA, TV, k. 18, Nr. 2923, Flugblatt an die italienischen Soldaten, ohne Datum (1943).

114 NARA, T-821, R. 414, Nr. 222, „Alamari nei boschi“, in La tradotta Nr. 26/I, 29.11.1942.

115 VA, TA, k. 565a, reg. br. 5/6-5, CPCG, Zara, relazione quindicinale dal $1^{\circ}$ al 15 aprile 1942. 
die nur der Verachtung und der Zerstörung würdig“ seien, beschrieben. ${ }^{116}$ Diese Empfindung wurde bestärkt, wenn sie Opfer von Anschlägen wurden. So schrieb ein Soldat, dass sie ihm alles Wertvolle abgenommen hätten. In Karikaturen, die Soldaten an die Redaktion der Tradotta schickten, machten sie sich über die „crucchi ribelli“117 lustig, die den Italienern nicht das Wasser reichen könnten. ${ }^{118}$ Doch manchmal blitzte zwischen den Zeilen auch ein wenig Bewunderung für die „Banditen“ hervor: „Was für eine Brut! Es scheint, dass sie dem Tod trotzen, um sich zu rächen und die Bahnen in die Luft zu jagen."119

Wenn dann „Erfolge“ im Partisanenkampf verbucht werden konnten, wurden sie auch an die Bekannten und Verwandten gemeldet. Dabei ist auch hier die Ähnlichkeit in der Sprache zwischen den Briefen und der offiziellen Propaganda unübersehbar:

...vor einigen Tagen sind wir zu einer Durchkämmungsaktion aufgebrochen und hatten einen harten Kampf gegen die Rebellen und neun unserer Kameraden, und zwei Offiziere sind gestorben und zudem wurden 21 verwundet, aber wir hatten die Genugtuung, etwa $200 \mathrm{zu}$ töten, also eine ganze Bande, wir haben sie vernichtet. ${ }^{120}$

In diesen Tagen hatten wir, wie ich dir erzählt habe, Arbeit aufgrund von diesen verfluchten crucchi kommunistischen Rebellen, diesen ohne Gesetz, und ohne Humanität, [...], aber sie haben von uns Soldaten Italiens die Antwort bekommen, und für jeden unseren Gefallenen trifft das italienische Blei dreifach. Ich nehme an diesen Operationen teil, ich sage dir, dass ich mit Willen arbeite, weil ich festgestellt habe, dass diese unzivilisierten und hässlichen Leute die Strafe verdienen und bald wird auch hier der gerechte Frieden von Rom hergestellt sein... ${ }^{121}$

Ob dies bedeutet, dass die Soldaten die Propaganda verinnerlicht hatten, oder ob sie ihrem Frust nur in den ihnen bereits bekannten Worten freien Lauf ließen, kann nicht mit Sicherheit beantwortet werden.

Die antikommunistische Propaganda wurde auch deshalb stark betrieben, weil die Kommunisten ihre Propaganda beständig und von Anfang an nicht nur unter der Bevölkerung, sondern auch unter den italienischen Soldaten verbrei-

116 VA, TV, k. 543, reg. br. 10/17-(6, 7, 11, 14), CPCG, Zara, Relazione quindicinale dal 16 al 30 novembre 1941; VA, TV, k. 565a, reg. br. 4/6-13, Censura postale di guerra - relazione quindicinale dal 15 al 31 marzo 1942.

117 Pejorativer Ausdruck für Deutsche und Jugoslawen, der vom kroatischen Wort für Brot (kruh) stammt. Er wurde auch in der Propaganda verwendet, allerdings nur für Jugoslawen: NARA, T-821, R. 440, Nr. 968, „I crucchi e la speranza“, in: La tradotta, Nr. 24/II, 22.8.1943. 118 NARA, T-821, R. 440, Nr. 397, Zwei Karikaturen des Gefreiten Giuseppe Maugeri. 119 VA, TV, k. 565a, reg. br. 1/6, Censura postale di guerra - Relazione quindicinale del 15 al 31 gennaio 1942.

120 VA, TA, k. 565a, reg. br. 9/6-8, CPCG, Zara, relazione quindicinale dal $1^{\circ}$ al 15 agosto 1942. 121 VA, TA, k. 565a, reg. br. 11/6-7, Anfang fehlt, aber Zensurbericht über die Zeit Ende September 1942. 
teten. ${ }^{122}$ Die Arbeit der italienischen Propagandaabteilungen war, wie dargestellt wurde, darauf ausgerichtet, den Soldaten die Kommunisten stets als die größten und hinterhältigsten Feinde vor Augen zu führen und so ihren Kampfgeist aufrecht zu erhalten. Gleichzeitig musste die Propaganda die eigenen Soldaten für die aktive kommunistische Propaganda unempfänglich machen. Dem gleichen Ziel dienten auch manche Anweisungen, Befehle oder andere Schriften der Vorgesetzten. Der Gouverneur von Dalmatien ließ sich alle kommunistischen Propagandaerzeugnisse zuschicken, um auf diese entsprechend antworten zu können. ${ }^{123}$

Anfang 1942 wies General Balocco seine Untergebenen an, die Propaganda der Kommunisten zu bekämpfen, die in den „einfachen und naiven Seelen“ der italienischen Soldaten leicht haften bleiben könnte. Dazu sollten sie die Propaganda der Kommunisten umkehren, die betonte, dass sie keinen Hass gegen die Italiener hegten und nur deshalb gegen sie kämpfen müssten, weil diese sie angriffen. Sie sollten ihren Soldaten erklärten, dass sie nur dazu da seien, um die Bevölkerung zu beschützen und zu verteidigen, sowie das eigene „gesunde Sozialleben“ gegen ,jede Barbarei“ zu verteidigen, die sich in den grundlosen Angriffen der Kommunisten gegen „friedliche italienische Soldaten“ sowie gegen jede Kultur äußerten. Diese „Barbarei“ sollte sich nicht auf das „gesunde“ Italien ausdehnen. ${ }^{124}$

Auch wenn es in den Berichten hieß, dass die Soldaten kommunistische Flugblätter sofort an ihre Vorgesetzten abgaben, so blieb die Gefahr der Beeinflussung doch bestehen - häufig auch durch die Kontakte zur (vor allem weiblichen) Lokalbevölkerung. ${ }^{125}$ Dies äußerte sich auch im Umgang mit den Soldaten, die Gefangene der Partisanen gewesen waren. Die Partisanen behandelten gefangengenommene italienische Soldaten relativ gut, wenn es sich dabei nicht um Offiziere oder Faschisten handelte. Sie unterzogen die Soldaten der eigenen Propaganda und luden sie außerdem dazu ein, sich ihnen anzuschließen. Wenn die italienischen Soldaten ablehnten, nahmen sie ihnen meistens ihre Kleidung ab und entließen sie aus der Gefangenschaft. Da die Partisanen so auf

122 HDA, TV, k. 14, Nr. 2396, R. Questura di Zara: Situazione politica della provincia 28.11. 7.12.1941; AUSSME, DS, b. 543, All. 452 al DS di novembre 1941, Propaganda comunista, 18.11.1941. Davide Rodogno schreibt, dass die italienischen Armeen auf dem Balkan der kommunistischen Propaganda relativ wenig Bedeutung beimaßen. Rodogno: Il nuovo ordine mediterraneo, S. 194. Aus den vorhandenen Quellen ergibt sich zumindest für Kroatien jedoch ein anderes Bild.

123 NARA, T-821, R. 415, Nr. 78, Schreiben des Büros „I“ der 2. Armee, 3.5.1942.

124 NARA, T-821, R. 415, Nr. 90 f., False e vere ragioni, 27.1.1942; AUSSME, DS, b. 525, All. 52, Fucilazione di nostri prigionieri, 22.2.1942.

125 VA, TA, k. 646, reg. br. 43/3, Propaganda comunista, 6.3.1942. 
die Kampfmoral der gegnerischen Truppe Einfluss nehmen wollten, standen die italienischen Soldaten nach ihrer Befreiung zunächst unter Beobachtung oder wurden vom Kriegsgericht befragt. ${ }^{126}$ Im Zirkular 3C versuchte Roatta die „Legende“ von der humanen Behandlung der Gefangenen von Seiten der Partisanen zu zerstören. Einzelnen solcher Fälle stünden zahlreiche andere gegenüber, in denen die Gefangenen malträtiert oder ermordet würden. ${ }^{127}$ In der Tradotta konnten die Soldaten lesen, dass auf italienische Offiziere und Unteroffiziere die Hinrichtung wartete, wenn sie den Partisanen in die Hände fielen. Diese Propaganda hatte einen wahren Kern, wie auch die geschilderten Episoden um erschossene italienische Gefangene zeigen, doch die Partisanen untergruben sie, indem sie immer wieder Soldaten frei ließen. ${ }^{128}$

Im April 1943 meldete die 2. Armee auch die ersten vereinzelten Anzeichen für die Existenz von kommunistischer Propaganda unter den Soldaten. ${ }^{129}$ General Roatta sah sich persönlich veranlasst, sich in einem Flugblatt an seine Soldaten $\mathrm{zu}$ wenden und das Thema der kommunistischen Propaganda, die versuchte, italienische Soldaten zum Überlaufen $\mathrm{zu}$ animieren, $\mathrm{zu}$ thematisieren. Er ermahnte sie, den Kommunisten nicht zu glauben, und erinnerte sie daran, dass Kommunisten ihre Kameraden „hasserfüllt massakriert, häufig vorher geblendet, immer gefoltert“ hätten. Diese „Mörderbanden“ sollten für immer zerstört werden. So wurden auch Flugblätter, die kommunistische Propaganda bekämpften, unter den eigenen Soldaten verteilt. ${ }^{130}$ Die Versuche, die kommunistischen Aufständischen zu dämonisieren, griffen häufig (ähnlich wie bei der Wehrmacht) auf Verstümmelungen und Folter zurück. Das VI. Armeekorps ver-

126 HDA, TV, k. 18, Nr. 2886, Bericht des Segretario del Fascio aus Zara/Vodice, 9.7.1943; Tagebuch von Florio Rossi, 152. Regiment „Sassari“, abgedruckt in: L'imperialismo italiano e la Jugoslavia. Atti del convegno italo-jugoslavo, Ancona 14-16 ottobre 1977, Urbino 1981, S. 603-617, hier S. 614. Eine gute Behandlung der Gefangenen bescheinigt den Partisanen auch William Jones, ein kanadischer Offizier, der im Rahmen einer alliierten Mission ein Jahr bei ihnen verbrachte. Jones, William: 12 Months with Tito's partisans, Bedford 1946, S. $36 \mathrm{f}$.

127 Legnani, Massimo: Il „ginger“ del generale Roatta: Le direttive della 2. armata sulla repressione antipartigiana in Slovenia e Croazia, in: Italia Contemporanea 209/10 (1997/98), S. 159174, hier S. 160.

128 NARA, T-821, R. 440, Nr. 933, „Uomini al muro“, in: La tradotta, Nr. 17/II, 26.4.1943; Vgl. Tagebuch von Florio Rossi, S. 604, 614.

129 AUSSME, H 1, b. 34, Sintesi delle Relazioni sul servizio „A“ per il mese di aprile inviate dai Comandi delle G. U. dislocate fuori del territorio.

130 HDA, TV, k. 18, Nr. 2924, Flugblatt an die Soldaten der 2. Armee. Das Flugblatt wurde auch in der La tradotta abgedruckt. NARA, T-821, R. 440, Nr. 944, La tradotta, Nr. 15/II, 11.4.1943; ACS, MCP, Gabinetto, b. 135, Propaganda svolta tra le popolazioni civili dei territori occupati dal Comando 2. Armata, Rom, 5.6.1943. 
teilte ein Flugblatt, das die Kastration eines italienischen Soldaten zeigte. ${ }^{131}$ Nackte Leichen italienischer Soldaten schienen der Propaganda recht zu geben. ${ }^{132}$ Gleichzeitig verstümmelten italienische Soldaten getötete Partisanen in einer ähnlichen Art und Weise. So wurden einem toten Partisan die Ohren abgeschnitten und der Katze im Kommando zum Fraß vorgeworfen. Ein anderer toter Partisan wurde von den italienischen Soldaten gepfählt. ${ }^{133}$ Ein Angehöriger eines Bataillons „M“ schrieb in einem privaten Brief:

\begin{abstract}
...Mit uns ist der Rest des 7. Squadristen-Bataillons, und sie haben uns Sachen erzählt, die einfach zum Weinen sind. Sie waren vor 20 Tagen umzingelt und hatten viele Verluste. Mir ist unverständlich, dass diese verfluchten Aufständischen so viele Ressourcen finden, um den Kampf, so wie sie ihn führen, durchzuhalten. Wir hoffen, dass wir uns bald begegnen werden, und dem ersten, den ich erwische, werde ich die Nase abschneiden und als Andenken schicken... ${ }^{134}$
\end{abstract}

Die Mischung aus Propaganda und Erlebtem führte dazu, dass sich die Spirale der Gewalt immer weiter drehte. Entscheidend waren dabei die Erlebnisse der Soldaten; die Propaganda wirkte nur dann, wenn sie durch das Erlebte bestätigt wurde. ${ }^{135}$ So wurde die Botschaft von den „hinterhältigen“ und „blutrünstigen“ Partisanen durchaus aufgenommen, eine Trennung in „gute“ Kroaten und andere „Slawen“ ist hingegen gescheitert.

\title{
Propaganda für die Bevölkerung
}

Als Dennis Mac Smith argumentierte, dass Propaganda eine der Hauptwaffen des Faschismus während des Zweiten Weltkrieges gewesen ist, meinte er Propa-

131 AUSSME, H 1, b. 43, cart. 3, SMRE, Sintesi della relazione sul servizio „P“ inviata dal Comando Superiore FF. AA. Slovenia-Dalmazia per il mese di giugno, 14.8.1942.

132 Mafrici: Guerriglia, S. 53; Erzählung von Tolmino Ghetti, in: Frontali, Arturo (Hg.): Dai fronti di guerra, 1940-1945, Milano 2001, S. 79-83; Erinnerungen von Perni Luigi, Division „Cacciatori delle Alpi“ in: Fronte jugoslavo-balcanico, S. 166.

133 AJ, Fond 110, k. 28, Nr. 961-963, Operazioni di rastrellamento a Crni Lug, 19.10., 23.10. und 29.10.1942; Tagebuch von Florio Rossi, S. 609.

134 Saopćenje o talijanskim zločinima protiv Jugoslavije i njenih naroda, hgg. v. Državna komisija za utvrđivanje zločina okupatora i njihovih pomagača, Belgrad 1946, S. 125.

135 Ähnliches hat Heer auch für die deutschen Soldaten in Russland festgestellt. Heer, Hannes: How Amorality Became Normality. Reflections on the Mentality of German Soldiers on the Eastern Front, in: Heer, Hannes/Naumann, Klaus (Hg.): War of Extermination. German Military in World War II, 1941-1945, New York/Oxford 2006, S. 329-344, hier S. 333 f.; Heer, Hannes: Vom Verschwinden der Täter. Der Vernichtungskrieg fand statt, aber keiner war dabei, Berlin 2004, S. 111-115. 
ganda für die italienische Bevölkerung, deren Unterstützung für den Krieg gesichert werden sollte. ${ }^{136}$ Doch genauso wurde auch eine auf die Bevölkerung ausgerichtete Propaganda in den besetzten Gebieten betrieben. Sie verfolgte mehrere Ziele. Primär sollte die Bevölkerung für das faschistische Imperium gewonnen werden, sekundär war die Propaganda auch eine Waffe im Kampf gegen die Aufständischen. Die Abteilung Gegenpropaganda kümmerte sich dabei um die Propaganda für die Bevölkerung. Sie gab die sogenannte Gegenpropagandazeitung sowie eine Zeitung für Kinder heraus, stellte zwei Wandzeitungen, Manifeste und Flugblätter her. Generelle und größer angelegte Propaganda wurde von den Armeekorps produziert. ${ }^{137}$

Sofort mit der Besetzung des NDH machten sich italienische politische und militärische Stellen daran, die italienische Propaganda $\mathrm{zu}$ verbreiten. Hierzu wurde nicht nur die kroatische Presse überwacht, um Zeitungen und Magazine, die schlecht über Italien schrieben, aus dem Verkehr ziehen zu können. Auch wurde im besetzten Gebiet präventiv Zensur angewandt. ${ }^{138}$ Die Kommunisten verbreiteten ebenfalls vom ersten Tag der Besatzung an ihre Propaganda und verstärkten diese deutlich nach der Kriegserklärung an die Sowjetunion. Die italienischen Propagandaabteilungen versuchten, dem entgegen zu wirken, wobei sie teilweise auch Aufgaben der kulturellen Propaganda übernahmen, die auf deutscher Seite die Gesandtschaft erledigte. ${ }^{139}$ Im Gegensatz zu Slowenien, wo es zu einer Auseinandersetzung zwischen den Militärs und den Zivilbehörden um die Propagandazeitung kam, entstanden im NDH, wo italienische Militärbehörden das Sagen hatten, solche Schwierigkeiten nicht. ${ }^{140}$ Auch in Dalmatien gerieten die zivilen Behörden unter Bastianini und das Militär in dieser Frage nicht aneinander, da die Gegenpropagandazeitung dort nicht verteilt wurde. Bastianini ließ eine eigene Zeitung und auch eigene Propagandablätter herstellen.

Die Direzione Generale per i Servizi di Propaganda fasste die 1941-42 von ihr in Kroatien durchgeführten Aktionen so zusammen, dass sie die Errungenschaften des faschistischen Regimes hervorhoben und die „hinterhältige und heimtü-

136 Mack Smith, Denis: Mussolini’s Roman Empire, New York 1975, S. 252.

137 NARA, T-821, R. 415, Nr. 82, Assegnazione fondi assistenza e propaganda presso le popolazioni civili, 2.4.1942; AUSSME, L 10, rac. 28, cart. 2, SMRE: Servizio „A“, 28.1.1943.

138 AUSSME, DS, b. 580, rac. 32, Nr. 7, Schreiben des Kommandos der 2. Armee, 1.5.1941.

139 Beispielsweise baten sie das Ministerium für Kultur und Propaganda um die Übersendung von Büchern, um sie dem kroatischen Arbeitsdienst zu schenken und so Freundschaften zu pflegen. ACS, MCP, dgp, Prop. stati esteri, b. 149, Nachfrage des Ufficio „P“ des SMRE, 8.6.1942. 140 ACS, MCP, Gabinetto, b. 141, Emilio Grazioli an Comando II. Armata, 6.5.1942; ACS, MCP, Gabinetto, b. 141, Diffusione del Bolletino, 3.6.1942. 
ckische“ kommunistische Propaganda bekämpften. ${ }^{141}$ Genauso wurde bei der von der Armee betriebenen Propaganda zum Einen versucht, der Bevölkerung deutlich zu machen, dass italienische Truppen „mit Gerechtigkeit, aber absoluter Standfestigkeit“ agierten. Gleichzeitig sollte die Bevölkerung positiv für Italien eingenommen werden. ${ }^{142}$ Die Propagandamacher bei den Armeekorps kamen grundsätzlich zum Schluss, dass der Bevölkerung als Antwort auf kommunistische Propaganda noch mehr die Errungenschaften des faschistischen Italiens aufgezeigt werden sollten. ${ }^{143}$ Sie regten zudem an, LUCE-Filme mit kroatischen Untertiteln zu zeigen sowie italienische Grammatikhefte zum Selbststudium zu verteilen. ${ }^{144}$ Auch hier übernahm die Armee über die eigentlichen militärischen auch politische Aufgaben wahr.

Ende 1941 wurde endgültig festgestellt, dass man die Partisanenpropaganda, die aus London und Moskau unterstützt wurde, und „bei den primitiven Bevölkerungsmassen Fuß gefasst hatte“, mit Gegenpropaganda bekämpfen musste. ${ }^{145}$ Dabei war bei der italienischen Armee die Idee der Propaganda als einer Mischung aus Assistenz und „echter“ Propaganda viel stärker verwurzelt als bei der Wehrmacht. Vorgesehen waren schriftliche Propaganda, Radiopropaganda und Hilfe für die Bevölkerung. Im Dezember 1941 beantragte die 2. Armee beim SMRE 250.000 Lire und im Februar 1942 eine Million Lire, um sie im Rahmen dieser Propagandamaßnahmen der bedürftigen Bevölkerung zur Verfügung zu stellen. ${ }^{146}$ Für die Propaganda wurden schließlich nur 200.000 Lire genehmigt, die später auf 500.000 erhöht wurden. Im April erhielt die 2. Armee 30.000 Lire für Hilfen und 15.000 Lire für Propaganda bei der Zivilbevölkerung. ${ }^{147}$ Kurze

141 ACS, MCP, Gabinetto, b. 95, Pro Memoria sull'attività svolta della Direzione Generale della Propaganda durante l'anno 1941-1942. Dies waren bereits die Aufgaben der italienischen Auslandspropaganda auch im Frieden gewesen. Siehe Garzarelli, Benedetta: „Parleremo al mondo intero“. La propaganda del fascismo all'estero, Alessandria 2004, S. 4 f., 225.

142 AUSSME, H 1, b. 29, cart. 4, Stralcio delle relazioni sul servizio „P“ del mese di luglio (1941) della 2. Armata e FF. AA. Albania.

143 AUSSME, DS, b. 583, rac. 157, Nr. 3, VI CdA: Relazione mensile sul servizio „P“, 15. giugno 15. agosto 1941.

144 AUSSME, DS, b. 584, cart. 175, Nr. 3, Relazione mensile sul servizio „P“, 115 . Agosto - 15. settembre 1941.

145 AUSSME, DS, b. 727, All. 930, Comando 2. Armata: Compiacimento-Direttive-Auguri, 16.12.1941.

146 AUSSME, H 1, b. 34, Sintesi delle Relazioni sul servizio „P“ inviate dai Comandi Superiori FF. AA. Albania e Grecia e dal Comando della 2. Armata per il mese di gennaio, 17.3.1942.

147 Della Volpe: Esercito e propaganda, S. 86; NARA, T-821, R. 415, Nr. 1167 f., Proposte per la contropropaganda, febbraio 1942; NARA, T-821, R. 415, Nr. 82, Assegnazione fondi assistenza e propaganda presso le popolazioni civili, 2.4.1942. 
Zeit später wurde Mussolini von einer neuerlichen Bitte Roattas um weitere Geldmittel berichtet:

\begin{abstract}
General Roatta macht auf die Möglichkeit aufmerksam, mit Geldkompensationen die Arbeit der Verlockung aufständischer Elemente zu unterstützen, um sie auf zu splitten und die Gruppen gegeneinander einzusetzen. Auf diese Weise soll das Terrain für unsere Durchdringung vorbereitet werden. Er weist auch auf die Assistenzarbeit zugunsten der Bevölkerung hin, die zweifellos wohltuende propagandistische Resultate erreichen könne. ${ }^{148}$
\end{abstract}

Obwohl er zwei Millionen Lire im Monat beantragt hatte, bekam Roatta für die Monate Juni und Juli zusammen zwei Millionen und für die Zeit vom August 1942 bis inklusive Januar 1943 weitere dreieinhalb Millionen Lire nur für die politische Arbeit zugeteilt. ${ }^{149}$ Propagandainstrumente, die Roatta vorschwebten, beinhalteten so unterschiedliche Maßnahmen wie Geldhilfen für die Bevölkerung, Nahrungsmittel und Bekleidung für arme Bevölkerungsschichten, Hilfen für Familien von Partisanenopfern, Prämien für Gefangennahme von Partisanenführern, Prämien für kroatische Eisenbahner und MVAC-Angehörige, Geschenke für MVAC-Führer als auch für kroatische Beamte und Ähnliches. ${ }^{150}$ Aus den Listen, die für den Zeitraum September 1942 bis August 1943 erhalten sind, geht hervor, dass pro Monat ca. 300.000-400.000 Lire für diese Zwecke ausgegeben wurden und nur in den letzten beiden Monaten die Ausgaben auf knapp 100.000 Lire sanken. ${ }^{151}$

Darüber hinaus spielte die medizinische Versorgung eine wichtige propagandistische Rolle. Italienische Militärärzte behandelten immer wieder die Bevölkerung. ${ }^{152}$ Dies wurde von der Armee auch als ein willkommenes Mittel gesehen, um die Bevölkerung für sich einzunehmen. ${ }^{153}$ Die Bemühungen wurden durch schriftliche Propaganda unterstützt, die von der ärztlichen Versorgung für die Armen in allen besetzten und annektierten Gebieten berichtete. Dabei fehlten nie die Hinweise auf italienische Menschlichkeit:

148 ASMAE, GAB-AP 1923-1943, b. 1506, Appunto per il duce, 22.4.1942.

149 ASMAE, GAB-AP 1923-1943, b. 1506, Disponibilità e spese di Supersloda a tutto il 31.1.1943.

150 ASMAE, GAB-AP 1923-1943, b. 1506, 11.9.1942, Fondi riservati per la propaganda politica di Supersloda, 11.9.1942.

151 ASMAE, GAB-AP 1923-1943, b. 1506, Spese per propaganda politica sostenute da Supersloda per il mese di: settembre 1942 - agosto 1943.

152 Zeev Milo erinnerte sich, dass italienische Militärärzte immer bereit waren, Juden zu helfen und sie zu behandeln - so auch ihn, als er eine Blinddarmreizung bekam. Milo, Zeev: Im Satellitenstaat Kroatien: eine Odyssee des Überlebens 1941-1945. Mit ausführlicher Beschreibung der historischen Ereignisse, Klagenfurt ${ }^{2} 2010$, S. 108.

153 Bassi: Due anni, S. 74, $93 \mathrm{f}$. 
Nun hat diese Bevölkerung [...] endlich die hohen menschlichen Ziele verstanden, die sich die Italiener sogar gegen ihre unmittelbaren Gewinne auferlegt haben. Heute strömt diese Bevölkerung freiwillig in die Militärhospitäler, um Rat und Hilfe in jeder Angelegenheit zu holen, und ihre Worte, Blicke und Taten zeigen Dankbarkeit, die diese einfache aber gesunde Bevölkerung gegenüber dem empfindet, der ihr etwas Gutes getan hat, ohne von ihr dafür irgendetwas zu verlangen. ${ }^{154}$

Ein Flugblatt informierte über den Typhus-Tod eines italienischen Sanitätsoffiziers, der infizierte Flüchtlinge behandelt hatte. Er schloss mit den Worten:

Das ist das [italienische] Volk, das zu lieben und zu kämpfen weiß. Das ist das Volk, das alles auf eine Gewinner-Karte setzt, auf die es ein Anrecht hat, aber das über allen anderen Gefühlen jene Liebe besitzt, nach der ein Fremder, und sei er der Feind, als Bruder angesehen werden kann. Das ist eine Tugend großer, starker und gebildeter Völker. ${ }^{155}$

Auch die Propagandaeinheiten berichteten, dass kostenlose ärztliche Versorgung von der Bevölkerung geschätzt würde. Allerdings sollte darauf geachtet werden, keine Medizin zu geben, die nicht sofort an Ort und Stelle gebraucht würde, da sie eventuell zu den Partisanen gelangen könnte. ${ }^{156}$ Im Juni 1943 meldeten die Propagandaeinheiten einen erhöhten Geldmittelbedarf, um Propaganda noch entsprechend gestalten zu können, aber auch um der Bevölkerung eine bessere medizinische Versorgung anbieten zu können. Genauso sollte energisch bei den kroatischen Behörden eingegriffen werden, damit sie sich um die Bedürftigen kümmerten. ${ }^{157}$ Geldmangel mag ein Grund gewesen sein, warum die Bevölkerung im Sommer 1943 nicht mehr zufriedenstellend medizinisch versorgt werden konnte - ein Umstand, der sofort zur Beschwerde der Abteilung „A“ der 2. Armee führte. ${ }^{158}$

Auch andere Mittel wurden eingesetzt, um die Bevölkerung zu beeinflussen. Der Kontakt mit den Soldaten sollte ihr beispielsweise ermöglichen, Italien, seine Kultur und sein Regime kennenzulernen, die sie leider nur aus der feindlichen Propaganda kennen würde. In Dalmatien gehörten zur Propaganda der Tat auch Begnadigungen von verurteilten Partisanen bzw. Kommunisten. Im Oktober 1942 sprach sich Bastianini jedoch gegen die Fortsetzung dieser Praxis aus, da sie nicht den erhofften Effekt hatte. Er regte an, Begnadigungen nach

154 ACS, MCP, Gabinetto, b. 141, Ispravan čovjek Nr. 3, Jg. 2, 14.02.1943. Ein ähnliches Thema wurde bereits in der Ausgabe Nr. 10 vom 11.6.1942 behandelt. ACS, MCP, Gabinetto, b. 141.

155 NARA, T-821, R. 415, Nr. 708, Flugblatt „Tod aufgrund von Typhus...“

156 AUSSME, DS, b. 859, Df Murge: Relazione mensile sul servizio „Propaganda“, 18.8.1942; NARA, T-821, R. 418, Nr. 331, Propaganda, 16.7.1943.

157 ACS, MCP, Gabinetto, b. 135, Propaganda svolta tra le popolazioni civili dei territori occupati dal Comando 2. Armata, 5.6.1943.

158 NARA, T-821, R. 418, Nr. 299, Comando della 2. Armata: Contropropaganda, 11.8.1943. 
dem Krieg wieder in Erwägung zu ziehen, um die Bevölkerung zu beruhigen, im Augenblick aber davon Abstand zu nehmen. ${ }^{159}$ Noch im August 1943 versammelte General Spigo, der zu jener Zeit auch die zivilen Zuständigkeiten in Dalmatien übernahm, die angesehenen Bürger von Split, um sie um die Zusammenarbeit zu bitten. Dabei versprach er allen Dalmatinern die Freiheit, egal welchen Glaubens, welcher Nationalität oder politischer Tendenz sie waren. ${ }^{160}$

Im April 1942 nahm die geschriebene Propaganda in Form von Zeitungen Gestalt an. Nach vorheriger Verständigung mit dem MinCulPop übernahm die Sektion „Propaganda für die Bevölkerung der besetzten Gebiete“, eine Unterabteilung der Propagandastelle der 2. Armee, deren Herstellung für Slowenien und den NDH. Das MinCulPop beteiligte sich an den Kosten. ${ }^{161}$ Zunächst ging es vor allem darum, die Bevölkerung mit Informationen zu versorgen, die konform mit der Politik der Achse waren und ein Gegengewicht zur kommunistischen Propaganda darstellten. Gleichzeitig war man sich aber der unterschiedlichen Bevölkerungsgruppen im NDH bewusst und passte das Bolletino di contrapropaganda, wie die Zeitung intern hieß, an die jeweiligen Empfänger an. Zunächst wurde die kroatische Version Ispravan hrvatski čovjek. Prava istina za narod (Der aufrichtige kroatische Mensch. Echte Wahrheit für das Volk) herausgegeben. Sie erschien wöchentlich in einer Auflage von 100.000 Exemplaren (ab Juli 1942 vierzehntägig mit 50.000 Exemplaren). ${ }^{162}$ Die Zeitung wurde mit Hilfe der italienischen Garnisonen und der kroatischen Gendarmerie in öffentlichen Gebäuden, in Schulen, in Firmen und bei entlegenen Orten durch Abwurf aus dem Flugzeug verteilt. ${ }^{163}$ Es handelte sich hierbei um eine Art grauer Propaganda, denn die Zeitung sollte auf die Bevölkerung Einfluss ausüben, indem sie „Neutralität“ vorspielte, ohne sofort zu erkennen zu geben, wer sie hergestellt hat. Daher kam es den Machern auch nicht auf die Aktualität der Nachrichten an. Trotzdem sollte sie die Siege der Achse betonen und so die Widerstandskraft des Feindes untergraben. Die Zeitung war so konzipiert, dass auf der ersten Seite die neuesten Kriegsnachrichten sowie ein Grundsatzartikel zu lesen waren, auf der zweiten und dritten Seite folgten italienische und deutsche Kriegsnachrichten, und auf der letzten Seite kamen dann die wichtigsten politischen Nach-

159 VA, TA, k. 554, reg. br. 8/34, Schreiben von Bastianini an das Ministerratspräsidium, 9.10.1942.

160 HDA, TV, k. 18, Nr. 2930, Die Rede des Generals Spigo in Split, 2.8.1943.

161 ACS, MCP, Gabinetto, b. 141, Schreiben des SMRE, Ufficio Propaganda, an das Ministerium für Volkskultur, 4.7.1942.

162 NARA, T-821, R. 414, Nr. 658, Relazione per il mese di luglio sullo sviluppo della propaganda presso le popolazioni civili dei territori occupati, 10.8.1942.

163 NARA, T-821, R. 414, Nr. 1117, Comando V CdA: Bollettino settimanale di contropropaganda di Armata, 9.5.1942. 
richten aus der ganzen Welt. Dazu waren immer einige Fotos abgebildet und meistens eine Karikatur.

Die Partisanengefahr und die daraufhin einsetzende Kollaboration mit den Tschetniks setzten den in Italien vom Ministerium für Volkskultur erarbeiteten Grundsatz für Propaganda in Kroatien ein schnelles Ende. Danach hätte der Unterschied zwischen der westlich orientierten kroatischen Kultur und den Serben, die den balkanischen Slawismus darstellten, sowie feste Bindungen Italiens mit der kroatischen Nation betont werden müssen. ${ }^{164}$ Stattdessen wurden die Serben zu Verbündeten. Dies drückte sich auch in der Propaganda aus. Bald wurde das Repertoire erweitert, um auch die serbische Bevölkerung entsprechend versorgen zu können. Diese Zeitung hieß Slobodna Srbija (Freies Serbien), was angesichts der Tatsache, dass Deutschland Serbien besetzt hatte, und Kroatien ein Serbenproblem zu haben glaubte, einen äußerst provokanten Titel für italienische Verbündete darstellte. Der Unterschied zur kroatischen Ausgabe war am Anfang minimal. Aufgrund technischer Schwierigkeiten war zunächst nur der Titel der Zeitung (ab Juni 1942 auch die Titel der Artikel) in Kyrillisch geschrieben, während der Rest dem kroatischen Teil gleich war, jedoch anders angeordnet, um eine andere Zeitung vorzutäuschen. Beide Zeitungen wurden im Juni bzw. Juli 1942 umbenannt, um ihre weitestmögliche Verbreitung zu ermöglichen, vor allem auch in ethnisch gemischten Gebieten: Bei der kroatischen Version wurde das Wort „kroatisch“ fallengelassen, und die serbische Zeitung wurde komplett in „Istinički list“ (Giornale della verità; Zeitung der Wahrheit) umbenannt. ${ }^{165}$ Im Frühjahr 1943 wurden beide Zeitungen nochmals umbenannt. Die kroatische Ausgabe hieß dann „Novine“ (Die Zeitung) und die serbische „Novosti“ (Nachrichten). Der Untertitel „Prava istina za narod“ wurde bei beiden beibehalten. ${ }^{166}$

Schon kurze Zeit nach dem Erscheinen der ersten Ausgabe regte das MinCulPop kleine Veränderungen an. Um einen noch größeren Effekt zu erzielen, sollten auch kurze Artikel abgedruckt werden, die die Richtlinien der italienischen Politik in Kroatien bzw. Slowenien behandelten, die materiellen Vorteile, die Italien brachte, sowie einige fixe Rubriken von praktischem (z. B. agrarischen oder veterinären) Nutzen, aber auch Ankündigungen von Messen. ${ }^{167}$ Die Umsetzung der Ideen hätte aber sofort die Macher der Zeitung entblößt, was im

164 Santoro, Stefano: L'Italia e l'Europa orientale. Diplomazia culturale e propaganda 19181943, Mailand 2005, S. 343.

165 AUSSME, DS, b. 646, All. 287 al DS aprile 1942, Relazione mensile 15 marzo - 15 aprile, 29.4.1942; ACS, MCP, Gabinetto, b. 141, Ispravan čovjek Nr. 11, 18.6.1942 bzw. Istinički list Nr. 13, 2.7.1942.

166 ACS, MCP, Gabinetto, b. 141, Novine/Novosti Nr. 7, Jg. 2 vom 15.4.1943.

167 ACS, MCP, Gabinetto, b. 141, Appunto per il Capo di Gabinetto, Rom, 3.5.1942. 
Gegensatz zur „gewollten Verborgenheit“ gestanden hätte. Während man sich in Slowenien auf einen Kompromiss einigte und die Zeitung stärker auf die politischen Interessen Sloweniens ausrichtete, setzten sich diese Ideen bei den beiden für den NDH bestimmten Versionen langsam und abgewandelt durch. ${ }^{168}$ Die meisten Themen betrafen die Siege der Achse bzw. die Niederlagen der Alliierten. Hin und wieder wurden aber auch italienische, kroatische oder italienisch-kroatische Themen behandelt, die kulturelle Fragen oder Errungenschaften des Faschismus berührten. ${ }^{169}$ In der Ausgabe vom 4. Juni 1942 wurde mithilfe der historischen Beziehung der Städte Venedig und Zagreb die italienische Kultur herausgestellt. Man konnte beispielsweise darin lesen, dass alle Schriftsteller und Künstler aus Dubrovnik perfekt die italienische Sprache beherrschten, weil es bei den besseren dalmatinischen Familien Brauch war, ihre Söhne an italienische Universitäten zu schicken. Am 25. Juni wurde über die Errichtung der kroatischen orthodoxen Kirche berichtet. ${ }^{170}$

Ab dem Sommer brachte die Zeitung dann hin und wieder konkrete Propaganda, die meistens der Bekämpfung von Partisanenpropaganda diente oder als Rechtfertigung für das Vorgehen der italienischen Armee verstanden werden kann. Am 13. August 1942 wurde über die „überaus guten“ Bedingungen in den italienischen Lagern für Kriegsgefangene und Zivilinternierte berichtet, die auch vom Roten Kreuz und dem Vatikan bescheinigt würden. ${ }^{171}$ Hier wird auch deutlich, dass die zuständige Abteilung nicht nur mit Auslassungen, sondern mit konkreten Unwahrheiten arbeitete, denn die Lager des Kriegsministeriums, in denen sich die Zivilinternierten aus den besetzten Gebieten befanden, durfte niemand inspizieren. In Anbetracht der im Sommer 1942 stark zunehmenden Internierungen kann dieser Beitrag als ein schwacher Versuch betrachtet werden, die Bevölkerung zu beruhigen. Im Artikel „Das richtige Licht“ wurden hingegen die Partisanen und ihre Requirierungen angeprangert und in Kontrast zum italienischen Verhalten gesetzt. Nachdem italienische Truppen in Kroatien zu kroatischem Schutz geblieben waren, hätten die Italiener nichts von der Bevöl-

168 ACS, MCP, Gabinetto, b. 141, Diffusione del Bolletino, 3.6.1942. ACS, MCP, Gabinetto, b. 141, Beiblatt zu Ispravan hrvatski čovjek, Nr. 12 vom 25.6.1942. In Slowenien machte ab dem 11. Juni die Propagandaabteilung von Grazioli die erste Seite, die fortan gegen Partisanen gerichtete Artikel brachte. ACS, MCP, Gabinetto, b. 141, Testo del bollettino sloveno Nº10, Utopie dei partigiani; Bisogna saper apprezzare i benefici.

169 ACS, MCP, Gabinetto, b. 141, Ispravan čovjek Nr. 3, Jg. 2 vom 14.02.1943.

170 ACS, MCP, Gabinetto, b. 141, Ispravan hrvatski čovjek/Slobodna Srbija, Nr. 9 vom 4.6.1942; ACS, MCP, Gabinetto, b. 141, Ispravan hrvatski čovjek/Slobodna Srbija, Nr. 12 vom 25.6.1942 171 ACS, MCP, Gabinetto, b. 141, Ispravan hrvatski čovjek/Slobodna Srbija, Nr. 18 vom 13.8.1942. 
kerung verlangt, sondern sogar noch Essen für die armen Gebiete gebracht. ${ }^{172}$ Angesichts der Plünderungen durch italienische Soldaten waren solche Versuche, die Bevölkerung zu beeinflussen, zum Scheitern verurteilt. Die propagierte italienische Güte ging jedoch mit der Akzeptanz der italienischen Überlegenheit einher. Was aber passierte, wenn die Bevölkerung sich gegen Italien auflehnte, erklärte eine Metapher von Caesars Umgang mit Barbaren. Sie illustrierte, dass italienische Güte nicht Schwäche bedeutete, und dass jeder, der nicht ein Teil der römischen Zivilisation sein wollte, vernichtet werden würde. ${ }^{173}$

Im Oktober 1942 wurde die Gegenpropaganda-Zeitung auf zwei Seiten gekürzt, umbenannt und die serbische dann auch ganz in kyrillisch und sogar im ekavischen Dialekt geschrieben. ${ }^{174}$ Die beiden Ausgaben unterschieden sich jetzt deutlicher voneinander, wenn auch immer noch mehr als die Hälfte der Artikel gleich waren. Es fand auch ein Umdenken bei der inhaltlichen Gestaltung statt. Die kurzen Nachrichten wurden reduziert, um Platz für etwas längere Artikel zu geben, die die „Barbarei des Feindes“ zeigten sowie spezielle Themen behandelten, die mehr die serbische bzw. kroatische Leserschaft interessierten oder beeinflussen sollten. So wurden in der kroatischen Ausgabe hin und wieder katholische Themen gebracht, wohingegen in der serbischen Ausgabe auch explizit die Unvereinbarkeit zwischen den Serben und dem Kommunismus angesprochen wurde. ${ }^{175}$ Die Benutzung der kyrillischen Schrift, die im NDH abgeschafft worden war, führte unweigerlich zum Konflikt mit den kroatischen Behörden. Die Abteilung für Zivilangelegenheiten der 2. Armee wies daraufhin die Propagandastellen zwar an, kyrillische Buchstaben nicht mehr zu verwenden, doch nicht einmal die für die Herausgabe der Propagandazeitung verantwortliche Abteilung bei der 2. Armee hielt sich daran. ${ }^{176}$

Im zweiten Erscheinungsjahr wurde die konkrete Antipartisanenpropaganda noch verstärkt. Mindestens jede zweite Ausgabe behandelte ein Antipartisanenthema. Häufig wurden die Partisanen für ihre Taten angeprangert. Viele Artikel waren eindeutig als Antwort auf Partisanenpropaganda verfasst. Die kroatische Ausgabe brachte am 14. Februar 1943 den Artikel „Wölfe werden zu Lämmern“. Darin wurde der Versuch der Partisanen, die Gläubigen durch die Hinweise, dass sich in ihren Reihen auch Geistliche befanden, für sich zu ge-

172 ACS, MCP, Gabinetto, b. 141, Ispravan hrvatski čovjek, Nr. 20, 17.9.1942.

173 ACS, MCP, Gabinetto, b. 141, Ispravan hrvatski čovjek/Slobodna Srbija, Nr. 19, 27.08.1942. 174 NARA, T-821, R. 722-725, 2. Armata: Relazione mensile sull'attività svolta presso le popolazioni civili dei territori occupati nel mese di novembre 1942.

175 ACS, MCP, Gabinetto, b. 141, Ispravan čovjek Nr. 24 vom 9.11.1942; ACS, MCP, Gabinetto, b. 141, Istinički list Nr. 22 vom 16.10 .1942$.

176 AUSSME, DS, b. 859, Df Murge: Relazione mensile sul servizio „Propaganda“, 18.8.1942; NARA, T-821, R. 415, Nr. 1093, 1096, Uso dei caratteri cirilici, 9.9. und 1.9.1942. 
winnen, durch die Behauptung entkräftet, dass es sich dabei um Gefangene handeln müsste sowie den Verweis, dass sie dieses Verhalten von Stalin gelernt hätten. ${ }^{177}$ Die Ausgabe vom 15. April 1943 wandte sich in einem Artikel der „Grausamkeit der Partisanen“ zu. Darin sollten vor allem die Zerstörungen der italienischen Armee von Kirchen und anderen kulturell wertvollen Gebäuden entschuldigt und den Partisanen angelastet werden. ${ }^{178}$ Das vortreffliche Verhalten der Italiener, die im Gegensatz zu den Partisanen nicht nur nicht requirieren, sondern sich sogar um die medizinische und die Nahrungsmittelversorgung der Bevölkerung kümmern würden, war ein weiteres wiederkehrendes Thema. Auf diese Weise sollte gezielt gegen die Partisanenpropaganda vorgegangen werden, die die Nahrungsmittelknappheit den Italienern zuschrieb. ${ }^{179}$ Ein anderes Thema waren die Verluste, die die Partisanen von der Achse hinnehmen mussten. Dies wurde insbesondere während der Operationen „Weiß“ und „Schwarz“ betont. ${ }^{180}$

Die Regierung von Dalmatien brachte eine eigene Zeitung heraus: Pravi Dalmatinac. List za radnike u poljima, u radionicama, na moru, za zanatlije, za sav dalmatinski puk. (Der echte Dalmatiner. Das Blatt für die Arbeiter auf dem Feld, in Werkstätten, auf dem Meer, für Handwerker, für das ganze dalmatinische Volk). Dafür wurde ab Anfang 1942 das ganze kommunistische Propagandamaterial, das in italienische Hände geriet, auch der Regierung von Dalmatien zur Verfügung gestellt. ${ }^{181}$ Im Prinzip wurden mit der dalmatinischen Zeitung die gleichen Ziele wie mit der Armeezeitung verfolgt. ${ }^{182}$ Daher waren auch ihre Inhalte ähnlich. Sie ging jedoch offensiver gegen die Partisanenpropaganda vor und insbesondere auf Dalmatien ein. Darin wurden Partisanenflugblätter angesprochen und Aufrufe an die Bevölkerung gestartet, weder Sabotagen zu verüben, noch sich den Kommunisten anzuschließen. Den Dalmatinern wurde vor Augen geführt, wie viel Italien in Dalmatien investierte und dass es dafür sorgte, dass es mit der Wirtschaft voranging. ${ }^{183}$ Gleichzeitig berichtete die Zeitung

177 ACS, MCP, Gabinetto, b. 141, Ispravan čovjek Nr. 3, Jg. 2 vom 14.02.1943. 178 ACS, MCP, Gabinetto, b. 141, Ispravan čovjek Nr. 7, Jg. 2 vom 15.4.1943.

179 NARA, T-821, R. 418, Nr. 259-263, Comando 2. Armata: Relazione mensile sull'attività svolta presso le popolazioni civili dei territori occupati nel mese di luglio 1943; NARA, T-821, R. 418, Nr. 412-414, 521-524, und 635-638, Berichte vom Mai, April und Februar 1943.

180 ACS, MCP, Gabinetto, b. 141, Ispravan čovjek Nr. 4, Jg. 2 vom 28.2.1943; NARA, T-821, R. 418, Nr. 259-263, Comando 2. Armata: Relazione mensile sull'attività svolta presso le popolazioni civili dei territori occupati nel mese di luglio 1942.

181 NARA, T-821, R. 415, Nr. 78, Schreiben des Büros „I“ der 2. Armee, 3.5.1942.

182 VA, TA, k. 566, reg. br. 1/4, Schreiben des Governo di Dalmazia, 4.2.1942.

183 VA, TA, k. 554, reg. br. 13/7, Pravi Dalmatinac, Nr. 1 vom 19.2.1942. 
auch von den Prozessen gegen Kommunisten vor Militärgerichten. Weiterhin wurde angedroht:

Die Opferbilanz des kommunistischen, von London bezahlten Verbrechertums ist schon zu wuchtig für den Zorn und das Prestige Italiens. Es ist dabei, ein kraftvolles „genug“ zu schreien und normale Straf- und Repressionssysteme aufzuheben. Es ist dabei, ein Talionsgesetz einzuführen mit Repressalien vier Mal schlimmer als der fanatische Angriff. Der Schreiber weiß das und sagt es euch, Dalmatiner. ${ }^{184}$

Neben den zentral gemachten produzierten manchmal auch die Armeekorps weitere Zeitungen, die vor allem als Nachrichtenblätter dienen sollten. Das VI. Armeekorps gab ab Februar 1943 Dnevne vijesti (Tagesnachrichten) heraus, um sie bei der bäuerlichen Bevölkerung, die in Kontakt mit Partisanen war, zu verteilen. ${ }^{185}$ Ab März/April 1942 wurden vom XVIII. Armeekorps wöchentlich Nachrichten von den Kriegsschauplätzen in kroatischer Sprache in einer Auflage von 25.000 Stück verteilt. ${ }^{186}$

Obwohl eine Truppenzeitung, informierte La Sentinella auch die Bevölkerung in der Gegend um Dubrovnik. Dies war durchaus intendiert, wie auch der Untertitel Quotidiano raguseo in grigioverde (Die graugrüne Dubrovniker Tageszeitung) zeigt. Möglich war dies, weil ein gewisser Teil der Dubrovniker Bevölkerung Italienisch verstand. Die zweite Seite war Nachrichten aus Dubrovnik gewidmet. Neben Informationen über Theateraufführungen und Konzerte, nützlichen Informationen und Kleinanzeigen war ein großer Teil der Seite der Nahrungsmittelsituation gewidmet. Es wurde aufgelistet, was es auf dem Markt zu welchem Preis zu kaufen gab, der Schwarzmarkt als unsozial angeprangert und von den Anstrengungen des VI. Armeekorps, die Situation zu verbessern, berichtet. Auch hier konnte man lesen:

Noch ein Mal also interveniert das italienische militärische Kommando, um die Schwierigkeiten der Bevölkerung in den Gegenden um Dubrovnik und Mostar zu mildern. Wie immer ist es dem hohen Werk der Zivilisation getreu, das es in jeder Situation mit unbändiger Energie und mit einem hohen christlichen und humanitären Gefühl verfolgt. ${ }^{187}$

Auf der dritten Seite, die Sport- oder Kulturnachrichten gewidmet war, wurde sowohl italienische Kultur verbreitet (z. B. Beiträge über Puccini) als auch das

184 VA, TA, k. 554, reg. br. 16/7-3, Pravi Dalmatinac, Nr. 5 vom 19.3.1942.

185 NARA, T-821, R. 418, Nr. 642-647, Comando VI CdA: Relazione sul servizio di propaganda assistenza e contropropaganda verso le popolazioni civili in zona di occupazione per il mese di febbraio 1943.

186 AUSSME, DS, b. 646, All. 287 al DS aprile 1942, Relazione mensile 15 marzo - 15 aprile, 29.4.1942.

187 NARA, T-821, R. 433, Nr. 1424 f., La Sentinella Nr. 100, Jg. 2, 26./27.4.1943. 
Band zwischen Italien und Dubrovnik hervorgehoben, insbesondere durch die Geschichte der Republik Ragusa.

Eine Besonderheit bei der italienischen Propaganda stellte die von der 2. Armee ab Juni 1942 herausgegebene monatliche Kinderzeitung in Farbe „Novine za djecu" bzw. „Novine za decu“ dar. Sie orientierte sich am italienischen Corriere dei piccoli und hatte genauso wie die Zeitung für Erwachsene jeweils eine serbische und eine kroatische Version. Sie wurde kostenlos in Schulen, am Strand oder in der Warteschlange für das Mittagessen verteilt und erzielte so gute Erfolge, dass ihre Auflage im Juli 1942 von 40.000 auf 60.000 erhöht wurde. ${ }^{188}$ Die Idee dahinter war, die kleineren Kinder, die Italien gegenüber noch nicht negativ eingestellt waren, mit der Zeitung positiv zu beeinflussen und die Inhalte der Zeitung damit in die Familien zu tragen. Dabei handelte es sich nicht nur um harmlose Kindergeschichten, sondern um eine durchdachte Propaganda, die vor allem die Güte der Italiener zeigen sollte. Auf der ersten Seite wurde ein Comic in Farbe abgedruckt, der die Hauptbotschaft der Propaganda trug und sich stets um Aufständische drehte. In der ersten Ausgabe wurde beispielsweise vom kleinen Frane berichtet, der zunächst beim Hüten der Schafe sieht, wie ein Aufständischer einen italienischen Soldaten aus dem Hinterhalt erschießt. Doch bereits am Abend erreicht die „heilige Gerechtigkeit“ den Täter, der gefangen genommen, vor Gericht gestellt und zum Tode verurteilt wird. Zu Hause hingegen beobachtet Frane, dass Männer den Vater mit in den Wald nehmen wollen. Er folgt ihnen und sieht, wo sie ihre Waffen verstecken. Später bringt er mit Freunden die Waffen weg, so dass der Vater, da es keine Waffen mehr gibt, nach Hause zurückkehren muss, worüber sich die ganze Familie freut. ${ }^{189}$ In der vierten Ausgabe handelte die Geschichte von Josip, einem jungen Mann, der Italien den Eid geschworen hatte und in der Antikommunistischen Miliz dienen wollte. Doch seine früheren Freunde, enttäuscht, weil er nicht mit ihnen in den Wald gehen wollte, versuchen, ihn zu töten. Er überlebt, schleppt sich bis zur nächsten italienischen Garnison und nennt die Täter bevor er stirbt. Ein italienisches Sonderkommando spürt die Täter im Wald auf, die mit dem Tod durch Erschießen bestraft werden. Josips Familie und seine Verlobte werden nach Italien geschickt, und auf seinem Grab zeugen „die Tricolore und Blumen von Italiens Gruß an den Märtyrer des roten Terrors“. ${ }^{190}$

Diese Beispiele zeigen, dass es den Propagandaverantwortlichen durchaus ernst mit der Propaganda für Kinder war. Sie hatte stets eine antibolschewisti-

188 NARA, T-821, R. 415, Nr. 191, Pubblicazione per la gioventù, 2.6.1942; NARA, T-821, R. 415, Nr. 193, Pubblicazioni a colori di contropropaganda, 3.6.1942.

189 NARA, T-821, R. 415, Nr. 224 f., Za vas djeco, Nr. 1, 11.6.1942.

190 NARA, T-821, R. 415, Nr. 226, Novine za djecu, Nr. 4, 3.9.1942. 
sche Ausrichtung gepaart mit der Betonung italienischer Überlegenheit - denn die Schuldigen wurden immer gefasst. Gleichzeitig wurde italienische „Güte“ betont: Italien sorgte für alle, die ihr treu ergeben waren, wie am Beispiel von Josips Familie deutlich wird. Darüber hinaus wurde die Kinderzeitung in Dalmatien zu einer bilingualen Zeitung, um den Kindern das Erlernen der italienischen Sprache zu erleichtern. ${ }^{191}$

Neben den Zeitungen wurden auch alle 14 Tage insgesamt 4.000 Kopien der großen und kleinen Wandzeitung Vijesti iz Svijeta (Nachrichten aus der Welt) abwechselnd an den Straßen, in Schulen, Theatern, Kinos, in kroatischen Kasernen, an Bahnhöfen, auf Schiffen usw. angebracht. ${ }^{192}$ Sie bestanden aus zwei bis drei Fotografien und manchmal noch aus einer Karikatur in Farbe. Inhaltlich berichteten sie von den Siegen der Achse auf unterschiedlichen Kriegsschauplätzen. Auch von den Wandzeitungen gab es unterschiedliche serbische und kroatische Varianten. ${ }^{193}$

Schließlich verteilte die Armee auch Flugblätter, welche die Bevölkerung davon überzeugen sollten, nicht mit den Partisanen zusammen zu arbeiten. Sie wurden in einer Auflage von meistens 100.000 Stück auf buntem Papier gedruckt, um Aufmerksamkeit zu erregen. Diese wandten sich - wie ihre deutschen Pendants auch - häufig an einzelne Bevölkerungsgruppen. ${ }^{194}$ Darin wurden die „Lügen der Bolschewisten demaskiert“, die „Gräueltaten der Partisanen" beschrieben sowie die Unvereinbarkeit der Partisanen mit Familie, Religion und Tradition betont. Stattdessen sollte die Bevölkerung Italien vertrauen, das auch in den Flugblättern einerseits als verzeihend und helfend dargestellt wurde, andererseits vernichtend gegenüber seinen Feinden. ${ }^{195}$ In Dalmatien wurden in Flugblättern zudem alle Vorteile betont, in deren Genuss die Dalmatiner durch die Annexion gekommen waren, wie der Bau von Straßen, die medizinische Versorgung oder die Gleichberechtigung aller Religionen. Die Kommunisten wurden hingegen häufig als wilde Tiere, Feiglinge, Banditen, Mörder usw. beschrieben und als Feinde des dalmatinischen Volkes dargestellt, um das sich Italien so sehr kümmerte. Doch auch die Flugblätter in Dalmatien kamen nicht ohne Drohungen aus. Wenn die Bevölkerung mit den Partisanen

191 NARA, T-821, R. 415, Nr. 230.

192 NARA, T-821, R. 418, Nr. 729 f., Attività editoriale di contropropaganda del Supersloda (ohne Datum).

193 AUSSME, DS, b. 859, Df Murge: Relazione mensile sul servizio „Propaganda“, 31.10.1942. 194 NARA, T-821, R. 418, Nr. 729 f., Attività editoriale di contropropaganda del Supersloda, (ohne Datum); NARA, T-821, R. 439, Nr. 55, Flugblatt „An die serbische Bevölkerung“.

195 NARA, T-821, R. 439, Nr. 408, 486, Flugblätter „Hört, hört“; NARA, T-821, R. 415, Nr. 92 f., Comando V CdA: Mene dei comunisti, 24.12.1941; NARA, T-821, R. 439, Nr. 678, Flugblatt „An die Bevölkerung von Lika, Bosnien und Dalmatien“. 
paktieren sollte, drohte man ihr mit dem Entzug der Privilegien. Den Arbeitern wurde beispielsweise konkret gedroht, ihre Essensrationen zu streichen, wenn sie nicht zur Arbeit kämen, wozu die Kommunisten sie aufriefen. ${ }^{196}$ Gleichzeitig wurde mit Flugblättern auch englische Propaganda bekämpft, indem die italienische Stärke hervorgehoben und gezeigt wurde, dass die Engländer sich im Gegensatz zu Italien nicht nur nicht um das Wohl der Bevölkerung kümmerten, sondern darüber hinaus Bombardierungen androhten. Flankiert wurden die Texte von unterschiedlichen Karikaturen, die die Feinde darstellten. ${ }^{197}$

Es ist auffällig, dass sich die Propaganda sehr lange nur auf Kroaten und Serben konzentrierte und die muslimische Bevölkerung, die es ebenfalls im italienischen Besatzungsgebiet gab, beiseitegelassen wurde. Im November 1942 meldeten die Armeekorps, dass sowohl serbische als auch muslimische Bevölkerungsteile gerne eine stärkere philoserbische bzw. philomuslimsiche Tendenz in der italienischen Propaganda gesehen hätten, um eine größere Gewissheit zu haben, dass die italienische Regierung sie beschützte. ${ }^{198}$ Seit Mai 1942 wurde zwar auch an einer Zeitung für Muslime gearbeitet, in der anhand der Zitate aus dem Koran die Unvereinbarkeit zwischen dem Islam und Kommunismus aufgezeigt werden sollte. Von der Zeitung sind jedoch keine Spuren erhalten, so dass anzunehmen ist, dass diese Idee wieder fallen gelassen wurde. Erst im Frühjahr 1943, als das Interesse an den Muslimen zunahm, wurde auch Propaganda für Muslime betrieben. Das italienische Oberkommando des Heeres schickte Propagandapublikationen für Muslime aus Nordafrika, um sie auch in Kroatien zu verbreiten. ${ }^{199}$ Diese waren auf Arabisch und sollten nur unter den gebildeten Muslimen verteilt werden. Im April 1943 bereitete das MinCulPop die Zeitschrift „Balcania Islamica“ vor, die auch im NDH in kroatischer Sprache verbreitet werden sollte. ${ }^{200} \mathrm{Ob}$ sie jemals erschienen ist, bleibt auch hier fraglich. Insgesamt ist aber die Propaganda für die Muslime weit hinter derjenigen für Serben und Kroaten zurückgeblieben. Dies ist wohl denselben Gründen geschuldet, wie die späte Kooperation mit dem muslimischen Teil der Bevölkerung. Zum einen stell-

196 VA, TA, k. 554, reg. br. 11/7-2, Flugblatt „Freunde!“; VA, TA, k. 564, reg. br. 8/2-10, „Was haben die ,Eroberer' in Dalmatien gemacht und was machen kommunistische Partisanen?“; VA, TA, k. 564, reg. br. 8/2-15, „Der Schwarzmarkt hat in Dalmatien keinen Grund zu existieren“; VA, TA, k. 564, reg. br. 6/2-3, Flugblatt „Arbeiter!“.

197 NARA, T-821, R. 439, Nr. 69, 71, 73 Flugblätter gegen England; NARA, T-821, R. 415, Nr. 314, „Unsere Feinde“.

198 NARA, T-821, R. 418, Nr. 722-725, 2. Armata: Relazione mensile sull'attività svolta presso le popolazioni civili dei territori occupati nel mese di novembre 1942.

199 NARA, T-821, R. 419, Nr. 373, Comando Supersloda: Opuscoli di propaganda in lingua araba, 3.3.1943.

200 NARA, T-821, R. 420, Nr. 167, Schreiben des Außenministeriums, 3.4.1943. 
ten die Muslime den geringsten Teil der Bevölkerung im italienisch besetzten Gebiet dar. Zum anderen wurde ihr Verhalten von der italienischen Seite relativ lange als reserviert und feindlich gegenüber Italien wahrgenommen. ${ }^{201}$ Zudem reflektiert dies die Bedeutung, die die militärischen Behörden den Muslimen beimaßen - also zunächst keine. Es ist kein Zufall, dass die italienische Propaganda für Muslime zeitgleich mit der Anwerbung der Muslime für die SS-Division „Handschar“ einsetzte, also erst dann, als sich die Italiener durch deutsches Vorgehen unter Zugzwang sahen. ${ }^{202}$

Zusätzlich zur schriftlichen Propaganda wurden auch Radio- und Filmpropaganda benutzt. Zu Beginn des Jahres 1942 plante die Regierung von Dalmatien, einen Radiosender in Zara zu installieren, der offizielle aber auch heimliche Radiosendungen ausstrahlen sollte, um sowohl die italienische Politik in Dalmatien zu unterstreichen, als auch Gegenpropaganda zu betreiben. ${ }^{203}$ Sehr spät nahm der Sender Ragusa seinen Betrieb auf, strahlte dann aber auch Sendungen in kroatischer Sprache aus. Manchmal wurden, wie etwa in Split, Lautsprecher angebracht, um italienische Propaganda und Musik zu verbreiten, doch auch hierfür fehlte es an geeigneten Mitteln. ${ }^{204}$ Filmpropaganda wurde durch kostenlose Kinovorstellungen, bei denen LUCE-Filme gezeigt wurden, betrieben. Auf diese Weise versuchte man, auch Bauern und Arbeiter zu erreichen, von denen man annahm, dass sie viel leichter für die kommunistische Propaganda empfänglich waren. ${ }^{205}$ Neben Spielfilmen wurden auch gerne Dokumentarfilme über die italienische Kultur, ferner Filme mit kriegerischem oder erzieherischem Inhalt gezeigt. Beide Propagandaarten blieben jedoch aufgrund vieler technischer Probleme weit hinter dem zurück, was sie hätten leisten können. ${ }^{206} \mathrm{Im}$ NDH stellte die gedruckte Propaganda das wichtigste Propagandamittel während des Zweiten Weltkriegs dar.

Neben dieser allgemeinen Propaganda für die slawische Bevölkerung gab es auch Propaganda, die auf Partisanen abzielte. Während die Propaganda für

201 ASMAE, GAB-AP 1923-1943, b. 1499, Telegramm des Konsulats in Dubrovnik an das Außenministerium, GAB-AP, 8.11.1941.

202 ASMAE, GAB-AP 1923-1943, b. 1497, Schreiben des Verbindungsbüros bei der 2. Armee an das Außenministerium, 2.4.1943.

203 ACS, MCP, Gabinetto, b. 135, fasc. Dalmazia, Der Gouverneur von Dalmatien an den Minister für Volkskultur, Alessandro Pavolini, 31.1.1942.

204 NARA, T-821, R. 418, Nr. 323-326, Comando 2. Armata: Relazione mensile sull'attività svolta presso le popolazioni civili dei territori occupati nel mese di giugno 1942.

205 AUSSME, DS, b. 1138, All. 14, Relazione mensile „A“, 18.4.1943.

206 AUSSME, DS, b. 585, cart. 278, Nr. 4, Relazione mensile sul servizio „P“ per il periodo dal 15. novembre al 15. dicembre 1941; AUSSME, DS, b. 996, All. 209 al DS dicembre 1942, Relazione mensile sul servizio „P“ dal 15 ottobre al 15 novembre 1942; AUSSME, DS, b. 1138, All. 14, Relazione mensile „A“, 18.4.1943. 
die Bevölkerung zentral von der Unterabteilung der Propaganda bei der 2. Armee gemacht wurde, wurde die meistens in Form von Flugblättern gemachte Propaganda für Partisanen dezentral von den Armeekorps oder Divisionen produziert und verteilt (z. B. über Partisanengebieten abgeworfen). Schon im April 1942 bekamen die Divisionen Mittel von der 2. Armee für solche Propagandaarbeit. ${ }^{207}$ So sollten sie in der Lage sein, auf Partisanenpropaganda schnell zu reagieren und auf besondere Umstände - vor allem Operationen - einzugehen. Die meisten Flugblätter riefen die Partisanen dazu auf, die Wälder zu verlassen, wobei ihnen das Leben und jenes ihrer Familien garantiert wurden. Besonders betont wurde wieder die Schonung aller und die italienische Großzügigkeit, wobei häufig Ultimaten gestellt wurden, bis zu welchem Zeitpunkt sich die Aufständischen ergeben sollten. ${ }^{208}$

Auf die Propaganda der Kommunisten sollte mit ähnlicher Propaganda geantwortet werden. Flugblätter, die denjenigen der Kommunisten ähnelten, verbreiteten italienische Propaganda. ${ }^{209}$ Im Gegensatz zu deutschen Flugblättern zeichneten sich italienische Propagandaerzeugnisse durch viel Text aus. Die Flugblätter bestanden meistens aus zwei Seiten, die voll beschrieben waren. Darin gaben die Italiener sehr genaue Angaben über die Kämpfe an diversen Kriegsschauplätzen und die Verluste insbesondere der Roten Armee wieder. ${ }^{210}$ Ähnlich wie die Deutschen versuchten auch die Italiener, ihrer Propaganda durch Geschichten ehemaliger Partisanen mehr Glaubwürdigkeit zu verschaffen. Ein Flugblatt, das mit Hammer und Sichel versehen worden war, rief die Studenten auf, den Partisanenführern nicht blind zu vertrauen. Nach der Landung der Alliierten in Sizilien, riefen falsche Partisanenflugblätter diese dazu auf, nicht zuzulassen, dass Engländer und Amerikaner den Balkan besetzten. ${ }^{21}$

207 NARA, T-821, R. 415, Nr. 82, Comando 2. Armata: Assegnazione fondi assistenza e propaganda presso le popolazioni civili, 2.4.1942.

208 NARA, T-821, R. 415, Nr. 662 f., Flugblatt „Männer, die ihr im Wald kämpft“; NARA, T-821, R. 415, Nr. 698, Flugblatt für Partisanen „Kommt zurück“; NARA, T-821, R. 415, Nr. 806, Flugblatt für Partisanen „Arbeiter von Kroatien, Dalmatien, Lika und Bosnien!“; HDA, TV, k. 18, Nr. 2921, Flugblatt vom August 1942; HDA, TV, k. 18, Nr. 2928, Flugblatt vom 7.4.1942.

209 AUSSME, DS, b. 1188, All. 97, Relazione mensile sul servizio „A“ per il periodo dal 15 febbraio al 15 marzo 1943; AUSSME, DS, b. 1188, All. 97, Relazione mensile sul servizio „A“ per il periodo dal 15 marzo al 15 aprile 1943; NARA, T-821, R. 415, Nr. 698, Broschüre „Dalmatinerin im Kampf“, Mai 1943.

210 NARA, T-821, R. 414, Nr. 665, Relazione per il mese di agosto [1942] sullo sviluppo della contropropaganda.

211 NARA, T-821, R. 439, Nr. 44 f., Flugblatt „Ein Partisan Berichtet“; NARA, T-821, R. 439, Nr. 18, An die kroatischen Studenten; NARA, T-821, R. 439, Nr. 252 f., Flugblatt „An die Partisanen Jugoslawiens“ vom August 1943. 
Die Propagandaabteilungen berichteten auch stets, wie sie die Wirksamkeit der eingesetzten Propaganda beurteilten. Das korrekte Verhalten der italienischen Soldaten und die materielle Hilfe für die verarmte Bevölkerung wurden stets als die beste Art der Propaganda bezeichnet. Daher wurde die Hilfe, die insbesondere Müttern und Kindern zuteil wurde, als von großer propagandistischer Bedeutung gewertet. ${ }^{212}$ Bei der schriftlichen Propaganda gingen die Meinungen auseinander. Die Verantwortlichen beim VI. Armeekorps fanden beispielsweise, dass die Wandzeitungen hervorragende Propagandaarbeit leisteten. ${ }^{213}$ Die Abteilung „P“ des XVIII. Armeekorps stellte hingegen fest, dass die Form der Propaganda, wie sie in Italien gemacht wurde, bei der Bevölkerung in annektierten und besetzten Gebieten nicht wirkte. Diese schätze nicht die einfache Widergabe italienischer Errungenschaften und Kriegserfolge, sondern objektive, begründete Berichte, die auf Zahlen basierten. Eine fast identische Einschätzung kam neun Monate später auch von der Sektion „A“ des V. Armeekorps. ${ }^{214}$ Dies alleine zeigt, dass trotz solcher Einwände wenig gemacht wurde, um die Propaganda den Umständen anzupassen. Die Zeitungen brachten bis zum Schluss italienische Erfolge, nur bei den Flugblättern für Partisanen arbeitete man mit vielen Daten und Zahlen. Besonders schlecht wirkten sich Nachrichten aus italienischen Zeitungen aus, die von der Vernichtung der Partisanen genau dort berichteten, wo die Bevölkerung lebte und sich täglich vom Gegenteil überzeugen konnte. ${ }^{215}$ Ein anderes Problem stellte die kroatische bzw. serbische Übersetzung dar. So wurde beispielsweise eine Wandzeitung, die in den Konzentrationslagern verteilt wurde, von den Internierten korrigiert. Sie verbesserten die serbische Schreibweise bzw. korrigierten bestimmte kroatische Wörter ins Serbische. ${ }^{216}$ Gute propagandistische Resultate wurden stets der Kinder-

212 AUSSME, DS, b. 582, All. 4 al DS del giorno 28.6.1941, Relazione mensile sul servizio „P“ per il periodo dal 15 maggio al 16 giugno 1941; AUSSME, DS, b. 1264, All. 4, Relazione mensile sul servizio „P“, 5.2.1942; AUSSME, DS, b. 646, All. 287 al DS Aprile 1942, Relazione mensile 15 marzo - 15 aprile, 29.4.1942; AUSSME, DS, b. 859, Df Murge: Relazione mensile sul servizio „Propaganda“, 18.8.1942.

213 NARA, T-821, R. 415, Nr. 325, Comando V CdA: Cartelloni di propaganda, 24.8.1942.

214 AUSSME, DS, b. 782, All. 208 al DS luglio 1942, Relazione mensile dal 15 giugno al 15 luglio 1942; NARA, T-821, R. 433, Nr. 528-525, Comando V CdA: Andamento e sviluppo del Servizio „A“ dal 16 marzo al 15 aprile 1943.

215 NARA, T-821, R. 433, Nr. 1066-1074, XVIII CdA: Relazione mensile sul servizio „A“ per il periodo dal 15 marzo al 15 aprile 1943.

216 NARA, T-821, R. 415, Nr. 333, „Vesti iz sveta“; NARA, T-821, Nr. 334, SMRE: Fotografie, 30.7.1942; NARA, T-821, R. 420, Nr. 99-101, Norme per la diffusione del materiale di propaganda e contropropaganda per le popolazioni civili, 1.7.1943. 
zeitung zugesprochen und meistens auch den Wandzeitungen. ${ }^{217}$ Die Propagandamacher waren sich aber auch stets darin einig, dass ihre Propaganda derjenigen der Partisanen unterlegen war.

\subsection{Die Wehrmacht}

Der Führerbefehl vom 10. Februar 1941 definierte den Stellenwert und die Bedeutung der Wehrmachtpropaganda. Die Propagandatruppen waren grundsätzlich dem OKW unterstellt, die geistige Betreuung der Truppe und die Abwehr der Feindpropaganda fielen in den Bereich der Abteilung Wehrmachtpropaganda. ${ }^{218}$ Die geistige Betreuung umfasste ,alle Maßnahmen zur seelischen Entspannung, inneren Auffrischung und geistigen Auflockerung der Truppe“. Ihre Vorbedingung bestand aus der „materielle[n] Fürsorge (Unterkünfte, Beleuchtung, Beheizung, Verpflegung, Feldpost, Marketenderwaren)“. Zur geistigen Betreuung zählten die Verteilung von Lesestoff, die Durchführung von Berufsförderungsveranstaltungen und Wettbewerben, das Hören vom Rundfunk, das Spielen von Musik, Basteln, sowie die in die Maßnahmen der Division fallenden Veranstaltungen (Film, Musikkorps, Bunkertrupp, KdF). ${ }^{219}$

Am Balkanfeldzug waren drei Propagandastaffeln (PS) beteiligt. Im Anschluss wurden unter anderem die Propaganda-Kompanie 690 sowie die Propaganda-Abteilung Südost, mit den Propagandastaffeln Serbien und Griechenland, eingesetzt. Ihre Aufgaben umfassten gemäß den bereits erläuterten Aufgaben der Propagandastaffeln Berichterstattung, Truppenbetreuung sowie propagandistische Betreuung der Bevölkerung des besetzten Gebietes. ${ }^{220}$ Da die Truppen in Kroatien zunächst dem Bevollmächtigten Kommandierenden General in Serbien unterstellt waren, wurde auch deren „wehrgeistige Führung“ von dort aus geregelt. Im Herbst 1942 übernahm dies dann der Befehlshaber der Deutschen Truppen in Kroatien. Die dem Wehrmachtsbefehlshaber Südost un-

217 AUSSME, DS, b. 881, All. 102, al DS settembre 1942, Relazione mensile sul servizio „P“ dal 15 agosto al 15 settembre 1942; AUSSME, DS, b. 859, Df Murge: Relazione mensile sul servizio „Propaganda“, 18.8.1942; AUSSME, DS, b. 1068, Relazione mensile sul servizio „P“ dal 15 gennaio 1942 al 15 febbraio 1943.

218 Buchbender: Propaganda,, S. 23 f.; Buchbender/Schuh: Waffe, S. 20.

219 BArch, RM 35/III/164, Anl. 9, Politische Fragen, Abwehrdienst und geistige Betreuung, 5.11.1941; BArch, RH 26/117/12, Anl. 25, Besprechung am 28.4. 1943 beim Befehlshaber Südgriechenland; BArch, RM 35/III/164, Wehrgeistige Führung der Truppe, 15.10.1943.

220 BArch, RM 35/III/164, Dienstanweisung des Wehrmachtsbefehlshabers Südost für die im Befehlsbereich des Wehrmachtsbefehlshabers Südost eingesetzten Propaganda-Einheiten, 1.5.1942. 
terstellte Propagandakompanie (PK) 690 sowie die OKW-Außenstelle Belgrad führten die „geistige Betreuung“ durch. ${ }^{221}$ Insgesamt bemühte man sich, der Truppe ein breites Unterhaltungsprogramm zu bieten, das ihr die Langeweile vertreiben, sie aber auch gleichzeitig im nationalsozialistischen Sinn beeinflussen sollte. Neben Soldatenheimen wurden in großen Städten Soldatenkinos und KdF-Bühnen eingerichtet. Der eigene „Bunkertrupp“ bot zudem Vorstellungen mit Musik, Gesang und Aufführungen an und besuchte auch die entlegensten Truppen. So kann man davon ausgehen, dass alle Soldaten irgendeine Form von Unterhaltung erfuhren, selbst wenn sie sich nicht in Städten aufhielten. Gleichzeitig wurden die Donau-Zeitung, die Deutsche Zeitung in Kroatien sowie Tageszeitungen und illustrierte Zeitschriften verteilt. Von der Wehrmacht $\mathrm{zu}$ diesem Zweck produzierte Mitteilungen für die Truppe, OKW-Nachrichten, Tornisterschriften, Bilder der Woche, „Parole der Woche“ und Soldatenbriefe ergänzten das Angebot. Die Soldaten konnten in ihrer Freizeit diverse Filme sehen, die nach Möglichkeit häufig ausgetauscht wurden. Neben unterhaltenden Filmen kamen auch Lehrfilme wie z. B. „Bau von Flandernzäunen“, „Heeresreitund Fahrschule“ oder „Die motorisierte Batterie“ zum Einsatz. ${ }^{222}$ Ab April 1943 waren Vorträge über die Geschichte und Kultur des serbisch-kroatischen Raumes geplant und ab Mai wurde auch Deutschunterricht für neu eingegliederte volksdeutsche Soldaten durchgeführt. ${ }^{223}$

\section{Propaganda für Soldaten}

Der Angriff auf Jugoslawien zeigt die gesamte antiserbische Einstellung bei der deutschen Führung sehr deutlich sowie den Wunsch, Vergeltung für den Putsch und damit für die Ausschlagung des deutschen Kooperationsangebots zu üben. Der Krieg begann mit dem „Unternehmen Strafgericht“, dem Luftangriff auf Belgrad ohne vorherige Kriegserklärung an Jugoslawien. Belgrad, das keine Luftabwehrgeschütze besaß und von der jugoslawischen Regierung zur „offenen Stadt“2224 erklärt worden war, sollte „durch fortgesetzte Tag- und Nachtangriffe“

221 BArch, RM 35/III/164, Anl. 9, Politische Fragen, Abwehrdienst und geistige Betreuung, 5.11.1941.

222 BArch, RW 40/5, Nr. 193-194, Tätigkeitsbericht der Abt. Ic (August 1941); BArch, RH 26/ 114/17, Tätigkeitsbericht Februar 1943, Erfahrungsbericht über geistige Betreuung.

223 BArch, RH 26/114/18, Tätigkeitsbericht 114 I. D., Geistige Betreuung, April 1943; BArch, RH 26/114/20, Tätigkeitsbericht Mai 1943, Erfahrungsbericht über geistige Betreuung; BArch, RH 26/114/21, Tätigkeitsbericht Juni 1943, Erfahrungsbericht über geistige Betreuung.

224 Im Kriegsrecht gilt eine „offene Stadt“ als eine Stadt, die nicht verteidigt wird und besonderen Schutz genießt. Nach der Haager Landkriegsordnung durfte eine sich nicht verteidigende 
zerstört werden. Die „Strafabsicht“ wird auch dadurch sichtbar, dass zunächst die Stadt verwüstet wurde, um die Bevölkerung zu treffen, und erst in der zweiten Angriffswelle militärische Anlagen und Verwaltungszentren zerstört werden sollten. Die Benennung der Aktion erfolgte in Analogie zur „Strafexpedition“ der k. u. k. Monarchie von 1914. ${ }^{225}$ Hitler fühlte sich durch den Putsch persönlich so sehr abgewiesen und hintergangen, dass er dies noch 1944 für seine Ablehnung einer Zusammenarbeit mit den Tschetniks anführte:

Ich habe den Serben 1941 ein außergewöhnliches Angebot gemacht. Ich habe nur verlangt, dass sie neutral bleiben und dafür habe ich ihnen Saloniki versprochen. Einen höheren Preis hätten sie nicht bekommen können. In der Realität kam es aber zu einer Entwicklung, die in keiner Weise diesem großzügigen Angebot entsprach. 226

Propagandistisch hatte der Angriff eine Ausrichtung: Die serbische Regierung wurde als der alleinige Gegner Deutschlands dargestellt. Den deutschen Soldaten wurde eingetrichtert, der serbische Soldat sei „zäh, roh und gefühllos“. Darüber hinaus befahl das OKW, die serbischen Offiziere „ausgesucht schlecht“ zu behandeln. ${ }^{227}$ Darauf aufbauend hat die Verbindung von Ideologie und Befehl, wie Manfred Messerschmidt argumentiert, „eine beinahe unwiderstehliche Stringenz bewirkt.“

Eure Aufgabe ist in einem Landstreifen durchzuführen, in dem 1914 Ströme deutschen Blutes durch die Hinterlist der Serben, Männer und Frauen, geflossen sind. Ihr seid Rächer dieser Toten. Es muß ein abschreckendes Beispiel für ganz Serbien geschaffen werden, das die gesamte Bevölkerung auf das Schwerste treffen muß.228

Stadt nicht angegriffen werden. <http://www.admin.ch/ch/d/sr/i5/0.515.111.de.pdf> (24.01.2011).

225 Manoschek: Partisanenkrieg, S. 146.

226 Notiz des Abwehroffiziers des Kommandos Südost, 22.8.1944, abgedr. i. Zbornik, XII/4, Nr. 113, S. 524-532.

227 Schreiber/Stegemann/Vogel: Der Mittelmeerraum und Südosteuropa, S. 483; Pohl, Dieter: Die Herrschaft der Wehrmacht: deutsche Militärbesatzung und einheimische Bevölkerung in der Sowjetunion. 1941-1944, München 2008, S. 79.

228 Zit. nach Manoschek, Walter: Serbien: Partisanenkrieg und Völkermord, in: Benz, Wolfgang/ Houwink ten Cate, Johannes/Otto, Gerhard (Hg.): Anpassung, Kollaboration, Widerstand. Kollektive Reaktionen auf die Okkupation, Berlin 1996, p. 137 f.; Messerschmidt, Manfred: Ideologie und Befehlsgehorsam im Vernichtungskrieg, in: Ehlert, Hans/Lang, Arnim/ Wegner Bernd (Hg.): Militarismus, Vernichtungskrieg, Geschichtspolitik. Zur deutschen Militärund Rechtsgeschichte, Paderborn 2006, S. 221-243, hier S. 222. 
Hitler setzte auf dem Balkan überproportional viele Österreicher ein. ${ }^{229} \mathrm{Er}$ glaubte, dass aufgrund ihrer Geschichte nur die Österreicher die Serben kennen würden und wüssten, wie mit diesen umzugehen sei. Dies hatte zudem den Vorteil, dass Propaganda auf dem altösterreichischen Feindbild aus dem Ersten Weltkrieg aufbauen konnte. ${ }^{230}$

Bereits die ersten Befehle und Überlegungen transportierten auch ideologische Beschreibungen der Gegner. Hitler hatte beim Angriff auf Jugoslawien ähnlich wie in der Sowjetunion Emigranten, Saboteure, Terroristen, Kommunisten und Juden zu Feinden erklärt. ${ }^{231}$ Auf diese Weise wurden alle Feinde der „Neuen Ordnung" ins Visier genommen. Nachdem durch Massenerschießungen im Rahmen der „Sühnemaßnahmen“ bis zum Winter 1941 die jüdischen Männer Serbiens ermordet worden waren, blieben als Ideologiekonstanten Kommunisten und „Banditen“ übrig. ${ }^{232}$ Für den Winter 1941/42 machte der WB Südost den harten und rücksichtslosen Kampf gegen „Banden“ zur Grundlage der Aufständischenbekämpfung. Zudem sollten die Armeeführer danach streben, „sich im Bandenkampf vom handwerksmäßigen Gebrauch taktischer Formen und Gewohnheiten frei zu machen, vielmehr dem verschlagen kämpfenden Feind selbst verschlagen und überlegen zu begegnen.“233 In den „Richtlinien für die Behandlung der Aufständischen in Serbien und Kroatien“ vom 19. März 1942 beschrieb der WB Südost das Feindbild folgendermaßen:

\footnotetext{
„Dem deutschen Soldaten steht in Serbien und Kroatien in den Aufständischen ein brutaler, hinterhältiger und verschlagener Gegner gegenüber, der vor keinem Mittel zurückschreckt, meist einen Rückhalt an der feindlich gesinnten Bevölkerung findet und die Befriedung und wirtschaftliche Ausnutzung des Landes untergräbt.“‘234
}

229 Die 717. und die 718. I. D. wurden in der „Ostmark“ aufgestellt, genauso wie vier der insgesamt sechs in diesem Gebiet eingesetzten Landesschützenbataillone. Genauso waren die wichtigsten Wehrmachtsoffiziere sowie die ranghöchsten SS-Vertreter Österreicher. Shepherd: Terror in the Balkans, S. 8 f.; Manoschek: Kraljevo, S. 95 f. In Glaise von Horstenaus Korrespondenz wird beispielsweise sein Überlegenheitsgefühl gegenüber den Südslawen immer wieder deutlich.

230 Aussage Neubachers vom 20.9.1947, in: Glišić, Venceslav: Teror i zločini nacističke Nemačke u Srbiji 1941-1944, Belgrad 1970, S. 30 f.; Manoschek: Partisanenkrieg, S. 143-146.

231 Messerschmidt: Ideologie, S. 235.

232 Zur Judenverfolgung in Serbien vgl. Manoschek: „Serbien ist judenfrei!“, S. 55-108; Browning, Christopher: Wehrmacht Reprisal Policy and the Mass Murder of Jews in Serbia, in: Militärgeschichtliche Mitteilungen, (1983) 1, S. 31-47.

233 BArch, RH 20/12/110, Befehl des WB Südost betreffend Winterausbildung, 16.12.1941.

234 BArch, RH 20/12/218, Richtlinien für die Behandlung der Aufständischen in Serbien und Kroatien, 19.3.1942. 
Die sprachlichen Wendungen sollten über die gesamte Besatzungszeit keine großen Änderungen erfahren. Die Aufständischen wurden immer als „Banditen“, ihre Formationen als „Banden“ bezeichnet. ${ }^{235}$ Häufig diente das vorangestellte Wort „Balkan“ dazu, ihre „Verschlagenheit“ und „Hinterhältigkeit“ zu betonen. So ordnete General Böhme Anfang Oktober 1941 an, aufgrund von „Balkanmentalität“ und der großen Ausdehnung kommunistischer und nationalistischer Aufstände die Befehle des OKW in der schärfsten Form durchzuführen. ${ }^{236}$ Kasche warnte im Herbst 1941 davor, dass das Ansehen und die Stellung der deutschen Wehrmacht nicht durch Schwächen gegenüber einem Gegner, der die „Balkansituation“ ausnutzte, beeinträchtigt werden dürften. ${ }^{237}$ In den Richtlinien zur Winterausbildung der Truppen befahl der WB Südost, den Soldaten die Notwendigkeiten eines harten und rücksichtslosen Kampfes gegen „Banden“ einzuschärfen. Auch im Befehl zur Operation „Weiß“ forderte Löhr in Anbetracht der „hinterhältige[n] Kampfart der Banden [...] rücksichtsloses Durchgreifen ohne Milde und ohne Hemmungen“. ${ }^{238}$

Die „Balkanmentalität“ der „Banden“ sollte durch ein weiteres Element die Soldaten beeinflussen, Hass- und Angstgefühle schüren und dadurch die Truppe für die Befehle des schonungslosen Vorgehens aufnahmefähiger machen. Es handelte sich dabei um Nachrichten von der Verstümmelung deutscher Soldaten. Nachdem 21 deutsche Soldaten im Herbst 1941 in Serbien getötet worden waren, begründete General Böhme die Erschießung von 2.100 Geiseln mit der Sühne für diese Soldaten, die „auf bestialische Weise zu Tode gequält“ worden seien. Dabei hatte die Obduktion ergeben, dass die Soldaten nicht verstümmelt worden waren. ${ }^{239}$ Nach dem Angriff auf Drvar im Mai 1944 wurden beispielsweise 80 teils verstümmelte Leichen der SS-Angehörigen gefunden. Daraufhin

235 Grundsätzlich geben sich Aufständische im Konflikt einen Namen, der ihre Legitimität bestärken soll, während er von der Gegenseite verworfen wird. Diese nennen die Aufständischen Banditen, Kriminelle oder Terroristen und stellen den Konflikt als Banditentum, Bandenunwesen oder Terrorismus dar. Vgl. Kalyvas, Stathis N.: The Logic of Violence in Civil War, Cambridge [u. a.] 2006, S. 17. Ähnlich verfuhr die Wehrmacht mit den Partisanen in der Sowjetunion. Heer, Hannes: The Logic of the War of Extermination. The Wehrmacht and the Antipartisan War, in: Heer, Hannes/Naumann, Klaus (Hg.): War of Extermination. The German Military in World War II (1941-1944), New York/Oxford 2000, S. 92-126, hier S. 113.

236 Messerschmidt: Partisanenkrieg, S. $248 \mathrm{f}$.

237 PA-AA, StS Kroatien, Bd. 2, R. 29.666, Nr. 681, Nr. 177, Telegramm des Gesandten Kasche an das Auswärtige Amt, 8.9.1941.

238 BArch, RH 20/12/110, Befehl des WB Südost betreffend Winterausbildung, 16.12.1941; BArch, RH 26/114/16, Tagesbefehl des Oberbefehlshabers Südost, 18.1.1943.

239 Manoschek: „Serbien ist judenfrei“, S. 81-83, 187. 
rächte sich die SS nicht weniger grauenvoll an den Gefangen. ${ }^{240}$ Auch Glaise von Horstenau wiederholte diese Propaganda in seinem Tagebuch, indem er sich darüber beklagte „in welch kannibalischer Weise unser hiesiger Gegner deutsche Soldaten zu Tode zu massakrieren pflegte“.241 Die Deutsche Zeitung in Kroatien berichtete davon, auch wenn im Artikel einem kroatischen Soldaten das Herz herausgerissen worden war. ${ }^{242}$ Unter entwürdigendem Verhalten wurde auch das Zurücklassen entkleideter Leichen verstanden. Während die Verstümmelung eine bestrafende und erniedrigende Funktion hatte, war das bei der Entkleidung der Leichen jedoch nicht der Fall. Die toten Soldaten dienten den Aufständischen, aber auch der Bevölkerung, als „Lieferanten“ nicht nur von Waffen und Munition, sondern auch von Kleidung und Schuhen. ${ }^{243}$

1943 setzte eine neue Welle propagandistisch-weltanschaulicher Indoktrination ein. Bereits Anfang 1943 sollte der anhand jugoslawischer Beuteakten geschriebene Aufsatz „Das politische Kräftespiel auf dem Balkan“ unter den Offizieren verbreitet werden und ihnen helfen, sich in den „schwierigen Verhältnissen zu Recht zu finden“. ${ }^{244}$ Diese Propaganda gepaart mit dem bei den Soldaten verbreiteten Befehlsgehorsam scheint ihre Wirkung nicht verfehlt zu haben. Messerschmitt argumentiert, dass „der Hinweis auf den höheren Befehl genügte, um das Mitfunktionieren der Wehrmacht herbeizuführen."245 Diese These wird durch die Erfahrungen der Partisanen unterstützt, die sich ihren Misserfolg bei der „Umerziehung“ der gefangenen deutschen Soldaten eingestehen mussten:

Nach nahezu zweimonatiger politischer Arbeit, die von Kocmur, einem Fachmann der Komintern für die Umerziehung von Häftlingen, durchgeführt wurde, antworteten die Deutschen auf die Frage, ob sie - nachdem sie nun so schön über den Nationalsozialis-

240 Schraml, Franz: Kriegsschauplatz Kroatien: die deutsch-kroatischen Legionsdivisionen 369., 373., 392. Inf.-Div. (kroat.) - ihre Ausbildungs- und Ersatzformationen, Neckargemünd 1962, S. $192 \mathrm{f}$.

241 Broucek: General im Zwielicht, Eintrag vom Februar 1943, S. 178. Auch Partisanen hatten Angst vor der Schändung ihrer Anführer. Deshalb wurde der Leichnam von Ivo Lola Ribar, der bei einem Luftangriff ums Leben kam, an einem geheimen Ort beerdigt. Đilas: Der Krieg der Partisanen, S. 471.

242 NARA, T-821, R. 415, Nr. 1135, Artikel „Kampf an der unsichtbaren Front“, in: Deutsche Zeitung in Kroatien, 8.12.1942.

243 Das geht auch aus deutschen und italienischen Berichten hervor, die beschreiben, dass Partisanen alle möglichen Uniformen trugen, aber anhand des roten Sterns identifizierbar waren. Milovan Đilas schreibt, dass auch Bauern tote Kämpfer aller Seiten nach Waffen, Kleidung und Schuhen durchsuchten. Đilas: Der Krieg der Partisanen, S. 391.

244 BArch RH 31/III/4, „Das politische Kräftespiel auf dem Balkan“, 20.2.1943.

245 Messerschmidt: Ideologie, S. 232. 
mus bescheid wüßten - immer noch Wehrlose morden würden, zumeist mit: ,Befehl ist Befehl... 246

Dass die Banditen-Stereotype in der Propaganda durchaus einen Erfolg hatten, zeigen Argumentationsmuster ehemaliger Wehrmachtssoldaten, die noch lange nach Kriegsende bemüht wurden. Außer in Memoiren fanden sich solche Äußerungen auch in Lesebriefspalten deutscher Tageszeitungen, die durch die Wehrmachts-Ausstellung Ende der 1990er Jahre hervorgerufen wurden. Neben der Beschreibung der Partisanen als heimtückische Attentäter und Heckenschützen wurde vor allem das Argument der „legitimen Notwehr“ stets wiederholt. So hatten sich die Parolen der Propaganda tief in die Mentalität der (ehemaligen) Soldaten eingegraben. ${ }^{247}$

\section{Propaganda für die Bevölkerung}

Bereits 1938 wurde vom OKW eine Verfügung über die „Grundsätze für die Führung der Propaganda im Kriege“ erlassen, die in Zusammenarbeit von Propagandaministerium und Wehrmacht aufgestellt wurden. Für das Kampfgebiet wurde dabei Folgendes vereinbart: „Die aktive Propaganda im Kampfgebiet, also die Propaganda in die Bevölkerung und feindliche Wehrmacht von der Truppe aus, leiten die militärischen Dienststellen mit Hilfe der ihnen unterstellten Propaganda-Kompanien." ${ }^{248}$ In Jugoslawien sollten explizit die innenpolitischen Gegensätze ausgenutzt werden. Den Kroaten, Muslimen und Mazedoniern war zu zeigen, dass die Wehrmacht nicht als Feind kam, sondern um sie davor zu schützen, im serbischen Kalkül ,auf dem Schlachtfeld für englische Interessen hingeschlachtet zu werden“. Insbesondere den Kroaten sollte die deutsche Freundschaft explizit zugesichert werden. ${ }^{249}$

In Serbien begann die Propagandastaffel sofort nach der Besetzung damit, über den unbeschädigten Sender „Belgrad“ Rundfunksendungen auszustrahlen, der seinen ersten Erfolg mit der Ausstrahlung des Liedes „Lili Marleen“ ha-

246 Đilas: Der Krieg der Partisanen, S. 146.

247 Vgl. Klinkhammer, Lutz: Der Partisanenkrieg der Wehrmacht 1941-1944, in: Müller, RolfDieter/Volkmann, Hans-Erich (Hg.): Die Wehrmacht. Mythos und Realität, München 1999, S. 815-836, hier S. 815.

248 Zit. nach Buchbender, Ortwin: Das tönende Erz. Deutsche Propaganda gegen die Rote Armee im Zweiten Weltkrieg, Stuttgart 1978, S. $17 \mathrm{f}$.

249 Zit. nach Moll, Martin/Augustinović, Werner: Deutsche Propaganda im Balkanfeldzug 1941, in: Österreichische militärische Zeitschrift 38 (2000) 4, S. 459-466, hier S. 460. 
ben sollte, das zum offiziellen Lied des Senders avancierte. ${ }^{250}$ Neben solch unterhaltenden Beiträgen hetzte die nationalsozialistische Propaganda gegen Juden und machte sie als „Drahtzieher“ für kommunistische Anschläge verantwortlich. ${ }^{251}$ In Kroatien sah es zunächst anders aus. Bis zur Errichtung der Wehrmacht-PS waren die Kroaten für die militärische Propaganda zuständig. Diese wandte sich in der ersten Hälfte 1942 überwiegend an Tschetniks und zu geringeren Teilen an ihre Gefolgschaftsleute unter den Bauern sowie an Partisanen und wurde vor allem in Form von Flugblättern durch Abwurf aus Flugzeugen in Bosnien verteilt. ${ }^{252}$ Für die deutschen Kampfeinheiten im NDH wurden fallweise Propaganda-Kompanien aus Saloniki oder Belgrad entsandt. Wie umfangreich ihre Arbeit war, lässt sich aufgrund mangelnder Dokumente nicht mehr feststellen. Vermutlich beschränkte sie sich jedoch auf ein Minimum.

Im Winter 1942 kamen die deutschen militärischen und politischen Stellen dann überein, eine eigene Propagandastaffel für die Truppen in Kroatien (Propahandastaffel Kroatien, PSK) zu errichten. Im Gegensatz zu Propagandakompanien, die neben der Berichttätigkeit Feindpropaganda an der vordersten Front betrieben, beeinflussten die Propagandaabteilungen bzw. -staffeln darüber hinaus die Bevölkerung „,im Hinterland“. Die aus insgesamt neun Personen bestehende Propagandaabteilung für Kroatien mit Sitz in Zagreb und Nebenstellen in Sarajevo und Banja Luka sollte eine propagandistische Beeinflussung der Bevölkerung und vor allem der „Banden“ ausbauen. Die Entwicklung in Kroatien passte dabei in den allgemeinen Trend. Bis 1943 waren die Propagandakompanien vor allem für die schriftliche und bildliche Berichterstattung zuständig, die für die Propaganda in der Heimat diente. So waren im Januar 1943 nur 15 Prozent des Personals der PKs in der Aktivpropaganda eingesetzt. Nach der Niederlage in Stalingrad kam es dann zu einer deutlichen Schwerpunktverschiebung von der Berichterstattung zu Aktiv- bzw. Kampfpropaganda. ${ }^{253}$ Bei einem Treffen im Frühjahr 1943 in Südgriechenland waren sich deutsche Kommandeure aus dem Südosten einig, dass Propaganda, verstanden

250 Wedel, Hasso von: Die Propagandatruppen der deutschen Wehrmacht, Neckargemünd 1962, S. 47, 81. Auch die englische Mission hörte immer um 22.00 Uhr den Lili Marleen Song des Belgrader Senders. Maclean: Approaches, S. 254, 380.

251 Manoschek, Walter: „Gehst mit Juden erschießen?“ Die Vernichtung der Juden in Serbien, in: Heer/Naumann (Hg.): Vernichtungskrieg, S. 39-56, hier S. $40 \mathrm{f}$.

252 PA-AA, Gesandtschaft Zagreb, Geheimakten, P. 2, D kult 3 - A 167/42 - Ang. II, Propagandatätigkeit in den Monaten März und April 1942.

253 Buchbender/Schuh: Waffe, S. 20; Uziel: Propaganda, S. 20. 
als Kampf gegen die innere Einstellung, dem Kampf mit der Waffe gleichzusetzen war. 254

Die Errichtung einer Propagandastaffel im NDH bedrohte die bisherige besondere Stellung der Gesandtschaft, weil Kasche fast unumschränkten Einfluss auf die gesamte kroatische Propaganda ausübte. Da der NDH zu Beginn der Besatzung eindeutig „Ausland“ blieb, konnte sich das Auswärtige Amt hier leichter behaupten als in anderen besetzten Gebieten. ${ }^{255}$ Kasche schaffte es jedoch, sich auch weiterhin den maßgeblichen Einfluss zu sichern. Da Kroatien vom Auswärtigen Amt als selbständiger Staat behandelt wurde, sollten Ziele und Inhalt der Propaganda von der deutschen Gesandtschaft bestimmt werden, den Propagandastaffeln aber für die Durchführung dieser Aufgabe umfangreiche Mittel zur Verfügung stehen. Eine Ausnahme war nur für den militärischen Sektor im unmittelbaren Operationsgebiet vorgesehen, wo die Propagandaarbeit den deutschen Einheiten zugestanden wurde. Die PSK sollte auch den Aufbau der kroatischen Wehrmachtspropaganda betreiben. Im Oktober 1943 waren an der Propagandaarbeit bereits die SS, der SD, die Gesandtschaft und die Propagandaabteilung beteiligt. ${ }^{256}$

Kasche übersandte schon am 15. Januar 1943 die politischen Richtlinien für die Propaganda in Kroatien an den Leiter der PSK, Leutnant Dirksen. Diese beinhalteten sieben Punkte: Erstens, der NDH war ein mit dem Reich befreundeter und verbündeter Staat, und die Hoheitsrechte lagen bei diesem und seinen Behörden. Zweitens, der kroatische Staat befand sich noch in Kinderschuhen. Von deutscher Seite sollte er nicht aufgrund seiner Fehler abgelehnt werden. Aufgabe deutscher Stellen war es, die Autorität der Regierung zu festigen. Drittens, gab es im NDH unterschiedliche Kirchen. Vor allem gegenüber den Muslimen sollte man größte Freundlichkeit bekunden, um der Gegenpropaganda keine Angriffsfläche zu bieten. Viertens, sollte die Bezeichnung „Serbe“ in Kroatien durch „Orthodoxe“ ersetzt werden. Die Tschetniks seien Feinde, diejenigen von ihnen aber, die sich mit dem kroatischen Staate verständigten, waren als „or-

254 BArch, RH 26/117/12, Anlage 25, Besprechung am 28.4.1943 beim Befehlshaber Südgriechenland.

255 Im Gegensatz dazu konnte sich das Auswärtige Amt in Serbien nur auf die Presse einen gewissen Einfluss sichern. Vgl. Longerich, Peter: Propagandisten im Krieg. Die Presseabteilung des Auswärtigen Amtes unter Ribbentrop, München 1987, S. 228-233. Zur Propaganda der Gesandtschaft im NDH siehe auch: Jareb, Mario: Mediji i promidžba u Nezavisnoj Državi Hrvatskoj, Zagreb 2016, S. 349-353.

256 BArch, RW 4/193, Bl. 109-111; PA-AA, Gesandtschaft Zagreb, Geheimakten, P. 2, P2, Nr. 1 A 744/42, Propagandastaffel der deutschen Wehrmacht in Kroatien. Unterredung mit Leutnant Dirksen, Zagreb, 1.12.1942; BArch, RH 21/2/733, Nr. 89-92, Prop. Komp. 693, Tätigkeitsbericht 16.-31.10.1943. 
thodoxe Freiwillige“ $z u$ bezeichnen. Insgesamt sollte man im Kontakt mit den „Orthodoxen“ größte Zurückhaltung an den Tag legen, da diejenigen, die noch „serbisch“ dachten, versuchen würden, die Deutschen für sich zu gewinnen. Fünftens, war es zu vermeiden, die Versorgungswirtschaft zu zerstören und die „Preistreiberei“ zu fördern. Sechstens, sollte die Sicherung der Industrieanlagen sowie die Versorgung der Arbeiter gewährleistet werden. Gleichzeitig sollte den Kroaten die Möglichkeit gegeben werden, die Räume im Küstengebiet zu sichern, da die Italiener dies nicht geschafft hätten. Schließlich siebtens, bestand ein Interesse an der Anwerbung weiterer Arbeitskräfte vor allem in Bosnien und jenseits der Demarkationsline. ${ }^{257}$ Die Inhalte der so zu erfolgenden Propaganda wurden ab Anfang 1943 vom Oberbefehlshaber in Kroatien festgelegt, um eine gewisse Einheitlichkeit zu garantieren.

Anfang 1944 besuchte Hasso von Wedel, Leiter der Abteilung Wehrmachtpropaganda im OKW, Kroatien. Kasche wurde vom Auswärtigen Amt angewiesen, ihn „nett aufzunehmen und zu betreuen“ und dafür zu sorgen, dass sich seine Tätigkeit ausschließlich auf die Wehrmachtspropaganda beschränkte. ${ }^{258}$ Obwohl sich die Wehrmachtpropaganda bereits an den Vorstellungen der Gesandtschaft orientierte, versprach von Wedel, ihre Richtlinien sowie „die Ausrichtung der Truppe auf die hiesigen Gegebenheiten“ verbindlich zu machen. Kasche war erfreut, auf diese Weise die Wehrmachtpropaganda „noch enger auf die Ziele der Reichpolitik in Kroatien auszurichten “. ${ }^{259}$ Doch die Freude sollte nicht lange währen. Im September 1944 machte sich auch bei der Propagandaarbeit die mittlerweile eingetretene Dominanz der Wehrmacht über das Auswärtige Amt in Kroatien bemerkbar. Das Pz.AOK 2/Ic übernahm die gesamte Propagandaführung, die PSK wurde hierfür der Propagandaabteilung Südost, PK 693 unterstellt. Die Propaganda konzentrierte sich dabei auf folgende Punkte: Die bolschewistische Gefahr für die kroatische Staatlichkeit wie für das Leben jedes Einzelnen, Feindschaft Englands und der USA gegenüber Kroatien, deutsche Siegeszuversicht sowie die Förderung des Ustascha-Kurses. ${ }^{260}$

Offiziere und Soldaten konnten in einer Broschüre nachlesen, wie sie bei der Verbreitung von Propaganda vorgehen sollten. In Ortschaften sollten sie den Wehrmachtsbericht in der Landessprache vorlesen lassen, Plakate anbrin-

257 PA-AA, Gesandtschaft Zagreb, Geheimakten, P. 2, P1 - A 23/43, Politische Gesichtspunkte für Propagandaarbeit in Kroatien, 15.1.1943.

258 PA-AA, Gesandtschaft Zagreb, Akten, P. 222, D Kult 1 Nr. 3-216/44, Telegramm des Auswärtigen Amts an die Gesandtschaft, 2.2.1944.

259 PA-AA, Gesandtschaft Zagreb, Akten, P. 222, D Kult 1 Nr. 3-216/44, Besuch Generalmajor von Wedel in Agram, 16.2.1944.

260 PA-AA, Gesandtschaft Kroatien, P. 19/1a, D Kult 1 N. 3-1674/44g, Klartext zum FS vom 18.9.1944. 
gen, Flugblätter in Gaststätten und bei größeren Veranstaltungen verteilen, Propaganda-Auslagen in Schaufenstern errichten sowie kleine Wochenzeitungen selbst produzieren. Auf Fahrten sollten sie Flugblätter verteilen und durch „zwanglose Unterhaltungen“ Propaganda verbreiten. Bei Veranstaltungen mit der Bevölkerung sollten lokale Begebenheiten besprochen werden, das Vertrauen in und die Kameradschaft mit den deutschen Soldaten gestärkt und die Bevölkerung zur Mitarbeit animiert werden. Wenn z. B. ein deutsches Kommando von Partisanen entführte Personen aus einem Dorf rettete, so müsste dies so schnell wie möglich publik gemacht werden. ${ }^{261}$ In solch einer „Mitteilung“ wurde der „friedliebenden Bevölkerung“ mitgeteilt, dass am 2. April 1943 in Banja Luka sieben namentlich aufgeführte Personen hingerichtet wurden, weil sie Mitglieder einer kommunistischen Bande waren sowie sieben weitere Helfer ihre „gerechte Strafe“ erhalten hätten. Weiterhin hieß es fett gedruckt: „Die deutsche Wehrmacht vernichtet jeden, der sich um den Besitz oder das Blut der friedliebenden Bevölkerung verschuldet, da diese unter ihrem Schutz steht.“262 So sollte eine „straffe Zucht und Ordnung“ hergestellt und sofort propagandistisch ausgenutzt werden, zumindest in den Teilen, „die sich des Schutzes deutscher Truppen erfreuten“ - war in einem anderen Bericht zu lesen. ${ }^{263}$ Dass die Truppe sich aber nicht immer „klug“ verhielt, bezeugt auch eine Beschwerde des Generals Eglseer über die Standortkommandanturen, die durch unbedachtes Handeln die Bevölkerung vor den Kopf stießen und so die beste Propaganda zunichtemachten. In diesem Fall hatten sie den Bedarf an Arbeitern zu spät gemeldet, so dass kroatische Polizei diese willkürlich auf der Straße oder in Geschäften festnahm. ${ }^{264}$

Einen festen Bestandteil der Propaganda im Krieg, vor allem auch in den besetzten Gebieten, stellte die Nachrichtenverbreitung dar. Dies war im NDH umso wichtiger, als man mit gegnerischer Propaganda konkurrieren musste. Es ging in erster Linie um Nachrichten von den Kriegsschauplätzen. Dazu wurde täglich der Wehrmachtbericht ausgehängt. Das zentrale Element darin war die Betonung der Stärke der Wehrmacht. Nachrichten von Siegen in Afrika und der Sowjetunion sollten sowohl den Kommunisten, als auch den Nationalisten die Schwäche ihrer „großen Partner“ vorführen und sie von der Sinnlosigkeit ihres Kampfes überzeugen. Dazu dienten auch die „Wochennachrichten“, die in Form von Wandzeitungen verbreitet und von der Propagandastaffel als erfolg-

261 BArch, RH 45/56, „Aus der Praxis - für die Praxis des Propagandisten!“

262 BArch, RH 45/47, Bl. 24, Friedliebende Bevölkerung, 20.000 Stück, 5.4.1943.

263 BArch, RH 26/114/24, Propagandabericht 25.8.1943.

264 BArch, RH 26/114/26, Arbeitsdienst der kroat. Bevölkerung, 1.10.1943. 
reich gewertet wurden. ${ }^{265}$ Mittig waren Fotos mit kurzen Untertiteln, rechts und links kurze Meldungen aus der ganzen Welt zu sehen. Auf einer dieser Wandzeitungen zeigten beispielsweise viele bunte Bilder, wie das deutsche Afrikakorps im April 1941 die Engländer bekämpfte. Zum Schluss wurde die Washington Daily News mit der Aussage zitiert, dass deutsche Truppen unbesiegbar seien, egal gegen welche Soldaten oder auf welchem Terrain sie kämpften. ${ }^{266}$ Wandzeitungen verbreiteten unter dem Titel „Die deutsche Wehrmacht schlägt zu“ auch die Nachricht von der Besetzung Italiens nach dessen Kapitulation. ${ }^{267}$ Ungefähr die Hälfte der Beiträge der durchgesehenen Wochennachrichten vom Herbst 1943 sowie der ersten Jahreshälfte 1944 gingen auf die Partisanen ein. Erfolge im „Bandenkampf“, die Misserfolge der Aufständischen, ihre Schwierigkeiten, ihr „sinnloser Kampf“ und ihre Verluste stellten ein wiederkehrendes Thema dar. ${ }^{268}$

Ein großer Teil der Nachrichten entfiel auf den Vergleich mit England. Dabei wurden die deutsche wirtschaftliche Stärke und die Überlegenheit der deutschen Waffen dargestellt. Eine Postkarte vom Juni 1943 fasste beispielsweise unter dem Titel „Traurige Bilanz“ die Verluste der Alliierten auf dem Wasser in Tonnen zusammen. ${ }^{269}$ Auf einem Wandbild vom 1. Mai 1943 erfuhr der Leser, dass der deutsche Plan hinsichtlich des Baus von Lokomotiven erfüllt worden war, eine Wandzeitung stellte die Menge der „europäischen“ Waffen dar, die den Sieg sicherten. ${ }^{270}$ Grundsätzlich versuchte die deutsche Propaganda im Laufe der Zeit, immer mehr „europäisch“ zu argumentieren. Im Mai 1944 wurde die Broschüre „Kann Europa so weiterleben?“ verteilt, in der behauptet wurde, dass Europa im Krieg sein Recht erkämpfte, politisch und wirtschaftlich ein Kontinent zu sein und nicht von außen (England oder Sowjetunion) bestimmt

265 BArch, RH 26/114/24, Propagandabericht 25.8.1943.

266 ASMAE, GAB-AP 1923-1943, b. 1499, Wandzeitung „Deutscher Soldat vertreibt die Briten aus Nordafrika“. Eine ähnliche Wandzeitung soll auch die deutschen Bomber über dem Suezkanal behandelt haben. Da sie keine Bezüge zum Südosten oder dem NDH hat, handelte es sich hierbei wahrscheinlich um allgemeine Propaganda für unterschiedliche Kriegsschauplätze, die aus dem Reich geschickt worden war. ASMAE, GAB-AP 1923-1943, b. 1499, Attività tedesca a Mostar, 15.10.1941;

267 PA-AA, Gesandtschaft Zagreb, Akten, P. 222, Teil 2; Kult 1 Nr. 3, 2001/43, Druckschrift „Deutsche Wehrmacht schlägt zu“, Berlin, 17.9.1943.

268 BArch, RH 45/67, Wochenzeitungen 28.10.-20.11.1943; BArch, RH 45/67, Wandzeitungen 1.1.-5.2.1944; BArch, RH 45/54, Wandzeitungen 5.2.1944-13.5.1944.

269 BArch, RH 45/72, Bl. 20, „Traurige Bilanz“, 72.000 Stück, Juni 1943; ähnlich auch die Wandzeitung „Überseefahrten bedeuten für England und die USA die Fahrt in den sicheren Tod“; BArch, RH 45/72, S. 66-68, 9.000 Stück, 29.7.1943.

270 BArch, RH 45/72, Bl. 16, Wandbild, 8.000 Stück, 1.5.1943; BArch, RH 45/72, Bl. 55-57, Wandzeitung, 13.000 Stück, 16.4.1943. 
zu werden. Eine Wandzeitung zeigte die „Europäische Wirtschaftsmacht“ und verknüpfte dabei die Zukunft Europas mit dem deutschen Sieg. ${ }^{271}$ Ebenso fehlte es nicht an Propaganda gegen die Sowjetunion und den Bolschewismus. KatynBilder verbreiteten bolschewistische Untaten gegen die „slawischen Brüder“ oder stellten die Verbindung zwischen dem Bolschewismus und dem Judentum heraus. Gemäß einem Bericht aus Mostar war die Katyn-Propaganda aber wirkungslos. Die Menschen hätten sie nur damit kommentiert, dass die Verbrechen der Ustascha schlimmer gewesen seien. ${ }^{272}$

Zentral waren schließlich die Behandlung des eigenen „Kriegsschauplatzes“ und die Diffamierung der Aufständischen. Daneben wurden Flugblätter zu aktuellen Ereignissen im Schlagzeilenstil hergestellt. Der Druck erfolgte meistens gleichzeitig in lateinischer und kyrillischer Schrift. ${ }^{273}$ Die Vorgaben des Oberbefehlshabers der deutschen Truppen in Kroatien lauteten beispielsweise im Mai 1943, dass die Propaganda darauf abzielen sollte, Tito zu diffamieren und ihm die wirtschaftlichen Schwierigkeiten anzulasten (z. B. durch Abernten noch nicht reifen Getreides). Andererseits sollte auch auf Mihailovićs Englandhörigkeit und die Vergeblichkeit seines Kampfes eingegangen werden. Schließlich sollte auch der Beitrag jedes einzelnen zur Schaffung von Ruhe und Ordnung thematisiert werden. ${ }^{274}$ Diese Vorgaben wurden in Form von Flugblättern umgesetzt, zu abertausenden verteilt sowie aus Flugzeugen abgeworfen. Sie riefen Einzelne dazu auf, zur Vernichtung des Bolschewismus beizutragen, „entlarvten“ Titos Lügen oder „informierten“ die Tschetniks über die „wahren“ Absichten Englands. ${ }^{275}$ Deutsche Stellen meldeten, dass Partisanenführer sie sammeln und vernichten ließen, und schlossen daraus, dass sie wirksam waren. ${ }^{276}$

Die eingesetzten Propagandamittel waren zahlreich. Neben den klassischen Flugblättern und den Wandzeitungen griffen deutsche Propagandamacher auch auf Bierdeckel, Straßenbahnverkleidungen, Zigarettenbeutel, Postkarten

271 BArch, RH 45/72, Bl. 58-61, Broschüre „Kann Europa so weiterleben?“, 300.000 Stück, 10.5.1944; BArch, RH 45/68, Bl. 48, Wandzeitung „Europska gospodarska snaga“.

272 BArch, RH 45/66, Bl. 58 f., „Katyn“, 10.000 Stück, 10.5.1943; BArch, RH 45/66, Bl. 62f., „Katyn“, 9.000 Stück, 25.5.1943; PA-AA, Gesandtschaft Kroatien, P. 19/1a, Politische Situation und Propagandalage im Mostarer Bezirk und in Dubrovnik, 30.9.1943.

273 BArch, RW 4/237, Bl. 218 f., Propaganda-Abteilung „SO“: Lage- und Tätigkeitsbericht für den Monat August 1942, 4.9.1942. Wie die italienische Armee hielt sich auch die Wehrmacht nicht an das Verbot der kyrillischen Schrift im NDH.

274 BArch, RH 26/114/21, Richtlinien für die Propaganda (Nr. 5), 25.6.1943.

275 BArch, RH 45/67, Bl. 7, „Auch deine Arbeit hilft, den Bolschewismus zu vernichten“; BArch, RH 45/67, Bl. 83, „Warum die Zerstörungen?“; BArch, RH 45/46, Bl. 40, „Tito behauptet“; BArch, RH 45/45, Bl. 152, Nr. 47, „Cetniks!“; BArch, RH 45/45, „Was will England?“.

276 BArch, RH 26/114/21, 114. J. D.: Lagebericht Mai 1943. 
und Faltschachteln zurück. Im Gegensatz zur italienischen Propaganda scheinen echte Zeitungen eine nicht so große Rolle gespielt zu haben. Eine zweisprachige Satirezeitschrift „Vox“, die Nachrichten aus alliierten Radiomeldungen übernahm und karikierte, wurde in einer Auflage von 10.000-15.000 Stück produziert und im deutschen Einflussgebiet verteilt. ${ }^{277}$ Zudem sollten Soldaten selbst Propagandaträger sein, indem sie Kontakt zu angesehenen Persönlichkeiten herstellten, auf Fahrten Flugblätter verteilten und durch zwanglose Konversationen Mundpropaganda verbreiteten. ${ }^{278}$

Bei der Herstellung der Propagandaerzeugnisse orientierten sich deutsche Propagandamacher stark an der „Feindpropaganda“. Ein Flugblatt, das die Partisanen zur Reinlichkeit mahnte, wurde dabei beispielsweise als psychologisch geschickt und technisch weit über dem Durchschnitt beschrieben. Dabei war man sich auch nicht zu schade, von dieser zu lernen, denn sie wurde „von Leuten gemacht, die die Volksseele genau kennen und daher auch wissen, wo sie anzusetzen haben. “279 Im Spätsommer 1943 sollten dann für die eigene Propaganda neue Wege erschlossen werden. Aufgrund der geringen Bildung der Bevölkerung sollte sie so einfach und primitiv wie möglich gestaltet sein. Um dem hohen Analphabetismus besser Rechnung zu tragen, wurden Flugblätter mit vielen Bildern und kurzem, schlagkräftigen Text hergestellt. Im Herbst 1943 meldeten die Propagandaeinheiten, dass die Flugblätter, zu deren Verteilung die Tschetniks und die Ustascha eingesetzt wurden, bei der Bevölkerung immer größeres Interesse fanden. ${ }^{280}$ Auch Filme, die eigentlich für deutsche Soldaten vorgesehen waren, sollten der Bevölkerung gezeigt werden. Doch zentral sollte das gesprochene Wort sein. Teilweise dienten ehemalige Partisanenführer als Redner. Diese wurden gut behandelt und untergebracht sowie bei der eigenen Truppe verpflegt. Sie waren dadurch „begeistert bei der Sache“. Ihr Einsatz wurde als Erfolg bewertet. An die Reden schlossen sich manchmal Tanzabende oder kleine Theatervorführungen an, um so der Bevölkerung das Gefühl zu geben, dass man sich um sie kümmere - so wie es die Partisanen auch taten. ${ }^{281}$

Die Grundlagen der Propaganda speziell bei der Aufständischenbekämpfung fasste Kasche in seinem Bericht über die Propagandaarbeit von November 1942 bis Januar 1943 wie folgt zusammen: Zum einen sollten die unterschiedli-

277 BArch, RH 45/58, Vox, Zweisprachiges Journal für die Bevölkerung.

278 BArch, RH 45/56, Aus der Praxis - für die Praxis des Propagandisten!

279 BArch, RH 26/114/24, Propagandabericht, 25.8.1943.

280 BArch, RH 26/114/28, Ic-Lagebericht, 03.10.1943; BArch, RH 26/114/28, Propagandabericht, 25.11.1943; BArch, RH 26/114/28, Überläufer November 1943, 3.12.1943.

281 BArch, RH 26/114/26, Filmvorführungen, 15.10.1943; BArch, RH 26/114/28, Ic-Lagebericht, 03.10.1943; BArch, RH 26/114/26, Propagandabericht, 25.11.1943; BArch, RH 26/114/21, Propagandabericht, 24.6.1943; BArch, RH 26/114/24, Propagandabericht, 25.8.1943. 
chen Gruppen innerhalb der Partisanenbewegung positiv angesprochen und zum anderen an der Zersetzung der Aufständischen mit allen Mitteln gearbeitet werden. ${ }^{282}$ Bereits im Vorfeld der Errichtung der PSK war man bei der Wehrmacht zu der Einsicht gekommen, dass die verschiedenen Räume innerhalb Kroatiens unterschiedlich behandelt werden sollten, um ihren „rassischen“ und politischen Besonderheiten Rechnung zu tragen. Während man im bosnischherzegowinischen Raum, der stark von der orthodoxen und muslimischen Bevölkerung besiedelt war, auf die Draža Mihailović Bewegung eingehen musste, sollte im westlichen Teil des NDH insbesondere antikommunistische Propaganda verbreitet werden. Die Propaganda sollte auch an die örtlichen religiösen $\mathrm{Zu}$ sammensetzungen sowie an die Versorgungssituation angepasst werden. ${ }^{283}$ Die Vorurteile besonders gegenüber der Bevölkerung im bosnischen Raum wurden in einem Propagandabericht vom Sommer 1943 sichtbar. Darin wurde sie als nicht reif für nationalsozialistische Parolen und bestimmte Bevölkerungsgruppen als „nicht besonders arbeitsam“ betrachtet:

Die weit verbreitete Befürchtung, dass mit den Deutschen auch Arbeit und Sauberkeit ins Land kämen, darf durch die eigene Propaganda nicht zu sehr hervorgehoben werden. Das Volk wünscht weniger Arbeit als vor allem Ruhe, Behaglichkeit und Vergnügen. Es will leben, wie es früher zu leben gewohnt war. Wer das verspricht, hat die Unterstützung der breiten Masse. ${ }^{284}$

Nachdem Kasche gefordert hatte, Gruppen innerhalb der Aufständischen zu identifizieren und gesondert anzusprechen, wurde jede Gruppe, die die Propagandamacher nur ausmachen konnten, zur Zielscheibe ihrer Propaganda. Neben den klassischen ethnischen Gruppen wurde spezielle Propaganda auch für Menschen mit einem besonderen regionalen Bewusstsein, wie Dalmatiner, Likaner oder Bosnier aber auch für unterschiedliche Berufsgruppen, wie Bauern, Arbeiter und Eisenbahner oder auch für Frauen produziert. Gemeinsam war dieser Propaganda, dass es sich um Flugblattpropaganda handelte. Es waren relativ kurze, prägnante und plakative Aufrufe, nicht mit den Aufständischen zusammenzuarbeiten, bzw. sich an der Bekämpfung des Bolschewismus zu beteiligen. Bei ethnischen Gruppen wurden die bestehenden Spannungen ausgenutzt oder geschürt.

282 PA-AA, Gesandtschaft Zagreb, Akten, P. 19/1a, Propagandatätigkeit der Mission 11.194201.1943, S. 3.

283 BArch, RW 4/232, Bl. 53 f., Propaganda-Abteilung „SO“: Lage- und Tätigkeitsbericht für den Monat September 1942, 4.10.1942; BArch, RH 31/III/22, Richtlinien für die Propaganda in Kroatien, Agram, 6.3.1943.

284 BArch, RH 26/114/21, 114. J. D., Propagandabericht, 24.6.1943. 
Grundsätzlich riefen deutsche Propagandamacher zur Arbeit auf. Aktionen wie „Deine Arbeit verkürzt den Krieg“ oder „Verstärke deine Arbeit um den Krieg zu verkürzen“ wurden auf Bierfilzen, Straßenbahnverkleidungen und Zigarettenbeuteln gedruckt und tausendfach verteilt. ${ }^{285}$ Insbesondere Eisenbahner waren von beiden Seiten umworben, weil Sabotageakte für die Besatzer vor allem an Bahnverbindungen schmerzhaft waren. Die Partisanen versuchten durch Werben und Drohen, die Eisenbahner für ihre Ziele einzuspannen. ${ }^{286} \mathrm{Ge}-$ nauso versuchten die Deutschen, diese davon zu überzeugen, nicht für die Partisanen zu arbeiten, und darüber hinaus, alles Verdächtige sofort zu melden. ${ }^{287}$

Am häufigsten wurden Bauern oder Bürger dazu aufgerufen, Partisanen und ihre Verstecke, Druckereien, Verpflegungslager usw. anzugeben. Sie wurden aber auch offen zum Mord aufgerufen, die „Saboteure totzuschlagen“, um so der Wehrmacht zu helfen, Ruhe und Ordnung herzustellen. ${ }^{288}$ Manchmal waren in den Aufrufen auch Drohungen erhalten, dass alle, die „ihre Pflicht“ nicht erfüllten und dadurch zu Helfern der Partisanen würden, dies mit ihrem Leben bezahlen würden. ${ }^{289}$ Solchen Drohungen wurde mit Bekanntmachungen über Erschießungen von Partisanen und ihren Helfern Nachdruck verliehen. ${ }^{290}$

Obwohl die Serben den Feind darstellten, wurden auch sie in die Propagandamaßnahmen einbezogen, wobei eine zweifache Strategie verfolgt wurde. Einerseits sollte bei ihnen das Gefühl erzeugt werden, dass ihre traditionellen Alliierten und Beschützer sie verlassen hätten - sowohl ihre Regierung in London als auch die ehemalige Schutzmacht Russland, wo nun orthodoxe Kirchen brannten. Andererseits sollte sie „positive Propaganda“ davon überzeugen, dass der kroatische Staat sie beschützte. Diese Thesen propagierte Dr. Katschinka schon, als die Kroaten noch für die militärische Propaganda zuständig waren. ${ }^{291}$ Als die Propagandastaffel diese Aufgabe übernahm, wurden die Vor-

285 BArch, RH 45/72, Bl. 4-6, Bierfilze, 40.000 Stück, April 1943; BArch, RH 45/72, Bl. 7-11, Straßenbahnverkleidungen; BArch, RH 45/72, Bl. 17-20, Zigarettenbeutel mit Werbung, 1.000.000 Stück.

286 BArch, RH 21/2/754, Nr. 22f., Aufruf an die kroatischen Eisenbahner durch Partisanen.

287 BArch, RH 45/45, Bl. 48-50, Nr. 10, „Kroatische Arbeiter Eisenbahner!“; BArch, RH 45/45, S. $137 \mathrm{f}$., „Eisenbahner gebt Acht, was ihr tut!“ Dass dies durchaus seine Berechtigung hatte, belegt unter anderem die Tatsache, dass Edvard Kardelj getarnt als Gehilfe des Zugführers Anfang 1942 von Sarajevo über Zagreb nach Ljubljana reisen konnte. Dedijer, Vladimir: Dnevnik, Belgrad 1951, S. 62.

288 BArch, RH 45/45, Bl. 27 f., „Bauern von Bosnien!“; BArch, RH 45/45, Bl. 36 f., „Bürger!“; BArch, RH 45/45, Bl. 80 f., „Slunj brennt!“; BArch, RH 45/45, Bl. 201 f., „Bürger und Bauern!“, 289 BArch, RH 45/45, Bl. 72, „Der Winter geht zu Ende!“, 29.1.1943,

290 BArch, RH 45/47, Bl. 24, „An die friedliebende Bevölkerung!“.

291 BArch, RH 31/III/5, Bericht „Propagandaeinsatz in Bosnien“, 22.10.1942. 
schläge in die Tat umgesetzt, wobei nun die deutsche Wehrmacht als ihr Beschützer auftrat. ${ }^{292}$ Diese Propaganda entsprach jedoch in keinster Weise den Erfahrungen ihrer Rezipienten.

In allen Propagandaerzeugnissen hielt man sich dabei an Kasches Weisung, die Serben immer als „Orthodoxe“ anzusprechen. Die Propaganda für die Tschetniks wurde in Kroatien als „ein besonders schwieriges Kapitel“ betrachtet. Ihre Haltung war undurchsichtig und man kam in ihre Gebiete nicht hinein, sodass Flugblätter nur aus dem Flugzeug verteilt werden konnten. ${ }^{293}$ Im Zuge der Werbung für die bosnische SS-Division wurde gar versucht, nach „Muslimen und Katholiken“ nun auch die „Orthodoxen“ zum Beitritt zu überzeugen, um an der Seite „der besten Armee der Welt“ für das „geliebte bosnische Vaterland“ und gegen die Partisanen zu kämpfen. Dadurch sollten sie zeigen, dass sie „gute Bosnier“ seien. ${ }^{294}$ Die Bezeichnung „Bosnier“ sollte dabei wie eine Klammer alle drei Religionsgruppen umschließen. Diese Argumentation bezeugt noch einmal eindrücklich, dass die Wehrmacht gewillt war, Serben wie Kroaten orthodoxen Glaubens zu betrachten und die offizielle kroatische Stellung in dieser Hinsicht zu unterstützen. Hier passten sich deutsche Propagandamacher den kroatischen Vorgaben an. Ein weiterer Grund für dieses Verhalten lag in der Notwendigkeit, Anfang 1943 neue Männer zu rekrutieren. ${ }^{295}$

Ein besonderes Augenmerk wurde den Muslimen gewidmet, die zunächst als der minderwertigste Teil der kroatischen Bevölkerung und als stark opportunistisch galten. Aufgrund ihrer Geschichte und der angenommenen autoritätsfeindlichen Einstellung wurden sie als kommunistenfreundlich eingestuft. ${ }^{296}$ Am Anfang hielten sich deutsche Propagandamacher damit zurück, die Muslime direkt zu adressieren, da sie sich konform mit der offiziellen kroatischen Politik verhielten. Die Muslime wurden sehr häufig als „muslimische Kroaten“ angesprochen. Um diese trotzdem zu erreichen, wurde zunächst nur eine bei der Gesandtschaft vorhandene Broschüre über das Leben der Muslime in Deutsch-

292 BArch, RH 45/45, Bl. 164, „An die Orthodoxen“; BArch, RH 45/47, Bl. 41, „An die Tschetniks!“

293 BArch, RW 4/237, Bl. 219, Propaganda-Abteilung „SO“: Lage- und Tätigkeitsbericht für den Monat August 1942, 4.9.1942.

294 BArch, RH 45/48, Bl. 57, Aufruf an die Orthodoxen, der SS-Division beizutreten.

295 Aus dem gleichen Grund war es auch an der Ostfront zu einer Neuausrichtung der Propaganda gekommen. Nachdem Hitler die Aufnahme von Einheimischen und zwar vor allem von Russen in das Ostheer genehmigt hatte, wurde auch die bis dahin propagandistisch vernachlässigte russische Bevölkerung von der Propaganda erfasst, die dementsprechend verändert werden musste. Vgl. Quinkert, Babette: Propaganda und Terror in Weißrussland 1941-1944. Die deutsche „geistige“ Kriegführung gegen die Zivilbevölkerung und Partisanen, Paderborn 2009, S. 274 f., $291 \mathrm{f}$.

296 BArch, RW 4/232, Bl. 53 f. 
land in einer Auflage von 10.000 Stück verteilt. Sie zeigte vorwiegend junge Männer und Frauen, die an deutschen Universitäten studierten. Doch auch andere Themen, wie die deutsche wirtschaftliche und technische Vormachtstellung genauso wie Englands Feindschaft gegenüber den arabischen Ländern wurden in der Broschüre thematisiert. Sie war so beliebt, dass Anfang 1943 eine zweite Auflage von 20.000 Stück gedruckt und verteilt wurde. ${ }^{297}$

Im Zusammenhang mit der Errichtung der SS-Division „Handschar“ Anfang 1943 stieg die „Muselmanenbehandlung“ dann „zu einer Propaganda-Waffe ersten Ranges“ auf. ${ }^{298}$ Die positive Einstellung der Muslime gegenüber der österreichischen Herrschaft 1908-1918 war ein guter Ausgangspunkt, auf dem sich aufbauen ließ. Zusätzlich sollten die guten deutsch-türkischen Beziehungen sowie die Unterdrückung der Araber durch England und die USA betont werden. Auch die erste deutsch-italienisch-kroatische Propagandaaktion streifte die „Muselmanenpropaganda“ und berührte genau diese Punkte. ${ }^{299}$ Als aber die Muslime immer häufiger zu den Partisanen flüchteten, wurde eine Propagandakampagne eingeleitet, in der „verführte Muselmanen“ aufgerufen wurden, sich an die Seite der Achse zu stellen. Eine wichtige Rolle spielte dabei, dass der Großmufti von Jerusalem für die Achse eintrat, woran immer wieder erinnert wurde. ${ }^{300}$

Selbstverständlich sprach die Propaganda auch die „kroatische“ Bevölkerung (darunter verstand man katholische Kroaten) an. Dies war insbesondere deshalb nötig, weil sich die Einheiten der kroatischen Armee als unzuverlässig erwiesen hätten, und je länger der Krieg dauerte, umso häufiger zu den Partisanen überliefen. Folgerichtig wurde bei der großen Kriegspropaganda zum Thema „Ostfront“ der kroatische Kampf gegen den Bolschewismus hervorgehoben. ${ }^{301}$ Ein wichtiges Zugpferd der Propaganda für die Kroaten war die kroatische Unabhängigkeit bzw. die bolschewistische Bedrohung derselben. So wurde nach der italienischen Kapitulation die Rückkehr Dalmatiens zu Kroatien

297 BArch, RH 45/73, Bl. 30-44, Broschüre „So leben Muselmanen in Deutschland“.

298 BArch, RH 24/15/4, Bl. 49-55, Die nationale Aufstandsbewegung der Tschetniks im Unabhängigen Staat Kroatien, Slovenien [sic!] und Montenegro, 1.5.1943.

299 BArch, RH 24/15/4, Lagebericht vom 27.6.-26.7.1943, S. 55; PA-AA, Gesandtschaft Zagreb, Akten, P. 19/1a, Propagandatätigkeit der Mission 11.1942-01.1943, Anl. 1, Große Kriegspropaganda „Mittelmeerraum“, S. 3; BArch, RH 45/45, Bl. 124 f., Nr. 38, „Brüder Muselmanen!“.

300 BArch, RH 45/45, Bl. 172, „An die verführten Muselmanen“; BArch, Bl. 197, Nr. 65, „An Muselmanen“; BArch, RH 45/45, RH 45/47, Bl. 92, „Bist du Kommunist oder Muslim?“

301 PA-AA, Gesandtschaft Zagreb, Akten, P. 19/1a, Propagandatätigkeit der Mission 11.194201.1943, Anl. 1, Große Kriegspropaganda „Ostfront“, S. 2. 
betont, um die Kroaten Dalmatiens für die Achse zu gewinnen. ${ }^{302}$ Darüber hinaus versuchte man auch, den kroatischen Katholizismus gegen die gottlosen Bolschewisten sowie den Gegensatz zwischen Serben und Kroaten einzusetzen. Den Kroaten sollte erklärt werden, dass die Partisanen von Serben und Juden geführt und für großserbische Interessen kämpfen würden. ${ }^{303}$

Wie bereits gezeigt wurde, hatten ausbleibende Erfolge bei der Partisanenbekämpfung ab 1943 zu einer Veränderung der deutschen Einstellung vor Ort geführt. Neue Befehle erlaubten, Partisanen gefangen zu nehmen. Etwa gleichzeitig lancierten die Deutschen auch die Flugblattpropaganda, die darauf abzielte, die Moral der Partisanen zu zermürben. Die Bauern unter ihnen sollten an die Landbestellung im Frühjahr denken, andere wurden an Hunger und Kälte, an die Trennung von der Familie oder an die Verbrechen, die sie an ihrem eigenen Volk begangen hätten, erinnert und dazu aufgerufen heimzukehren, bevor es zu spät war. ${ }^{304}$ Viele Flugblätter hatten eine antisowjetische Komponente. Sie riefen die Partisanen dazu auf, ihren Kommissaren brenzlige Fragen zu stellen, wie beispielsweise nach den wahren Ausgängen der Kämpfe in Russland, wieder andere riefen sie gar dazu auf, ihre Anführer totzuschlagen. Häufig wurde gleichzeitig negative Propaganda über Stalin verbreitet. ${ }^{305}$

Als ab 1943 die Alliierten auch kroatische Städte bombardierten, entfalteten die Partisanen eine rege Propaganda. Sie verlautbarten, dass diese oder jene Stadt angegriffen würde, und rief die Bevölkerung dazu auf, in die Wälder zu fliehen. Die deutschen Propagandastellen mussten sich „infolge gänzlichen Mangels an erfolgversprechenden aktiven Abwehrmitteln“ darauf beschränken, zur Ruhe und Beachtung der für den Fall eines Luftangriffs gegebenen Richtlinien aufzurufen. Daher sahen sie eine aktive Luftabwehr auch für die Propaganda als dringend notwendig an. ${ }^{306}$ Die 114. J. D. meldete im Dezember: „Zweifellos stören die feindlichen Luftangriffe das durch die Div[ision] angebahnte

302 BArch, RH 45/45, Bl. 248, Karrikatur von Stalin und Tito; BArch, RH 45/45, Bl. 360 f., „Kroaten und Kroatinnen des gequälten Dalmatien!“; BArch, RH 45/46, Bl. 13f., „Kroaten!“; BArch, RH 45/46, Bl. 40, „Tito behauptet“.

303 BArch, RH 45/60, Bl. 22, „Katholische Brüder und Schwestern!“; BArch, RH 45/45, Bl. 78, „Kroaten in Partisanenreihen!“ Siehe auch Vukotić, Aleksandar: Neprijateljska propaganda u IV i V ofenzivi, in: Neretva-Sutjeska 1943. Zbornik radova naučnog skupa „Neretva-Sutjeska 1943“ održanog od 27. juna do 2. jula 1968. god. u Sarajevu, Belgrad 1969, S. 346-352, hier S. 349.

304 BArch, RH 45/45, Bl. 24 f., 29 f., 104 f., Aufrufe an Partisanen.

305 BArch, RH 45/45, Bl. 51 f., „Fragt einmal eure Kommissare!“; BArch, RH 45/45, Bl. 53 f., „Partisanen, habt ihr daran schon gedacht?“; BArch, RH 45/45, Bl. 65-67, „Stalin, der Maulheld".

306 BArch, RH 26/114/28, Ic-Lagebericht, 03.10.1943; BArch, RH 26/114/28, Propagandabericht, 25.11.1943; BArch, RH 26/114/28, Überläufer November 1943, 3.12.1943. 
Verhältnis zur Bevölkerung erheblich. Die kroat[ische] wie auch die serbische Bevölkerung ist den seelischen Belastungen dieser Kriegsführung in keiner Wei-

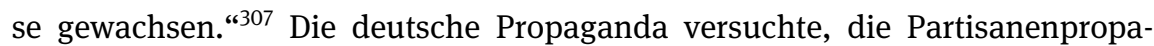
ganda umzukehren, und Tito den Schwarzen Peter zuzuschieben, indem sie ihn beschuldigte, an den Bombenangriffen auf Kroatien schuld zu sein bzw. diese nicht verhindert zu haben. ${ }^{308}$

Für das ehemals italienisch besetzte Gebiet urteilten deutsche Propagandamacher im Dezember 1943, dass das Vertrauen zur Wehrmacht als dem „einzigen Garanten für Gerechtigkeit, Ruhe und Ordnung“ bei der Bevölkerung immer weiter zunehme. Die eigene Propaganda baute dabei auf die Erfolge der Division, auf die Auswertung der feindlichen Beutepapiere, Überläufer- und Gefangenenaussagen sowie auf eigene positive Maßnahmen und politische Kampfparolen gegen den Kommunismus. ${ }^{309}$ Gleichzeitig bedauerten deutsche Propagandamacher, dass die „Aktivpropaganda in den Feind“ noch nicht zufriedenstellend entfaltet werde, da es an geeigneten Abwurfmitteln fehle, wobei sie besonders gerne den Propagandawerfer eingesetzt hätten. ${ }^{310}$ Verstärkt wurde in dieser Zeit die „schwarze Propaganda“, weil man ihr die besten Wirkungsmöglichkeiten bei der „Zersetzung des Feindes“ beimaß. ${ }^{311}$

Die politischen und militärischen Veränderungen nach der Kapitulation Italiens wirkten sich auch auf die Inhalte der Propaganda aus. Nach der Annäherung an die Tschetniks meldete die PK 693, dass im November 1943 die Aktivpropaganda darauf ausgerichtet wurde, „als einziges Angriffsziel den Kommunismus, verkörpert in den Banden Titos“ zu suchen. Die erste Aktion „Moskau-Konferenz“ brachte jedoch keinen großen Erfolg. Der Ic der 114. J. D., meldete zwar, dass sich die Đujić-Tschetniks nach der Propagandaaktion um die Vertiefung der Zusammenarbeit bemühten. ${ }^{312}$ Die Bevölkerung hatte aber durch die Propaganda den Eindruck gewonnen, die Sowjetunion sei sehr stark. Deshalb suchte sie vermehrt nach einem „kommunistischen Alibi“ in Form freiwilliger Abgaben (meist Lebensmittel und Bekleidung) an Partisanen. Auch um dieser Gefahr zu begegnen, sollte die nächste Aktion („Sowjet-Balkan“) auf die praktischen Auswirkungen einer Bolschewisierung des Balkans aufmerksam machen und vor allem jene Anhänger Titos, die keine überzeugten Kommunisten waren, erreichen. Für den kommenden Monat durften zudem keine propa-

307 BArch, RH 26/114/30, Lagebeurteilung, 5.12.1943.

308 BArch, RH 45/54, Bl. 38, Wochenzeitung.

309 BArch, RH 26/114/30, Lagebeurteilung, 5.12.1943.

310 BArch, RH 26/114/28, Überläufer November 1943. Der Propagandawerfer konnte eine mit ca. 200.000 Flugblättern gefüllte Rakete ca. $3 \mathrm{~km}$ weit schießen.

311 BArch, RH 21/2/733, Bl. 89-92, Prop. Komp. 693: Tätigkeitsbericht 16.-31.10.1943.

312 BArch, RH 26/114/28, Ic-Lagebericht, 03.10.1943. 
gandistischen Angriffe auf „national-gefärbte Bandenorganisationen und ihre Führung, insbesondere DM [Draža Mihailović]“ geführt werden. ${ }^{313}$

Bei der Operation „Kugelblitz“ sollte im Dezember 1943 sowohl eine Aktivpropaganda für Partisanen als auch Propaganda für die Bevölkerung in Form von Flugblättern betrieben werden. Die Aktivpropaganda scheiterte jedoch an schlechten Wetterbedingungen, dem Mangel an Flugzeugen sowie dem Mangel an Munition für die Propagandawerfer. Bei der Aktivpropaganda in Form der Lautsprecherwagen bewährten sich die serbischen Sprecher: „Der Wagen ist bei den Ansprachen immer umlagert. Die Bevölkerungspropaganda muss daher noch mehr Mittelpunkt unseres Einsatzes bleiben, sie erscheint ja auch als die wichtigere.“314 Die Aktion wurde weiterhin durch Spruchbänder und Plakate, Rundfunk sowie die serbische und kroatische Presse unterstützt. Die PK wertete vor allem die Tatsache, dass sich muslimische Frauen den deutschen Soldaten unverschleiert zeigten, als einen großen Vertrauensbeweis. Doch wäre die „Propaganda in den Feind“ sehr schwierig gewesen. So war letztlich ihre Wirkung nicht groß: wenige Überläufer, deren Vernehmungen nur dürftige Ergebnisse brachten. ${ }^{315}$

Als Erfahrung aus dem Einsatz bemängelten die Propagandamacher, dass der Bevölkerung nur allgemein gehaltene politische Argumentation angeboten wurde, ohne ihr ein „positives Ziel“ zu geben: „Es genügt nicht, gegen den Kommunismus zu polemisieren, wenn nicht demjenigen, der von ihm hinweggezogen werden soll, ein Weg gezeigt werden kann, der zu seinen politischen und wirtschaftlichen Erwartungen wie seinen persönlichen Hoffnungen hinführt. “316 Da die deutsche Propaganda jedoch nicht auf den Nachkriegszustand eingehen durfte ${ }^{317}$, erschöpfte sich dies in Feststellungen, dass Deutschland so vorgehe, wie „das im Kriege Brauch zu sein pflegt“, dies „,aber kein Zeichen des

313 BArch, RH 21/2/733, Bl. 56-62, Prop. Komp. 693: Tätigkeitsbericht für die Zeit vom 1.30.11.1943 sowie Anl. 1 .

314 BArch, RH 21/2/733, Bl. 23-26, Prop. Komp. 693, Tätigkeitsbericht für die Zeit vom 1.15.12.43.

315 BArch, RH 21/2/733, Bl. 23-26, Prop. Komp. 693, Tätigkeitsbericht für die Zeit vom 1.15.12.43.

316 BArch, RH 21/2/733, Bl. 23-26, Prop. Komp. 693, Tätigkeitsbericht für die Zeit vom 1.15.12.43.

317 Auch die zivile Propaganda durfte sich bei aller Betonung einer strahlenden Zukunft nicht über die Neuordnung Europas nach dem Krieg auslassen und litt daher an Glaubwürdigkeit. So verbreitete die nach Auflage sehr erfolgreiche Auslandszeitschrift Signal unter dem Motto „für Europa“ nichts als Plattitüden. Rutz, Rainer: Die netten Deutschen und das „Neue Europa“. Sympathiewerbung für die Wehrmacht, den Krieg und die Besatzung in der NS-Auslandsillustrierten Signal, in: Rother, Rainer/Prokasy, Judith (Hg.): Die Kamera als Waffe. Propagandabilder des Zweiten Weltkrieges, München 2010, S. 193-208, hier S. 202. 
kommenden Friedens, sondern ein Zeichen des gegenwärtigen Krieges“ sei. ${ }^{318}$ So unterbreitete die PK einen anderen Vorschlag: „Da politische und wirtschaftliche Versprechungen nicht möglich sind, ist aus Zweckmäßigkeit der Versuch zu unternehmen, die Partisanen davon zu überzeugen, daß ihnen von unserer Seite das Leben gesichert wird.“319

Dabei praktizierte die Wehrmacht zu dem Zeitpunkt bereits seit einem Jahr eine Überläuferpropaganda. Erste erhaltene Aufrufe zum Überlaufen stammen vom Januar 1943. Sie wurden im Vorfeld der Operation „Weiß“ gedruckt. Sie waren noch eine Mischung aus Drohung und Anreiz. Die Partisanen wurden dazu aufgefordert überzulaufen, anderweitig wurde ihnen die Vernichtung angedroht. Gleichzeitig versprach ihnen die Wehrmacht eine bevorzugte Behandlung. ${ }^{320}$ Viele der Flugblätter dienten gleichzeitig auch als Passierscheine. Ein großes Problem bei diesen Bemühungen stellte die bisherige Praxis dar, alle Partisanen sofort zu erschießen. Auch diejenigen, die eventuell zum Überlaufen bereit gewesen wären, konnten nach all ihren Erfahrungen der deutschen Propaganda nicht trauen. Es kam auch immer wieder vor, dass Wehrmachtsoldaten Überläufer - teils aus Bequemlichkeit - erschossen. ${ }^{321}$ Deshalb wurden parallel zur Partisanenpropaganda auch erste Befehle zum Umgang mit Überläufern erlassen, die ihre Behandlung festlegten. Danach sollten diese gut behandelt, getrennt von anderen Gefangenen untergebracht und eventuell sogar - da propagandistisch sehr wertvoll - aus Feldküchen verpflegt werden. ${ }^{322}$ Der IaTätigkeitsbericht meldete: „Im Kampfe gegen die Partisanen spielte auch während der Berichtzeit die Propaganda wieder eine hervorragende Rolle. Sie war hauptsächlich darauf abgestellt, die Zahl der Überläufer zu vergrößern.““323

Die Flugblätter verbreiteten die Botschaft, dass die Deutschen niemanden töten würden, der zu ihnen überliefe. ${ }^{324}$ Den Partisanen wurde versichert, dass deutsche Soldaten Befehl erhalten hätten, Überläufer gut zu behandeln. Es wur-

318 BArch, RH 45/45, Bl. 43 f., „Arbeiter!“; BArch, RH 45/45, Bl. 45 f., „Arbeiter, Bauern und Soldaten!“.

319 BArch, RH 21/2/733, Bl. 23-26, Prop. Komp. 693: Tätigkeitsbericht für die Zeit vom 1.15.12.43.

320 BArch, RH 45/45, Bl. 58 f., Flugblatt „Partisanen!“, vom 22.1.1943. Diese Flugblätter aus rotem Papier wurden unter anderem über einer Gruppe Partisanen, zu der auch Milovan Đilas und Vladimir Dedijer gehörten, abgeworfen. Ein Partisan kommentierte: „Das ist ein Durchlassschein nach Jasenovac“. Dedijer: Dnevnik, S. 322.

321 Vgl. Schmider: Partisanenkrieg, S. 256.

322 BArch, RH 26/114/17, 714. I. D.: Behandlung von Überläufern, 1.2.1943; Siehe auch BArch, RH 26/114/26, Divisionsbefehl Nr. 114, 6.10.1943.

323 BArch, RH 26/114/17, Tätigkeitsbericht Februar 1943.

324 BArch, RH 45/45, Bl. 62f., Nr. 15, „Partisanen!“; BArch, RH 45/45, S. 69f., Nr. 18, „Kommandeure! Partisanen!“ 
de gar ein komplementärer Flugzettel für die deutschen Soldaten hergestellt, der die Anweisungen beinhaltete, keinen Überläufer $\mathrm{zu}$ erschießen oder $\mathrm{zu}$ misshandeln, weil sie ansonsten die eigene Überläuferpropaganda sabotieren würden. ${ }^{325}$

Im Dezember 1943 sollten die Überläufer dann unter der Berufung auf ein OKW-Flugblatt als „Flüchtlinge“ bezeichnet werden. Dahinter stand folgende Überlegung: „Ein nationalbewußter freiwilliger ,Freiheitskämpfer““ würde nicht überlaufen. Wenn er aber erkenne, so die Erklärung weiter, dass er ausgenutzt würde, dann versuche er loszukommen und sei auch bereit, sich gegen die „Verführer“ zu wenden. Schließlich müsse er fliehen, weil er bedroht sei, und daher sei die Bezeichnung „Flüchtling“ angemessen. ${ }^{326}$ Dies scheint sich durchgesetzt zu haben, denn im Gegensatz zu ersten Flugblättern, die zum Überlaufen animieren sollten, hieß es nun: „Flüchtlings-Ausweis; Nicht erschießen, sondern zur nächsten Deutschen Kdo-Stelle bringen und gut behandeln.“327

Sogar eine Anleitung zum Überlaufen gab es. Darin hieß es, die zum Überlaufen bereiten Kämpfer sollten Bombenangriffe ausnutzen, um überzulaufen, da es in der Verwirrung nicht auffallen würde. Dabei sollten sie den Passierschein benutzen. ${ }^{328}$ Es wurden auch Flugblätter verteilt mit der Überschrift „Wie kannst du überlaufen, ohne zu sterben?“ und als Ausblick auf die Zeit danach „Womit kannst du als Überläufer rechnen?“ Darin wurde zunächst sehr detailliert erklärt, wie man überlaufen sollte. So war der Passierschein so gedruckt, dass er zusammengerollt wie eine Zigarette aussah und in der Zigarettenschachtel versteckt werden konnte. $\mathrm{Zu}$ diesen Bemühungen gehörten auch „phantasievolle“ Gestaltungen der Passierscheine, damit sie auf den ersten Blick nicht als solche erkannt wurden. So konnten sie das Aussehen eines Zehn-Dollar Scheins oder eines fünfzackigen Sterns annehmen und wurden in lateinischer und kyrillischer Schrift gedruckt. ${ }^{329}$

Mit der Zeit änderte sich auch der Schwerpunkt der Überläuferpropaganda. Am Anfang wurde den Partisanen häufig mit der deutschen Stärke und ihrer Vernichtung gedroht, die gerne mit steigenden Zahlen an toten Partisanen un-

325 BArch, RH 45/51, Bl. 227, „Deutscher Soldat!“ und Aufruf an Partisanen. Die Truppe bekam tatsächlich den Befehl, die Überläufer zu sammeln und gut zu behandeln. BArch, RH 26/114/26, Divisionsbefehl Nr. 114, 6.10.1943. Es ist jedoch mehr als fraglich, ob sich dieses Vorgehen durchsetzen konnte.

326 BArch, RH 21/2/733, Bl. 23-26, Prop. Komp. 693, Tätigkeitsbericht für die Zeit vom 1.15.12.43.

327 BArch, RH 45/50, Bl. 80 f. „Flüchtlings-Ausweis“.

328 BArch, RH 45/49, Bl. 90, Eine Anleitung zum Überlaufen vom Anfang 1944.

329 BArch, RH 45/45, Bl. 240 f, Passierscheine; BArch, RH 45/51, Bl. 4 f., Passierscheine. 
termauert wurden. ${ }^{330}$ Sie sollten so schnell wie möglich überlaufen, um ihr Leben zu schützen. Mit dem Anbrechen des Winters 1944 wurde vor allem an die Strapazen erinnert, die sie im Wald auf sich nehmen mussten. Alle Schwierigkeiten, mit denen Partisanen konfrontiert waren - Mangel an Essen, Bekleidung, Munition und Medikamenten -, wurden für die eigene Propaganda ausgenutzt. Die potentiellen Überläufer wurden mit ausreichendem Essen, warmer Unterkunft, komfortablem Bett, neuem Gewand und dem Kontakt zu Familie gelockt. Zudem wurden ihnen ärztliche Hilfe und Medikamente in Aussicht gestellt. ${ }^{331}$ Somit setzten die Propagandamacher genau dort an, wo die potentiell fluchtwilligen Partisanen am besten zu packen waren - fernab von hochtrabender, politischer Propaganda bei den Entbehrungen, denen sie als Partisanen ausgesetzt waren und der Sehnsucht nach der Familie. Wenn sie nicht überliefen, so sollte durch die psychologische Kriegsführung zumindest ihre Kampfmoral herabgesetzt werden. Gleichzeitig versuchte die Propaganda, die Soldaten und ihre Vorgesetzen zu entzweien. So hieß es in einem Flugblatt:

Angehörige der 7. Division!

Barfuss und in Lumpen gehüllt, hungernd und frierend seid ihr jetzt mit Anbruch des Winters gefährlichen Krankheiten und Seuchen ausgesetzt. Eure Körper, denen furchtbare Entbehrungen und Strapazen die Widerstandskraft genommen haben, werden die leichte Beute eines grimmigen Feindes, des Typhus! Habt ihr Typhus-Schutzimpfungen erhalten? Nein! $!^{332}$

Die Impfungen habe nur die Führung erhalten, so das Flugblatt weiter. Sie hingegen könnten sterben, da sie nur Titos Kanonenfutter seien. Daher sollten sie überlaufen und all die Vorteile genießen, die auf sie warteten. Für die Zeit nach dem Überlaufen wurden ihnen entweder Arbeit in Deutschland, in der Heimat oder der Beitritt zur neuen deutschen Division als Optionen versprochen. ${ }^{33}$ Bereits Anfang April 1943 hatten die Generäle Löhr und Glaise von Horstenau angedacht, die Überläufer nach Deutschland zur Arbeit zu schicken. ${ }^{334}$ So hätte man zwei Ziele gleichzeitig erreicht: Arbeitskräfte für die deutsche Industrie gesichert und gleichzeitig die Gefahr beseitigt, dass sich die Überläufer, wenn man sie nach Hause schickte, erneut - freiwillig oder nicht - den Partisanen anschlossen.

330 BArch, RH 45/46, Bl. 188, 191 Überläuferpropaganda.

331 Vukotić: Neprijateljska propaganda, S. 350.

332 BArch, RH 45/48, Bl. 221; Ähnlich: BArch, RH 45/49, Bl. 18 f., „Ihr Armen!“ (Winter 1944). 333 BArch, RH 45/46, Bl. 90, „Wie überzulaufen ohne zu sterben“; Bl. 93 „Womit kannst Du als Überläufer rechnen?“.

334 Notiz vom Treffen OB Südost mit dem Bev. Gen. in Kroatien, 4.4.1943, abgedr. i. Zbornik, XII/3, Nr. 47, S. 206-208. 
Wie erfolgreich die Überläuferpropaganda war, lässt sich - ähnlich wie bei aller Propaganda - nur sehr schwer bestimmen. Sowohl im März als auch im November 1943 wurden von der 114. J. D. fünf Flugblätter mit einer Auflage von insgesamt 220.000 Stück verteilt. Das Ergebnis waren 73 Überläufer im Oktober 1943, im November waren es 91. Für die ersten zehn Tage im Dezember wurden 44 Überläufer gemeldet, von welchen 27 „durch über dem Bandengebiet abgeworfene divisionseigene Flugblätter“ zum Überlaufen angeregt worden waren. ${ }^{335}$ Anfang 1944 wurde eine groß angelegte deutsch-kroatische Überläuferaktion durchgeführt, die in engem Zusammenhang mit der von Pavelić erlassenen Amnestie vom Januar 1944 stand. Dabei wurden über 11 Millionen Flugzettel im ganzen NDH verteilt. Sie wurde als ein Erfolg gewertet, denn in den ersten 14 Tagen sollen 7.200 Partisanen übergelaufen sein. ${ }^{336}$

Auch noch 1945 kämpfte die Propaganda den mit Waffen bereits verlorenen Krieg weiter. Nachdem die Partisanen Belgrad erobert hatten, wurden antijüdische Parolen verbreitet: In Belgrad hätten die Juden ihre Wohnungen zurückbekommen, während die Serben auf die Straße gesetzt würden. ${ }^{337}$ Auch der deutsche Rückzug wurde thematisiert und betont, dass die Deutschen nun in ganz Kroatien gegen „Titos Banden“ kämpften. ${ }^{338}$ Sogar als Hitler sich bereits das Leben genommen hatte, verkündeten die Flugblätter der deutschen Propaganda noch die Unbesiegbarkeit Deutschlands. ${ }^{339}$

\subsection{Auf welche Propagandastrategie setzen?}

Beide Besatzer haben rege Propaganda sowohl unter den eigenen Soldaten als auch unter der Bevölkerung und den Gegnern betrieben. Bei der Betreuung der eigenen Soldaten stehen im italienischen Fall deutlich mehr Quellen zur Verfügung, so dass für diesen Fall ein viel besseres Bild der Lage gezeichnet werden kann. Grundsätzlich setzte die Propaganda für die eigenen Soldaten bei beiden Armeen konsequent auf antikommunistische Parolen, auf die „Balkanisierung“ und „Verwilderung“ der Aufständischen sowie auf die Weigerung, diese als gleichberechtigte Gegner zu sehen. Sie waren und blieben (wilde) „Banden“ bis zum Ende des Krieges. Bei den Deutschen war zudem die Bindung an die Kroaten wichtig, während Serben meistens als Feinde betrachtet wurden. Die deut-

335 BArch, RH 26/114/29, Eintrag vom 11.12.1943.

336 PA-AA, Gesandtschaft Kroatien, P. 222, D Kult 1 Nr. 3-223/44, Großaktion zum Amnestiegesetz, 10.3.1944.

337 BArch, RH 45/53, Bl. 21 f., Antijüdische Propaganda.

338 BArch, RH 45/53, Bl. 33, „Kuda odlaze Niemci?“

339 BArch, RH 45/53, Bl. 42, „Deutschland ist unbesiegbar!“ 
sche Propaganda hatte also eine einheitliche Linie, die als „antiserbisch“ jedoch nicht als ,antislawisch“ charakterisiert werden kann. ${ }^{340}$

Die Auswertung der Betreuung italienischer Soldaten zeigt insbesondere, wie sehr diese unter den Umständen des Guerillakriegs gelitten haben. Die italienische Propaganda, die unter den Soldaten verbreitet wurde, war im Dilemma der eigenen Ideologie gefangen: Die Propaganda, insbesondere in Soldatenzeitungen, baute ihre Erklärungsmuster unermüdlich auf dem Erbe des Römischen Imperiums, auf der lateinischen, höher stehenden Zivilisation und der damit verbundenen Zivilisierungsmission vor Ort. Die Soldaten sollten sich als starke aber gerechte Verteidiger des italienischen Imperiums sehen, welche die Feinde vernichteten, die Schwachen aber schützten. Doch konnte sie diese Linie nicht konsequent durchhalten. Zudem konterkarierten die Art der Aufständischenbekämpfung und die Erlebnisse der Soldaten diese Propaganda, wie noch in den folgenden Kapiteln gezeigt wird. Letztlich konnten sich nur diejenigen Inhalte durchsetzen, die mit der Realität des Soldatenlebens im Einklang standen.

Die Propaganda für die Bevölkerung und in den Feind unterschied sich in den eingesetzten Mitteln, in den Adressaten, im Zeitpunkt und schließlich auch in den verfolgten Zielen. Darin spiegelte sich somit die allgemeine Position der beiden Achsenpartner wieder: die Stellung zum NDH, zu den Aufständischen und ihrer Bekämpfung sowie zur Bevölkerung. Bereits bei der Definition der Aufständischen gingen deutsche und italienische Ansichten auseinander. Während die deutsche Propaganda bis zur italienischen Kapitulation Partisanen und Tschetniks gleichermaßen darunter verstand, konzentrierten sich die Italiener auf die Bekämpfung der Partisanen. Dieser Unterschied fällt jedoch nicht so sehr auf, da deutsche Propaganda erst mit der Operation „Weiß“, also zu Beginn 1943, in größerem Umfang einsetzte und sich vor allem an die Partisanen richtete. Der Fokus der 1942 einsetzenden italienischen Propaganda lag auf der Schaffung eines breiten pro-italienischen Konsenses bei der Bevölkerung. Bei der deutschen Propaganda spielte dies erst ab 1944 eine Rolle. Diese Verzögerung von ca. zwei Jahren - ähnlich wie bei der Zusammenarbeit mit einheimischen Kräften - unterstreicht die These, dass die Hinwendung zur Bevölkerung vor allem die deutsche Ohnmacht, mit den Aufständischen militärisch fertig zu werden, widerspiegelt. Im Gegensatz hierzu war die Interaktion mit der Bevölkerung eine von den Italienern bewusst von Anfang an verfolgte Politik, im Rahmen derer sie sich nicht nur von ihren Bündnispartnern abgrenzten sondern auch ihr Ziel der Bildung eines italienischen Imperiums verfolgten.

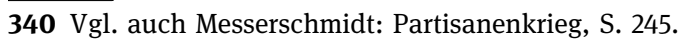


Um hierbei erfolgreich zu sein, mussten die Besatzer auf das „eigene“ Interesse der Bevölkerung, ja sogar jedes Partisanen verweisen. Da die Kosten-Nutzen-Analyse jedes Einzelnen für die Bewahrung von Ordnung spricht, wenn kurzfristige Nutzen betrachtet werden, ist es genau das, auf das sich die „ordnende“ Macht im Partisanenkampf berufen kann. ${ }^{341}$ Die Propaganda der beiden Besatzer zeigte daher die deutsche respektive italienische militärische und wirtschaftliche Stärke. Dazu dienten Nachrichten von anderen Kriegsschauplätzen, die die eigenen Siege und die Verluste des Gegners betonten. Diese sollten ihren Feinden deutlich machen, dass ihr Kampf zwecklos war, weil die entscheidenden und für die Achse siegreichen Kämpfe woanders ausgetragen würden. Darüber hinaus mussten sie sich als die ordnende Macht, die Aufständischen jedoch als Banditen, Räuber und Störenfriede darstellen, die für das Leid der Bevölkerung verantwortlich waren.

Während die Nachrichten von beiden Besatzern ähnlich verbreitet wurden, zeigten sich bei der Frage der Herstellung von „Sicherheit und Ordnung“ doch deutliche Unterschiede. Auch wenn in den Flugblättern immer wieder die deutsche ordnende Kraft betont wurde, konnte sie sehr selten durch Taten belegt werden. Die Wehrmacht ließ dem NDH viel zu lange freie Hand bei der inneren Gestaltung des Landes. Erst als deutlich wurde, dass die allgemeine Rechtslosigkeit auch auf das Bild der Wehrmacht abfärbte, schaltete sie sich als „Ordnungshüter“ ein. Anders war das Verhalten des italienischen Verbündeten. Der allgemeinen Verkündung der Gleichbehandlung aller Personen am 8. September 1941 waren schon Eingriffe zugunsten Verfolgter vorausgegangen. Dieser Teil der italienischen Politik, der sich im Umgang mit den unterschiedlichen Bevölkerungsgruppen zeigte, und der bewusst auch als Abgrenzung zur Politik seiner Bundesgenossen betrieben wurde, fand seinen Platz auch in der Propaganda. Freilich waren diese unterschiedlichen Herangehensweisen auch mit den letztlichen Zielen der Besatzer im NDH verknüpft.

Um die Bevölkerung von den Partisanen fern zu halten, mussten sie ihr echte Alternativen zum kommunistischen Zukunftsentwurf anbieten. Genau das versuchte Italien zu tun, indem es bei den Völkern im NDH offen für sich, den Faschismus und seine Errungenschaften warb. Das Bild von gerechten, humanen, zivilisierten Italienern war das Fundament, auf dem die ganze Propaganda aufgebaut wurde. Die Gleichstellung der Religionen, das Bild der Frau im Faschismus, sein Fortschritt, seine jahrtausendelange da auf dem römischen Imperium aufbauende Kultur, Zivilisation und Humanität waren die Inhalte, die immer wieder transportiert wurden. Unterstrichen wurden diese Parolen mit der

341 Münkler, Herfried: Die Gestalt des Partisanen. Herkunft und Zukunft, in: Ders. (Hg.): Der Partisan. Theorie, Strategie, Gestalt, Opladen 1990, S. 14-39, hier S. 27. 
„Propaganda der Tat“, die die Völker Kroatiens die Vorzüge des Faschismus am eigenen Leib erfahren lassen sollte - sei es durch Gleichbehandlung, medizinische Versorgung, Infrastrukturprojekte oder die Lebensmittelversorgung. Eine besondere Rolle spielte hierbei Dalmatien, das als annektiertes Gebiet zudem italianisiert werden sollte. Die Deutschen hingegen waren schon aufgrund der nationalsozialistischen Ideologie nicht in der Lage eine solche Vision zu verbreiten. Standen im April 1941 noch weite Teile der kroatischen Bevölkerung dem neuen Staat positiv gegenüber, schwand die Zustimmung mit den Gewaltexzessen der Ustascha. Als deren Unterstützer konnten die Deutschen diese Bevölkerung nicht abholen, ohne sich vom Ustascha-Kurs zu trennen. Doch das Gegenteil war der Fall: Bei aller internen Kritik standen sie bis zum Ende hinter der Ustascha und somit auch hinter ihrer Politik. Die Propaganda für die Bevölkerung spielte letztlich nur im Kampf gegen die Aufständischen eine Rolle. Sie war situativ, lokal beschränkt und konzentrierte sich vor allem auf Überläuferpropaganda und Aufrufe an die Bevölkerung, die Partisanen nicht zu unterstützen. Erst 1944 sahen die Deutschen ein, dass weitreichende Visionen angeboten werden mussten. Da aber keine konkreten Aussagen für die Zeit nach dem Krieg gemacht werden durften, blieb es bei vagen Prognosen von besseren wirtschaftlichen Zeiten und dem Verweis auf die deutsche ökonomische Stärke. ${ }^{342}$

Da die deutsche und italienische militärische Propaganda für die Bevölkerung des NDH ein klares Ziel verfolgte, kann und muss sie auch anhand dessen Erreichens bewertet werden. Da wir über keine Möglichkeiten verfügen, herauszufinden, wie groß der Teil der Bevölkerung war, der sie gelesen hat, und was dieser darüber dachte, müssen deutlich gröbere Verhaltensweisen als Indikatoren herangezogen werden. Letztlich hat es weder die deutsche noch die italienische Propaganda geschafft, die Bevölkerung auf Dauer von den Partisanen zu trennen. Hier spielten jedoch auch das allgemeine Verhalten der Besatzer sowie auch die Tatsache, dass sie nun einmal Besatzer waren, eine ebenso entscheidende Rolle. Die Italiener versuchten, ähnlich wie die Partisanen, eine Vision von einem besseren Leben zu verkaufen. Dass sie schließlich scheiterten, lag vor allem daran, dass sie nicht verstehen konnten, dass die Slawen nicht nur darauf gewartet hatten, in tiefster Dankbarkeit in den Genuss der Vorteile der italianità und der civiltà romana zu kommen. Erst recht nicht, wenn diese Vorteile bedeuteten, dass sie zum Teil, wie in Dalmatien, ihre eigene Kultur aufge-

342 Ferenc Szálasi beklagte sich - stellvertretend auch für andere faschistischen Bewegungen - noch 1945 darüber, dass Deutschland keine eindeutige Vision für die „neue Ordnung“ nach dem Krieg zeichnete. Siehe Grunert, Robert: Autoritärer Staatenbund oder nationalsozialistischer Großraum? „Europa“ in der Ideenwelt faschistischer Bewegungen, in: Zeithistorische Forschungen/Studies in Contemporary History, Online-Ausgabe, 9 (2012) 3, Textabschn. 2 $<$ http://www.zeithistorische-forschungen.de/16126041-Grunert-3-2012> (23.5.2019). 
ben mussten. Kurz vor dem Ende der Besatzung fasste ein Kontrapropagandabericht die Selbstsicht, das zu transportierende Bild und die Erfolge der italienischen Propaganda folgendermaßen zusammen:

Der Slawe sieht in unserem Soldaten einen Italiener, einen Feind, und versucht nicht, seine Seele, seine Kultur und vor allem seine Humanität kennenzulernen. Während unser Soldat sich selbst für das Wohl dieser Bevölkerung opfert, hilft diese hingegen entweder aus Gleichgültigkeit oder aus Undankbarkeit den Partisanen - Kommunisten. ${ }^{343}$

Die deutschen Versuche in dieser Hinsicht kamen zu spät und waren zu halbherzig. Nebulöse Prognosen von einer besseren Zukunft hätten schon zu Beginn der Besatzung nicht ausgereicht, um die Bevölkerung auf die eigene Seite zu rekrutieren und sie reichten 1944 erst recht nicht aus. Die Partisanen, unterstützt unter anderem durch ihre überlegene Propaganda - sowohl der Schrift als auch der Tat - konnten schließlich den Sieg im Kampf um die Unterstützung der Bevölkerung davontragen. ${ }^{344}$

343 NARA, T-821, R. 418, Nr. 268-270, XVIII CdA: Relazione di Contropropaganda, 25.6.25.7.1942.

344 Ähnlich scheiterte auch die deutsche Propaganda in der Provinz Ljubljana nach 1943. Kranjc, Gregor Joseph: Propaganda and the Partisan War in Ljubljana 1943-45, in: Shepherd, Ben/Pattinson Juliette (Hg.): War in a Twilight World. Partisan and Anti-Partisan Warfare in Eastern Europe, 1939-45, Basingstoke [u. a.] 2010, S. 233-256, hier S. 237-241. 